\title{
Hydrogen atom transfer oxidation by a gold-hydroxide complex
}

\author{
Marta Lovisari and Aidan R. McDonald*
}

School of Chemistry, Trinity College Dublin, The University of Dublin, College Green, Dublin 2, Ireland.

email: aidan.mcdonald@tcd.ie 


\section{Materials}

All solvents and reagents were purchased from commercial sources and used as received, unless otherwise stated. Complex 1 was synthesised as reported. ${ }^{1}$ Either $\mathrm{KAuCl}_{4}$ or $\mathrm{HAuCl}_{4}$ were used as starting materials for the synthesis of complex 1, they were purchased from Sigma Aldrich or Fisher Scientific and used as received. p-X-2,6-di-tert-butylphenols were recrystallized from hexane or ethanol/water prior to use. For reactions performed in the absence of oxygen, solvents (N,N-dimethylformamide, tetrahydrofuran, diethyl ether) were freezedpump-thawed three times and stored in a nitrogen atmosphere glovebox. TEMPOH (1-hydroxy2,2,6,6-tetramethyl-piperidine) and 4- $\mathrm{CH}_{3} \mathrm{O}$-TEMPOH (4-methoxy-1-hydroxy-2,2,6,6tetramethyl-piperidine) were synthesized according to reported procedures. ${ }^{2,3}$ 4-oxo-TEMPOH (4oxo-1-hydroxy-2,2,6,6-tetramethyl-piperidine) was synthesized by adapting a reported procedure for $4-\mathrm{CH}_{3} \mathrm{O}-\mathrm{TEMPOH}{ }^{3}{ }^{4}-\mathrm{CH}_{3} \mathrm{O}-[D]-2,6-\mathrm{DTBP}$ was synthesized according to a reported procedure. ${ }^{4}[D]_{4}-9,10$-dihydroanthracene $\left([D]_{4}\right.$-DHA) was synthesized according to a reported procedure $\left(\right.$ deuteration degree $=97 \%$ by $\left.{ }^{1} \mathrm{H}-\mathrm{NMR}\right){ }^{5}$

\section{Physical Methods}

${ }^{1} \mathrm{H}$ and ${ }^{13} \mathrm{C}$ nuclear magnetic resonance (NMR) analyses were performed on an Agilent MR400 instrument (400.13 MHz for ${ }^{1} \mathrm{H}$ NMR, $100.61 \mathrm{MHz}$ for ${ }^{13} \mathrm{C} \mathrm{NMR}$ ). Electronic absorption spectra were recorded on a Hewlett Packard (Agilent) 8453 diode array spectrophotometer. Gas chromatography experiments have been performed using a ThermoFisher TRACE ${ }^{\mathrm{TM}} 1300$ Gas Chromatograph equipped with a Flame Ionisation Detector. Hydrogen was provided by a Parker Hydrogen Gas Generator 20H-MD. Air was provided by Parker Zero Air Generator UHP-10ZA-S. The column used was a ThermoFisher TraceGOLD TG-1MS GC column. Electrospray ionization (ESI) mass spectra were acquired using a Micromass time of flight spectrometer (TOF), interfaced to a Waters 2690 HPLC. Attenuated total reflectance infra-red 
(ATR-FTIR) spectra were recorded on a Perkin-Elmer Spectrum 100 Fourier transform infrared spectrometer. Cyclic voltammetry $(\mathrm{CV})$ experiments were conducted with a $\mathrm{CH}$ Instruments $600 \mathrm{E}$ electrochemical analyzer, using a glassy carbon working electrode, a platinum wire counter electrode and an $\mathrm{Ag} / \mathrm{AgNO}_{3} 0.01 \mathrm{M}$ reference electrode.

Electron paramagnetic resonance: Electron paramagnetic resonance (EPR) spectra of frozen solutions were acquired on a Bruker EMX X-band EPR, equipped with an Oxford Instruments CE 5396, ESR9 Continuous Flow Cryostat, a precision Temperature Controller and an Oxford Instruments TTL20.0/13 Transfer Tube. EPR samples were prepared by freezing the EPR tubes containing the analyte solutions, previously prepared at the UV-Vis spectrophotomer, in liquid nitrogen. EPR spectra of the phenoxyl radicals were recorded at $77 \mathrm{~K}, 9.2 \mathrm{GHz}, 0.2 \mathrm{~mW}$ microwave power, with a $10 \mathrm{mT}$ field sweep in $84 \mathrm{~s}$, and $0.2 \mathrm{mT}$ field modulation amplitude. EPR spectra of 4-X-TEMPO were recorded at $77 \mathrm{~K}, 9.2 \mathrm{GHz}, 2.02 \mathrm{~mW}$ microwave power, with a $60 \mathrm{mT}$ field sweep in $84 \mathrm{~s}$, and $0.3 \mathrm{mT}$ field modulation amplitude. Integration, simulation, and fitting were performed with Matlab and the easySpin computational package. ${ }^{6}$ The simulation for the phenoxyl radicals spectra was modelled as an $S=1 / 2$ electron spin with an isotropic $\mathrm{g}$ tensor. The oxidation yield of the samples was calculated by quantification of the concentration of spin in the samples. This was obtained by comparison of the double integral of the signals to that of a frozen reference $3 \mathrm{mM}$ solution of (2,2,6,6-tetramethylpiperidin-1-yl)oxyl (TEMPO), measured under the same conditions.

Electrochemistry: Cyclic voltammetry experiments were conducted on a $1.0 \mathrm{mM}$ solution of $\mathbf{1}$ in DMF at room temperature, with a $0.05 \mathrm{~V} \mathrm{~s}^{-1}$. The supporting electrolyte was $0.1 \mathrm{M}^{\mathrm{n}} \mathrm{Bu}_{4} \mathrm{NPF}_{6}$ was used as the supporting electrolyte. Potentials were referenced against the $\mathrm{Fc}^{+} / \mathrm{Fc}$ couple $(\mathrm{Fc}=$ ferrocene $)$. The voltammograms of $\mathrm{Fc}$ were acquired under the same conditions. 
Gas chromatography-Flame Ionisation Detector (GC-FID) analysis: Post-reaction solutions from the reaction of $\mathbf{1}$ with different substrates were prepared at $25{ }^{\circ} \mathrm{C}$. Different amounts of substrate (4- $\mathrm{CH}_{3} \mathrm{O}-2,6-\mathrm{DTBP}, 2,4,6-\mathrm{TTBP}, 2,6-\mathrm{DTBP}$, DHA) were added as DMF solutions under continuous stirring until completion of the reaction, after which the mixture was analysed by GC-FID. A reference standard solution was prepared by adding the same amount of equivalents of substrate to $2 \mathrm{~mL}$ of pure DMF. The instrument method for anthracene was based on a temperature $\operatorname{ramp}\left(2 \mathrm{~min}\right.$ at $175{ }^{\circ} \mathrm{C}, 10{ }^{\circ} \mathrm{C} / \mathrm{min}$ to $250{ }^{\circ} \mathrm{C}, 2 \mathrm{~min}$ at $\left.250{ }^{\circ} \mathrm{C}\right)$ with splitless injections of $1 \mu \mathrm{L}$ each. Under these conditions, the retention time for anthracene was between 6.3-6.4 min. The instrument method for 2,6-di-tert-butylquinone was based on a temperature ramp $\left(2 \mathrm{~min}\right.$ at $75{ }^{\circ} \mathrm{C}, 10^{\circ} \mathrm{C} / \mathrm{min}$ to $200{ }^{\circ} \mathrm{C}, 2 \mathrm{~min}$ at $200{ }^{\circ} \mathrm{C}$ ) with splitless injections of $1 \mu \mathrm{L}$ each. Under these conditions, the retention time for 2,6-di-tert-butylquinone was between 12.3-12.4 min. The quantitative analysis of the analytes was based on a calibration curve. Yields were calculated as an average of four different solutions containing the same number of equivalents of substrate and repeating it for 2-3 different substrates concentrations. 
Although no problems were encountered during the syntheses reported herein, perchlorate $\left(\mathrm{ClO}_{4}\right)$ salts are potentially explosive and should be handled with care. We took great care to perform preparation of 1 at a scale of $0.5 \mathrm{~g}$ or smaller.

\section{Characterization of $\left[\mathrm{Au}^{\mathrm{III}}(\mathrm{OH})(\right.$ terpy $\left.)\right]\left(\mathrm{ClO}_{4}\right)_{2}(1)$ :}

${ }^{1} \mathrm{H}$ NMR peaks have been assigned based on data obtained for the related complex $[\mathrm{Au}(\mathrm{Cl})(\text { terpy })]^{2+}$ in DMSO-D ${ }^{7}$

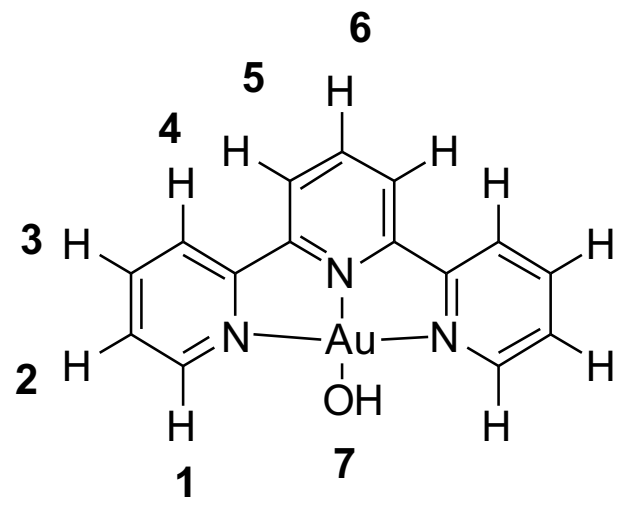

$\delta_{\mathrm{H}}(\mathrm{ppm})\left(400 \mathrm{MHz}, \mathrm{DMSO}_{6}\right): 9.09(\mathrm{dd}, \mathrm{J}=5.8,1.1 \mathrm{~Hz}, 2 \mathrm{H}, \mathbf{1}), 8.98(\mathrm{~m}, 1 \mathrm{H}, \mathbf{6}), 8.96(\mathrm{~m}$, 4H, 4,5), $8.83(\mathrm{td}, \mathrm{J}=7.9,1.3 \mathrm{~Hz}, 2 \mathrm{H}, 3), 8.27(\mathrm{ddd}, \mathrm{J}=7.5,5.8,1.4 \mathrm{~Hz}, 2 \mathrm{H}, 2), 6.35(\mathrm{~s}, 1 \mathrm{H}, 7)$. $\delta_{\mathrm{H}}(\mathrm{ppm})\left(400 \mathrm{MHz}, \mathrm{DMF}_{-} \mathrm{D}_{7}\right): 9.28(\mathrm{dd}, \mathrm{J}=5.8,1.3 \mathrm{~Hz}, 2 \mathrm{H}, \mathbf{1}), 9.16(\mathrm{~m}, 4 \mathrm{H}, 4,5), 9.13(\mathrm{~m}, 1 \mathrm{H}$, 6) $8.98(\mathrm{td}, \mathrm{J}=7.9,1.3 \mathrm{~Hz}, 2 \mathrm{H}, 3$ ), 8.44 (ddd, J = 7.5, 5.8, $1.3 \mathrm{~Hz}, 2 \mathrm{H}, 2), 6.65(\mathrm{~s}, 1 \mathrm{H}, 7)$.

$v_{\max }(\mathrm{FT}-\mathrm{IR}) / \mathrm{cm}^{-1}: 3425(\mathrm{O}-\mathrm{H}), 3082,3049,3034$ (terpy C-H stretch), 1605, 1597 (terpy C-H bend), 1574, 1503, 1481, 1453, 1443, 1406, 1327, 1303, 1297, 1268, 1254, 1188, 1171, 1071, $1052\left(\mathrm{ClO}_{4}\right), 1026,984,935,912,823,787,743,718,685,675,642,620,613,552$ 


\section{Synthesis and characterization of $[\mathrm{Au}(\mathrm{OD})($ terpy $)]\left(\mathrm{ClO}_{4}\right)_{2}(2)$ :}

Complex 2 was synthesized starting from $\left[\mathrm{Au}(\mathrm{Cl})(\right.$ terpy) $]\left(\mathrm{ClO}_{4}\right)_{2}$ by following the same procedure used to synthesize $\mathbf{1}^{1}$ but using $\mathrm{D}_{2} \mathrm{O}$ instead of $\mathrm{H}_{2} \mathrm{O}$ as solvent.

$\delta_{\mathrm{H}}(\mathrm{ppm})\left(400 \mathrm{MHz}, \mathrm{DMSO}_{-} \mathrm{D}_{6}\right) 9.10(\mathrm{dd}, \mathrm{J}=5.8,1.1,2 \mathrm{H}, \mathbf{1}), 8.98(\mathrm{~m}, 1 \mathrm{H}, \mathbf{6}), 8.96(\mathrm{~m}, 4 \mathrm{H}$, 4), $8.83(\mathrm{td}, \mathrm{J}=7.9,1.3 \mathrm{~Hz}, 2 \mathrm{H}, \mathbf{3}), 8.28(\mathrm{ddd}, \mathrm{J}=7.5,5.8,1.3,2 \mathrm{H}, 2)$.

$v_{\max }(\mathrm{FT}-\mathrm{IR}) / \mathrm{cm}^{-1}:$ 3082, 3049, 3034 (terpy C-H stretch), 2531 (O-D stretch), 1605, 1597 (terpy C-H bend), 1574, 1503, 1481, 1453, 1443, 1406, 1327, 1303, 1297, 1268, 1254, 1188, 1171, 1071, $1052\left(\mathrm{ClO}_{4}\right), 1026,984,935,912,823,787,743,718,685,675,642,620,613$, 552

The synthesis of $[\mathrm{Au}(\mathrm{OD})$ terpy $]\left(\mathrm{ClO}_{4}\right)_{2}(2)$ supported the assignment of the peak at $\delta=6.35$ ppm as that of the $-\mathrm{OH}$ proton in $\mathbf{1}$ (Figure S9-10).

\section{Synthesis of 4-methoxy-2,6-di-tert-butylphenoxyl radical:}

4-methoxy-2,6-di-tert-butylphenoxyl radical was synthesized by following a reported procedure. ${ }^{8}$ The purple oil obtained was washed three times with deoxygenated diethyl ether $\left(\mathrm{Et}_{2} \mathrm{O}\right)$, then the solvent was removed and the oil dried under vacuum for one hour. Then it was stored in a nitrogen atmosphere glovebox where the solutions for the calculation of the extinction coefficient in DMF (Figures S20-23) were prepared by using freshly deoxygenated DMF. Path length $=1 \mathrm{~cm}$.

$$
\begin{aligned}
& \varepsilon_{535 \mathrm{~nm}}=365 \pm 20 \mathrm{M}^{-1} \mathrm{~cm}^{-1} \\
& \varepsilon_{407 \mathrm{~nm}}=2090 \pm 100 \mathrm{M}^{-1} \mathrm{~cm}^{-1} \\
& \varepsilon_{390 \mathrm{~nm}}=1574 \pm 210 \mathrm{M}^{-1} \mathrm{~cm}^{-1}
\end{aligned}
$$




\section{Synthesis of 2,4,6-tris-tert-butylphenoxyl radical:}

2,4,6-tris-tert-butylphenoxyl radical was synthesized according to the reported procedure. ${ }^{9}$

The compound was then stored in a nitrogen atmosphere glovebox where the solutions for the calculation of the extinction coefficient in DMF (Figures S44-47) were prepared by using freshly freezed-pumped-thawed DMF. Path length $\mathrm{b}=1 \mathrm{~cm}$. The calculated molar extinction coefficients are $\sim 15 \%$ lower than those reported in acetonitrile, suggesting a lower stability of the radical in DMF.

$\varepsilon_{631 \mathrm{~nm}}=341 \pm 15 \mathrm{M}^{-1} \mathrm{~cm}^{-1}$

$\varepsilon_{402 \mathrm{~nm}}=1830 \pm 200 \mathrm{M}^{-1} \mathrm{~cm}^{-1}$

$\varepsilon_{384 \mathrm{~nm}}=1574 \pm 210 \mathrm{M}^{-1} \mathrm{~cm}^{-1}$

\section{4-oxo-1-hydroxy-2,2,6,6-tetramethyl-piperidine (4-oxo-TEMPOH):}

4-oxo-TEMPO-H was synthesized by adapting a reported procedure for 4- $\mathrm{CH}_{3} \mathrm{O}-\mathrm{TEMPOH}{ }^{3}$.

A suspension of 4-oxo-TEMPO $(1.00 \mathrm{~g}, 5.9 \mathrm{mmol})$ and $\mathrm{Na}_{2} \mathrm{~S}_{2} \mathrm{O}_{4}(2.15 \mathrm{~g}, 12.3 \mathrm{mmol})$ in acetone/water (1:1, $15 \mathrm{ml}$ each) was stirred for one hour at room temperature under inert atmosphere. During this time the bright yellow colour of the solution disappeared giving a colourless mixture. The solvent was then partially evacuated under vacuum to remove acetone. The residual aqueous layer was extracted with dry $\mathrm{Et}_{2} \mathrm{O}(3 \mathrm{x} 15 \mathrm{~mL})$ and the solvent was evaporated to give a white solid (890 mg, 88\%).

$\delta_{\mathrm{H}}(\mathrm{ppm})\left(400 \mathrm{MHz}, \mathrm{DMSO}-\mathrm{D}_{6}\right): 7.60\left(\mathrm{~s}, 1 \mathrm{H},-\mathrm{OH}\right.$, disappears by adding a drop of $\left.\mathrm{D}_{2} \mathrm{O}\right), 2.34$ $\left(\mathrm{s}, 4 \mathrm{H},-\mathrm{CH}_{2}\right), 1.07\left(\mathrm{~s}, 12 \mathrm{H},-\mathrm{CH}_{3}\right)$.

$\delta_{\mathrm{C}}(\mathrm{ppm})\left(100 \mathrm{MHz}, \mathrm{DMSO}-\mathrm{D}_{6}\right): 207.67(\mathrm{C}=\mathrm{O}), 60.93(\mathrm{C} 2), 52.89(\mathrm{C} 3), 26.53\left(\mathrm{CH}_{3}\right)$. 
Reactivity studies: Solutions of 1 were prepared at $25{ }^{\circ} \mathrm{C}$ and stored at $4{ }^{\circ} \mathrm{C}$ wrapped in aluminium foil up to 2 days after the preparation. The changes in the electronic absorption spectra were monitored at $25^{\circ} \mathrm{C}$. Substrates were added neat or as concentrated DMF solutions under continuous stirring. The formation of products was monitored using electronic absorption spectroscopy, by observing the decay of the band at $\lambda=369 \mathrm{~nm}$ (for reactions with 4-X-TEMPOH) or the growth of specific absorption bands of the oxidised products. The postreaction mixtures were used as obtained for GC analysis. For rate constant determinations a minimum of 12.5 equivalents of substrate (with respect to $\mathbf{1}$ ) were used to ensure pseudo-first order conditions. Values for $k_{\text {obs }}$ were obtained by fitting the decay of the band at $\lambda=369 \mathrm{~nm}$ for TEMPOH and its derivatives or the growth of the absorbance band of the phenoxyl radical products (see Table 1) as an exponential. Each set of experiments was repeated three times and these data were fitted following a saturation kinetic model. ${ }^{10-11}$

$$
\begin{gathered}
\mathrm{C}+\mathrm{S} \rightleftarrows \text { intermediate } \rightarrow \mathrm{C}+\mathrm{P} \\
k_{\mathrm{obs}}=k_{1} \frac{[\mathrm{S}]}{(\mathrm{K}+[\mathrm{S}])}
\end{gathered}
$$

$\mathrm{C}=$ complex $1 ; \mathrm{S}=$ substrate $; \mathrm{P}=$ products

The plot was linearized by using the following equation and from this plot the $k_{1}$ and the $\mathrm{K}$ were determined:

$$
\frac{1}{k_{\mathrm{obs}}}=\frac{\mathrm{K}}{k_{1}} \frac{1}{[\mathrm{~S}]}+\frac{1}{k_{1}}
$$



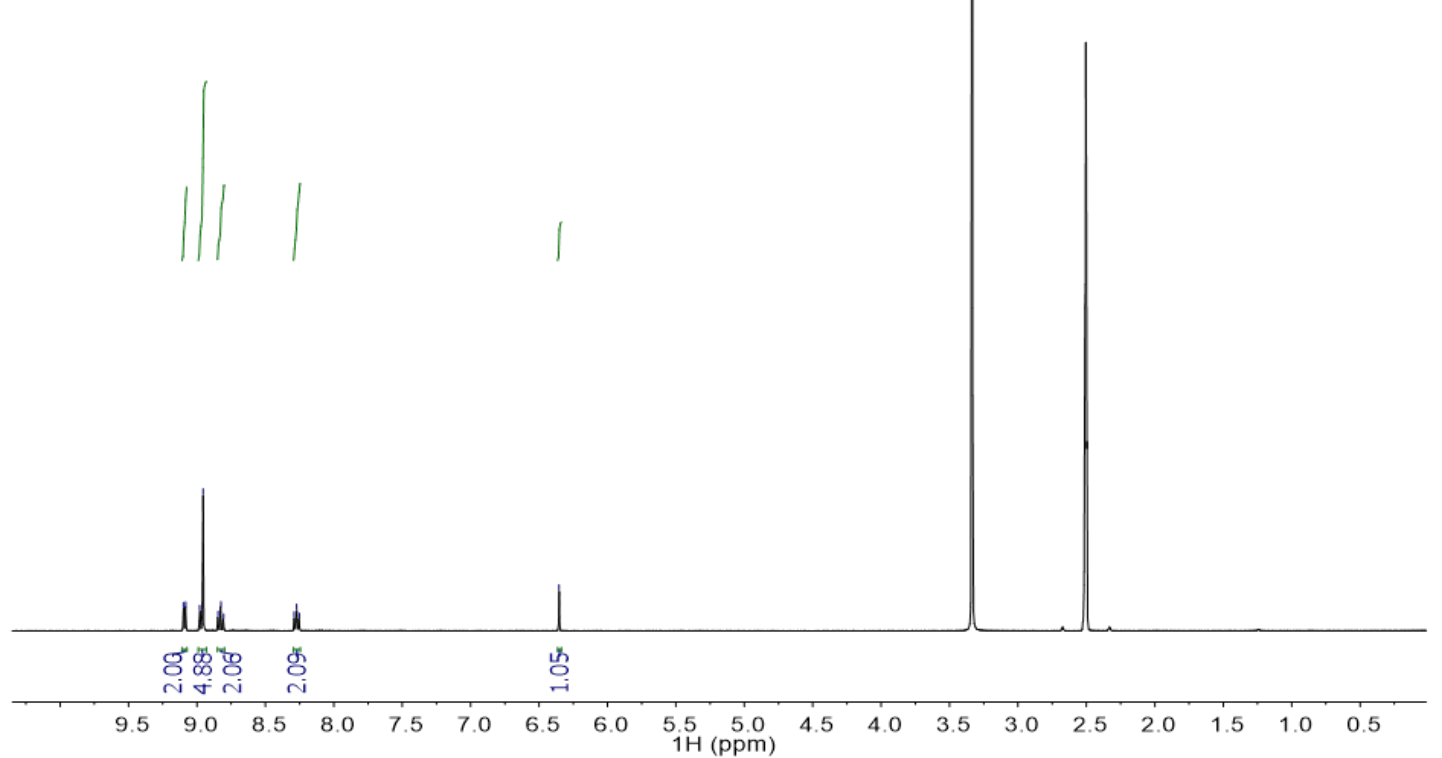

Figure S1. ${ }^{1} \mathrm{H}-\mathrm{NMR}$ spectrum of $\mathbf{1}$ in DMSO-D 6 . The signal at $3.30 \mathrm{ppm}$ is assigned to residual $\mathrm{H}_{2} \mathrm{O}$.

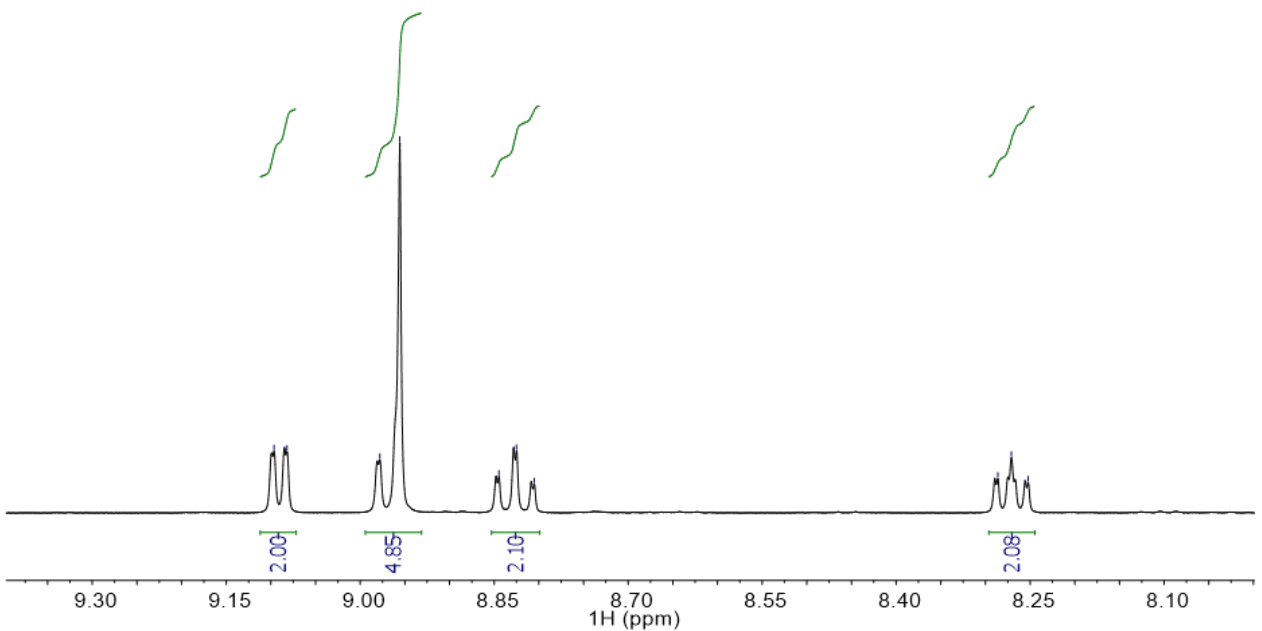

Figure S2. Zoom of the region between $\delta=8$ and $9.4 \mathrm{ppm}$ of the ${ }^{1} \mathrm{H}-\mathrm{NMR}$ spectrum of $\mathbf{1}$ in DMSO-D 6 . 


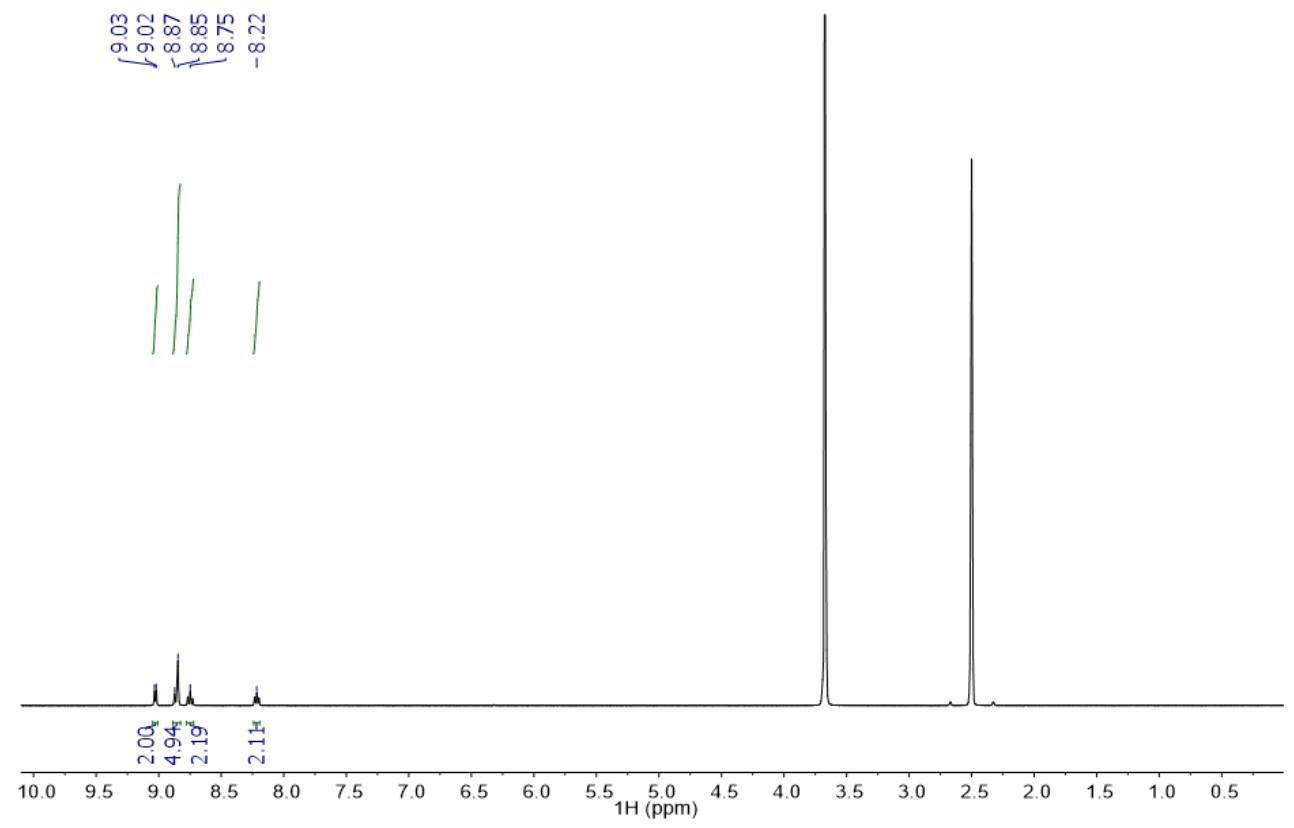

Figure S3. ${ }^{1} \mathrm{H}-\mathrm{NMR}$ spectrum of 1 in $\mathrm{DMSO}-\mathrm{D}_{6}$ in the presence of $\mathrm{D}_{2} \mathrm{O}$.

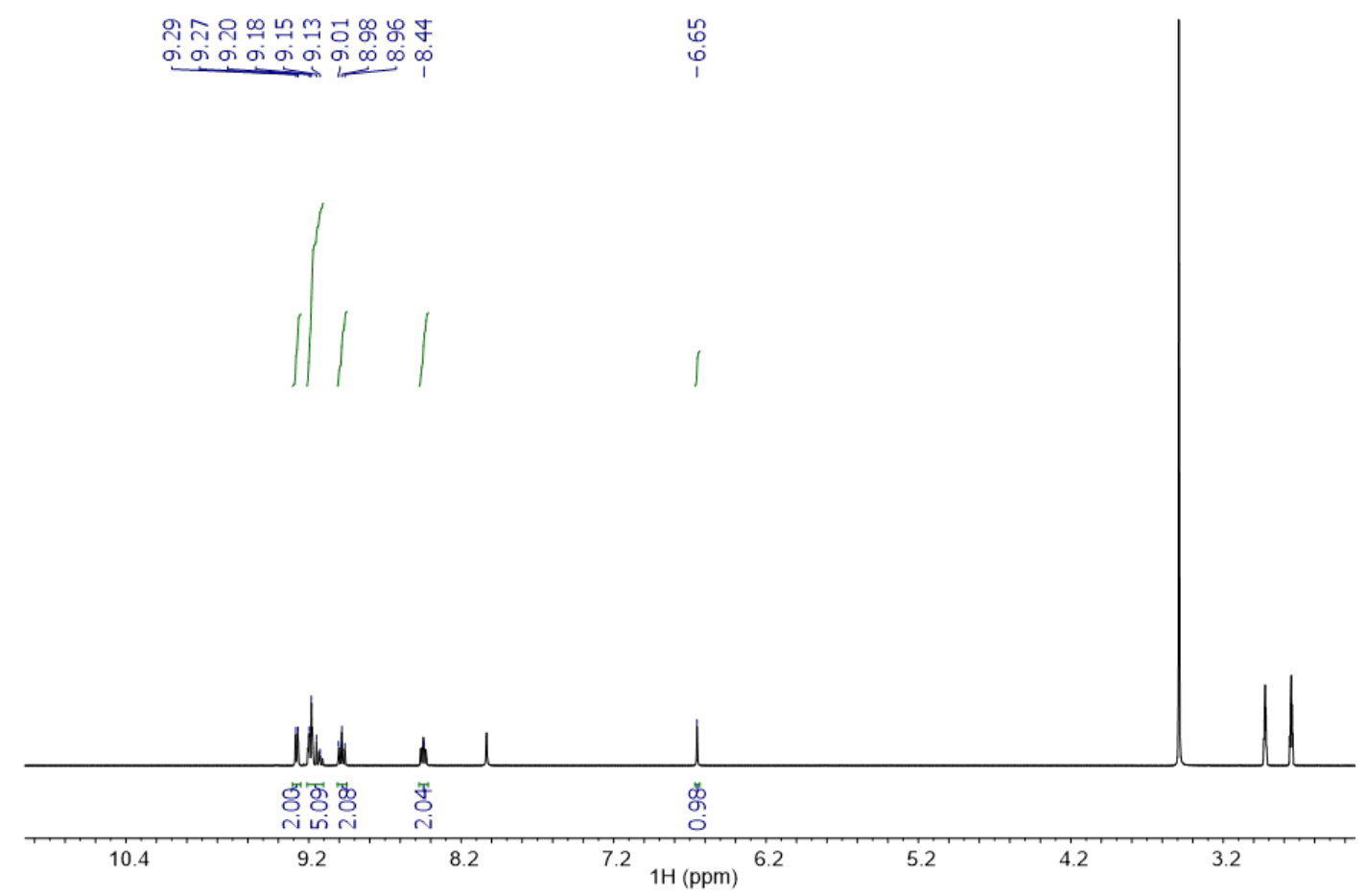

Figure S4. ${ }^{1} \mathrm{H}-\mathrm{NMR}$ spectrum of 1 in DMF-D 7 . 

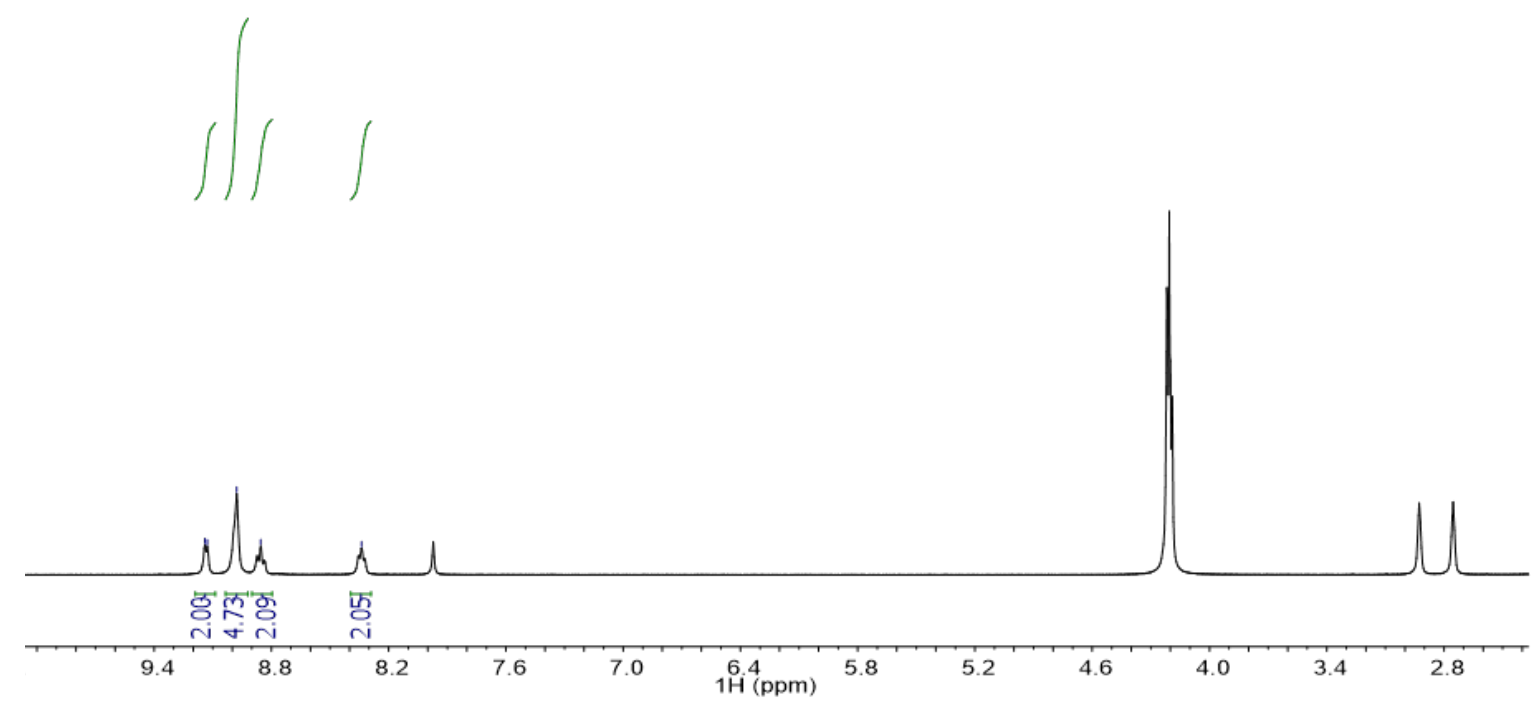

Figure S5. ${ }^{1} \mathrm{H}-\mathrm{NMR}$ spectrum of $\mathbf{1}$ in $\mathrm{DMF}_{-} \mathrm{D}_{7}$ in the presence of $\mathrm{D}_{2} \mathrm{O}$.

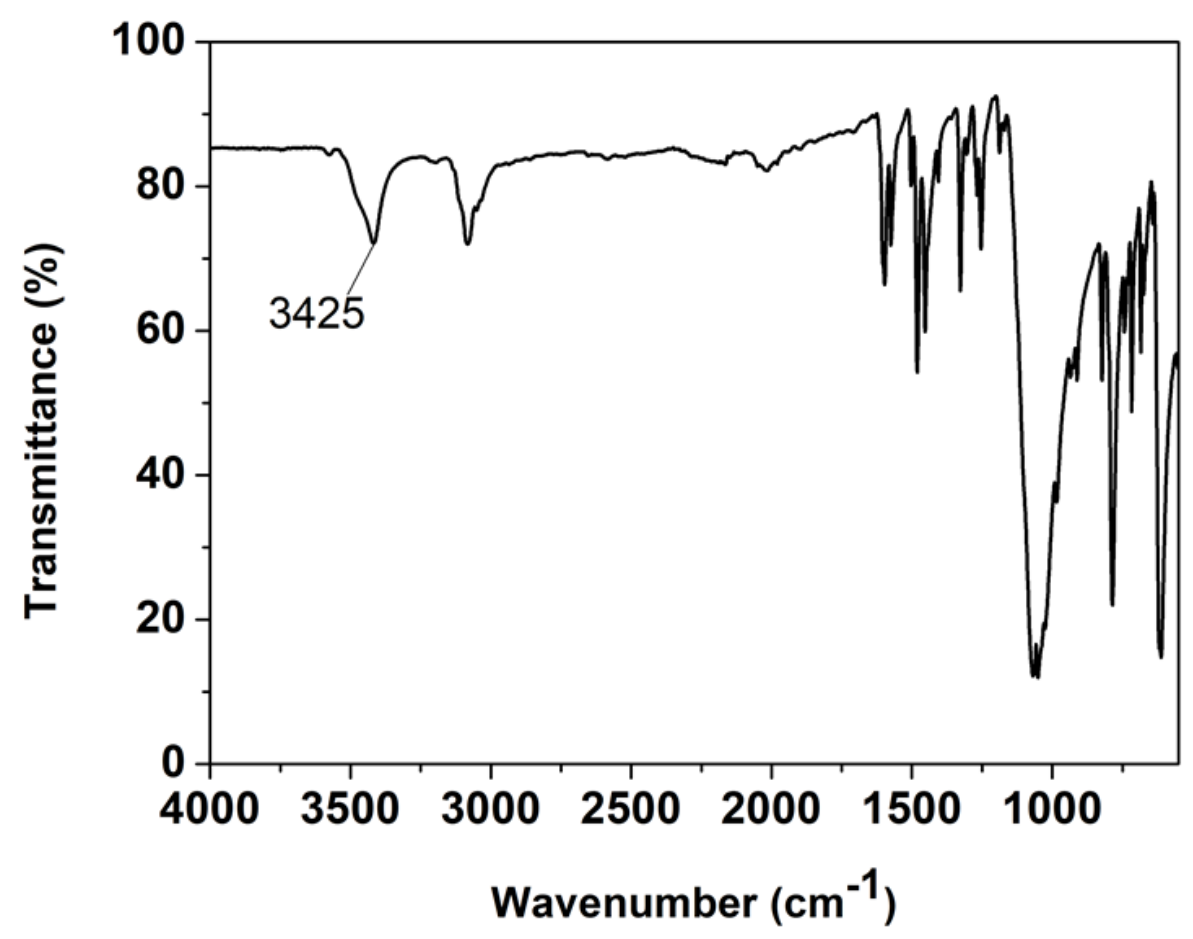

Figure S6. ATR-FTIR spectrum of 1. 


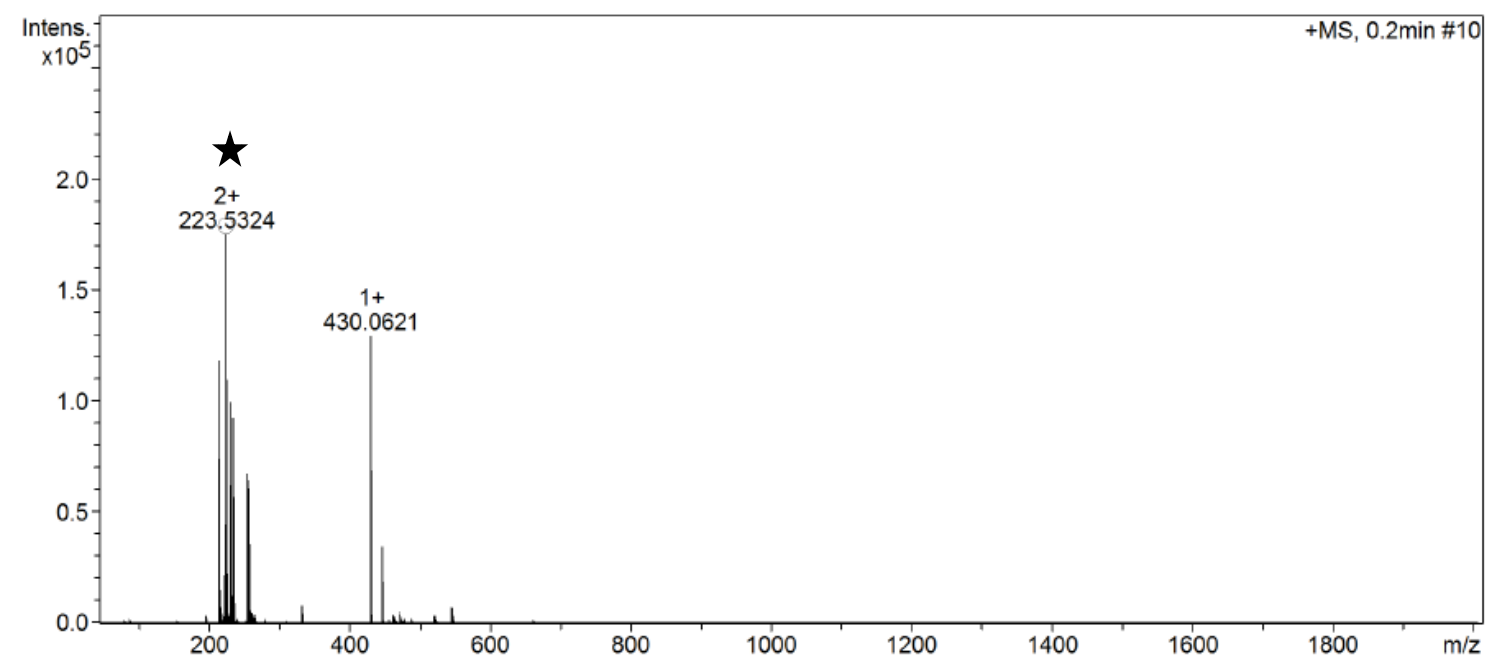

Figure S7. Positive mode ESI-MS spectrum of 1 (calculated $\mathrm{m} / \mathrm{z}$ of $[\mathrm{Au}(\mathrm{OH})(\text { terpy)})]^{2+}=$ 223.5317) .

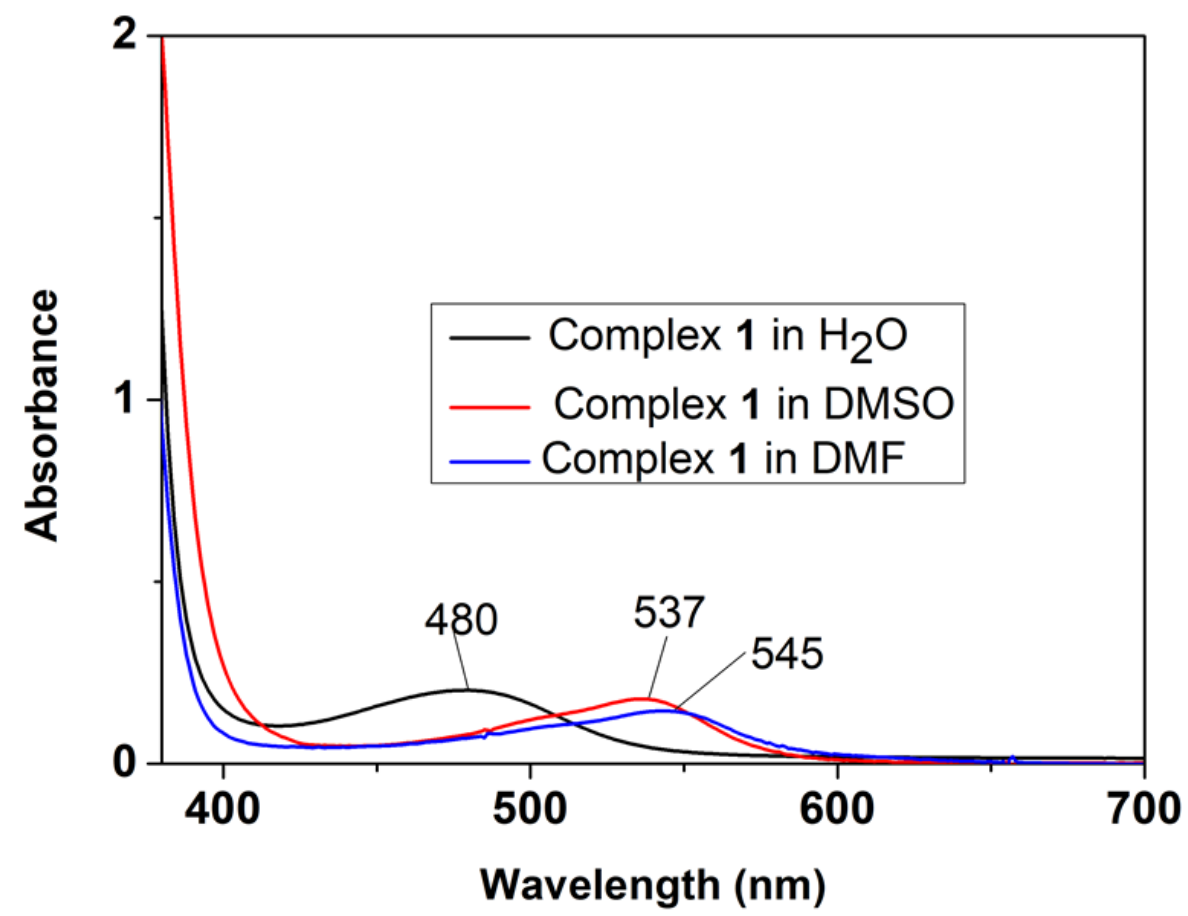

Figure S8. Electronic absorption spectrum of 1 in water (black trace), DMSO (red trace) and DMF (blue trace). 


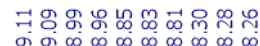

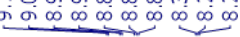

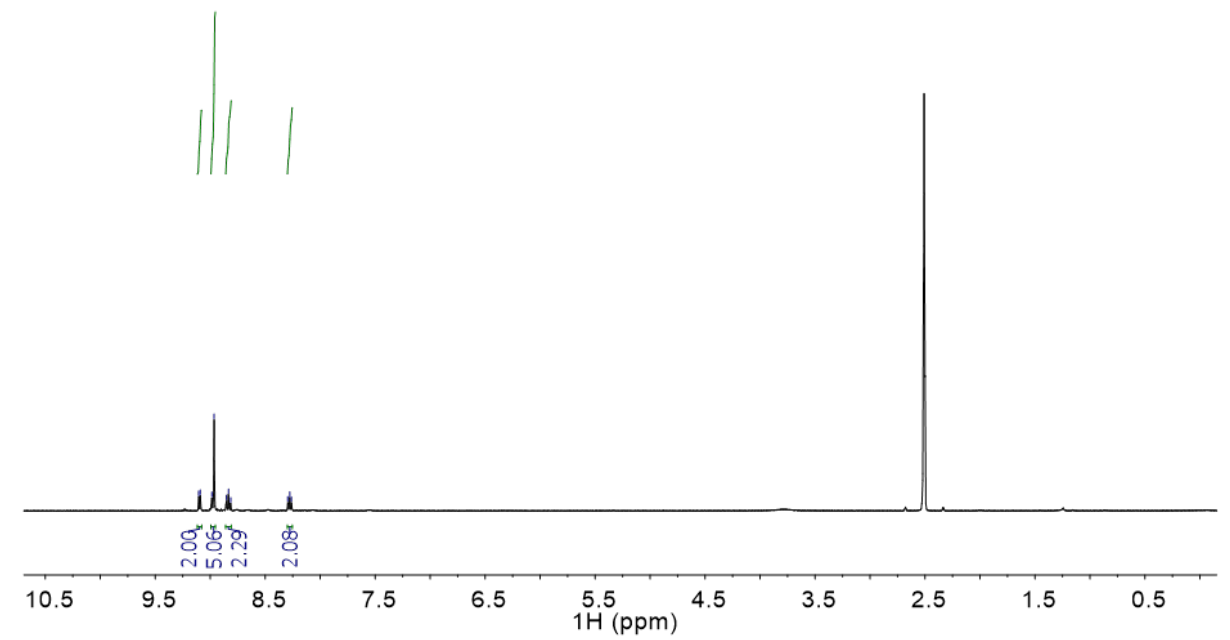

Figure S9. ${ }^{1} \mathrm{H}-\mathrm{NMR}$ spectrum $\left(400 \mathrm{MHz}, \mathrm{DMSO}_{-} \mathrm{D}_{6}\right)$ of 2.

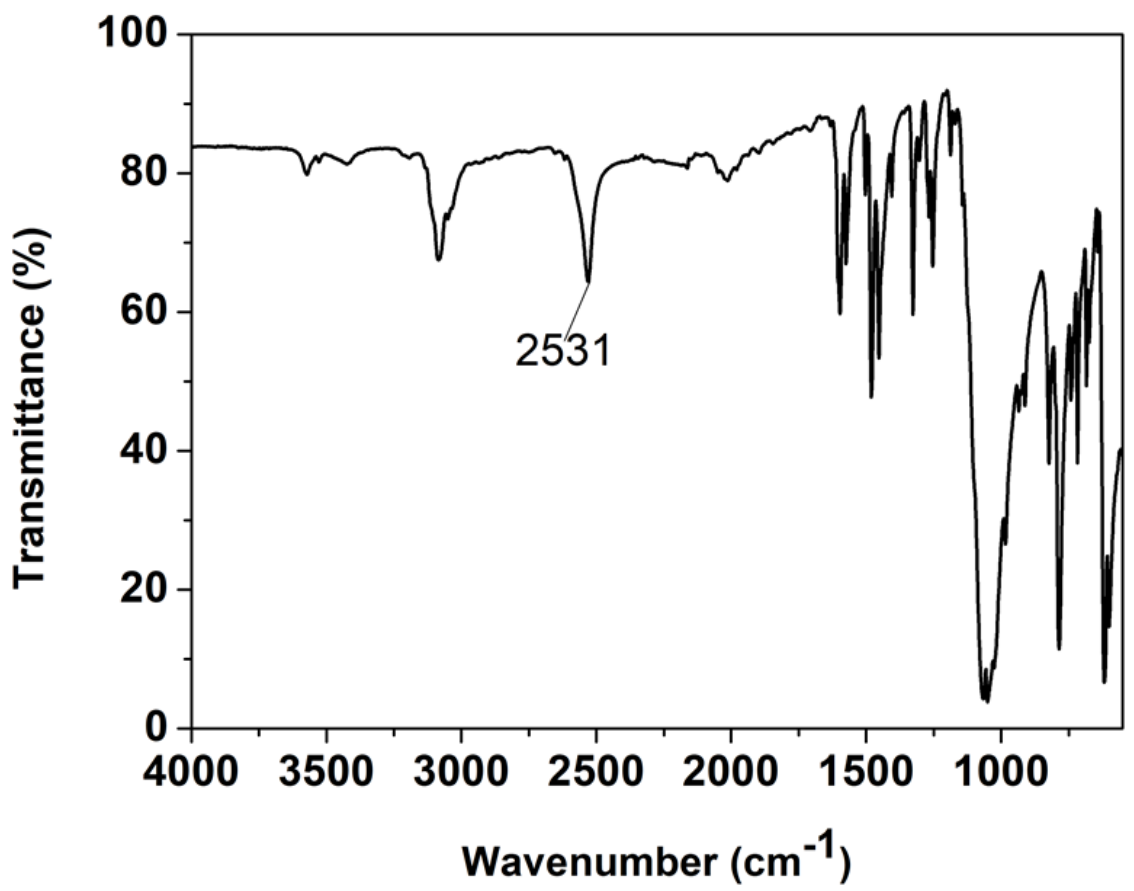

Figure S10. ATR-FTIR spectrum of 2. 


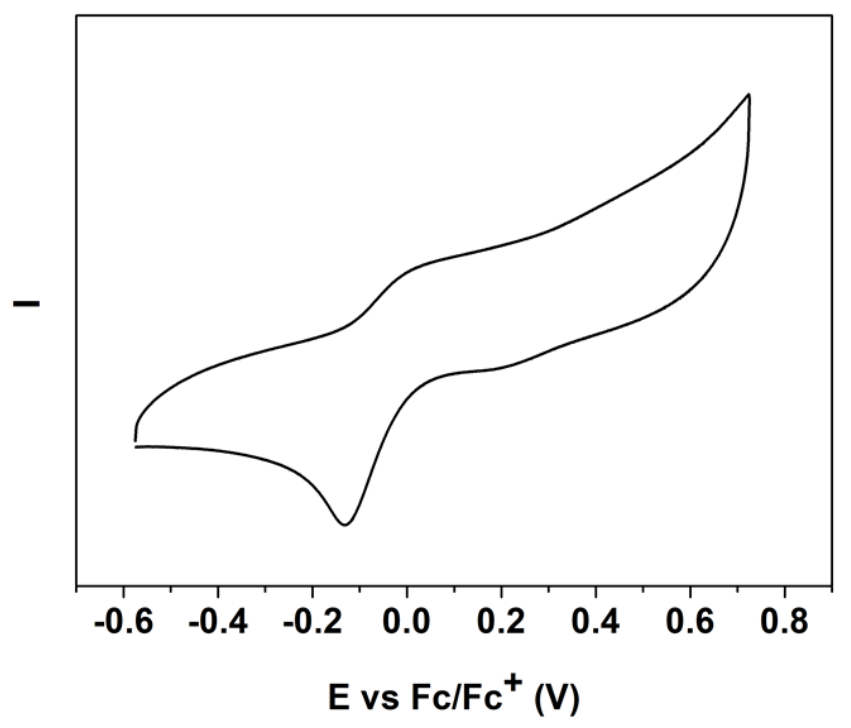

Figure S11. Cyclic voltammetry of 1 in DMF, supporting electrolyte: ${ }^{n} \mathrm{Bu}_{4} \mathrm{NPF}_{6} 0.1 \mathrm{M}$, working electrode: carbon, counter electrode: Pt wire, reference electrode: $\mathrm{Ag} / \mathrm{AgNO}_{3}$, scan rate: $0.1 \mathrm{~V} \mathrm{~s}^{-1}$.

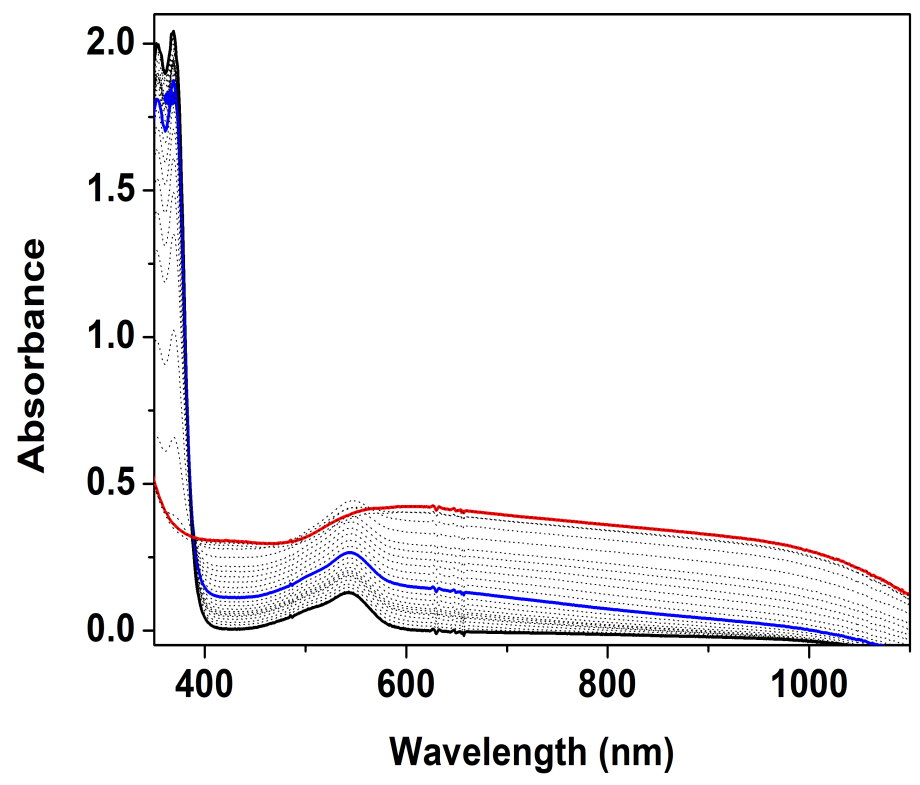

Figure S12. Electronic absorption spectra of the reaction between 1 (DMF, $\left.25^{\circ} \mathrm{C}, 0.55 \mathrm{mM}\right)$ and CHD (1000 equiv.). blue $=300 \mathrm{~s} ;$ red $=2000 \mathrm{~s}$. 


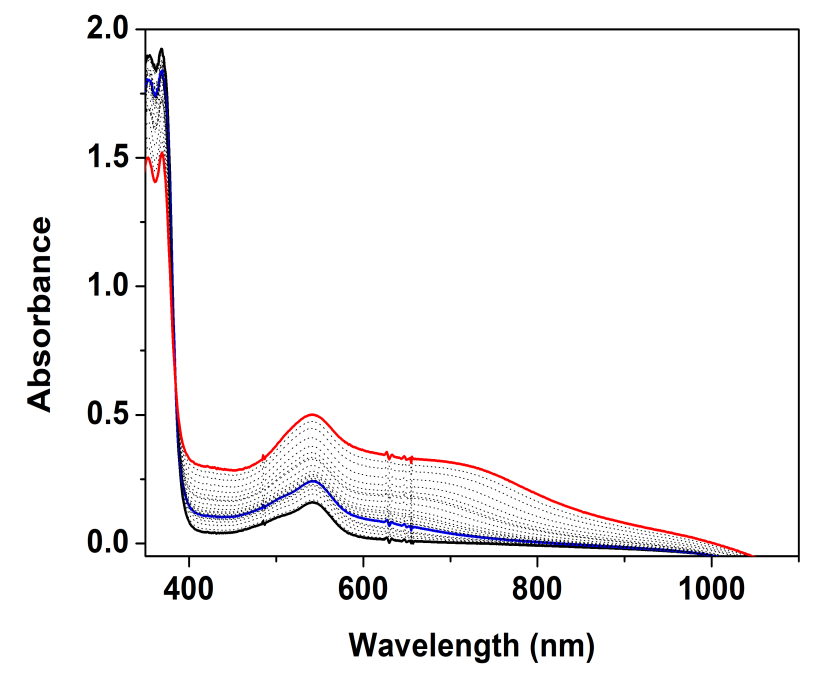

Figure S13. Electronic absorption spectra of the reaction between complex 1 (DMF, $25{ }^{\circ} \mathrm{C}$, $0.50 \mathrm{mM})$ and CHD (100 equiv.). blue trace $=3000 \mathrm{~s} ; \mathrm{red}=18000 \mathrm{~s}$.

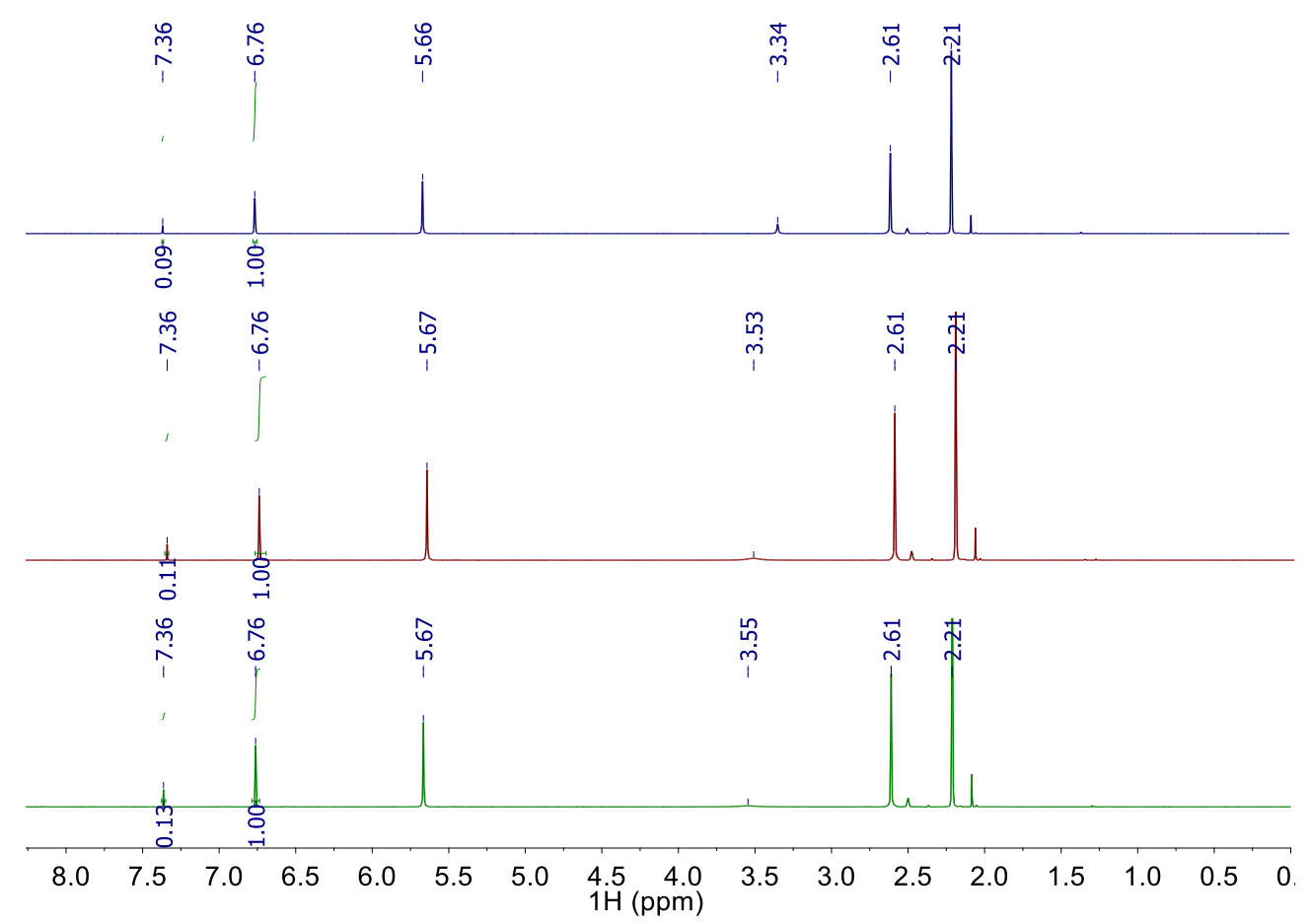

Figure S14. ${ }^{1}$ H-NMR spectra of the reaction between complex 1 and CHD (100 equiv.) in DMSO-D 6 ; blue $=0 \mathrm{~s}$, red $=2 \mathrm{~h}$, green $=5 \mathrm{~h}$; benzene $\mathrm{C}-\mathrm{H}: \delta=7.36 \mathrm{ppm} ; H_{2} \mathrm{O}: \delta=3.334-$ 3.55 ppm; CHD: $\delta=2.61$ and 5.67 ppm, 1,3,5-trimethylbenzene (internal standard): $\delta=2.21$ and $6.76 \mathrm{ppm}$. 


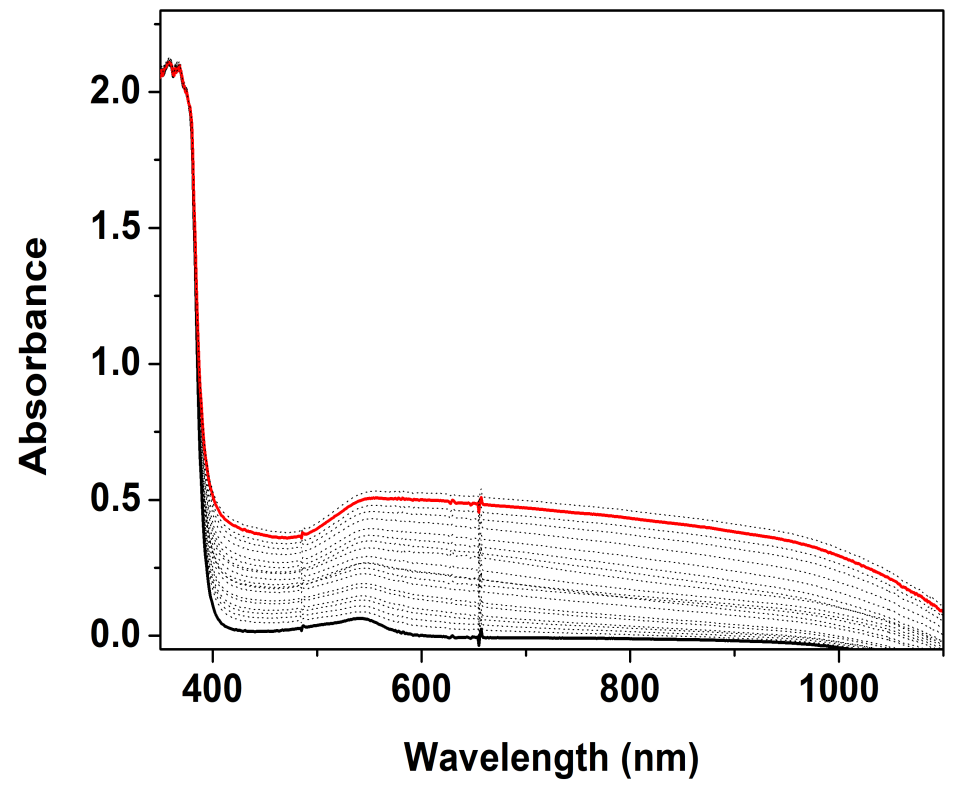

Figure S15. Electronic absorption spectra of the reaction between complex 1 (0.55 mM, DMF, $25^{\circ} \mathrm{C}$ ) and DHA (200 equiv.) monitored for $2200 \mathrm{~s}$.

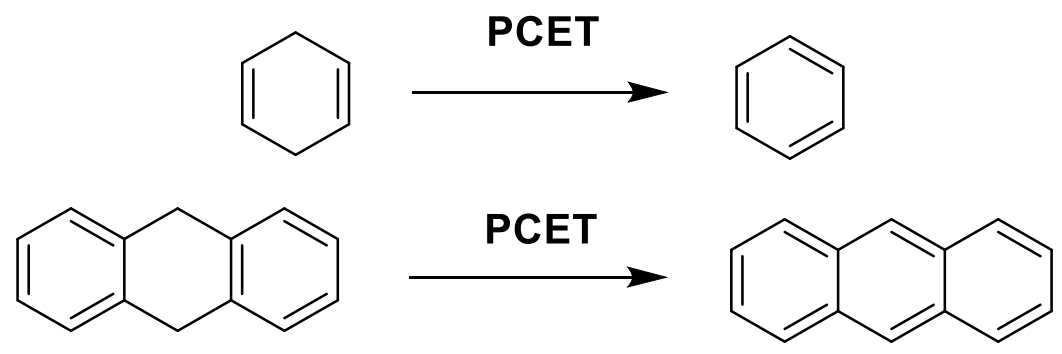

Figure S16. PCET oxidation products of CHD (top) and DHA (bottom). 


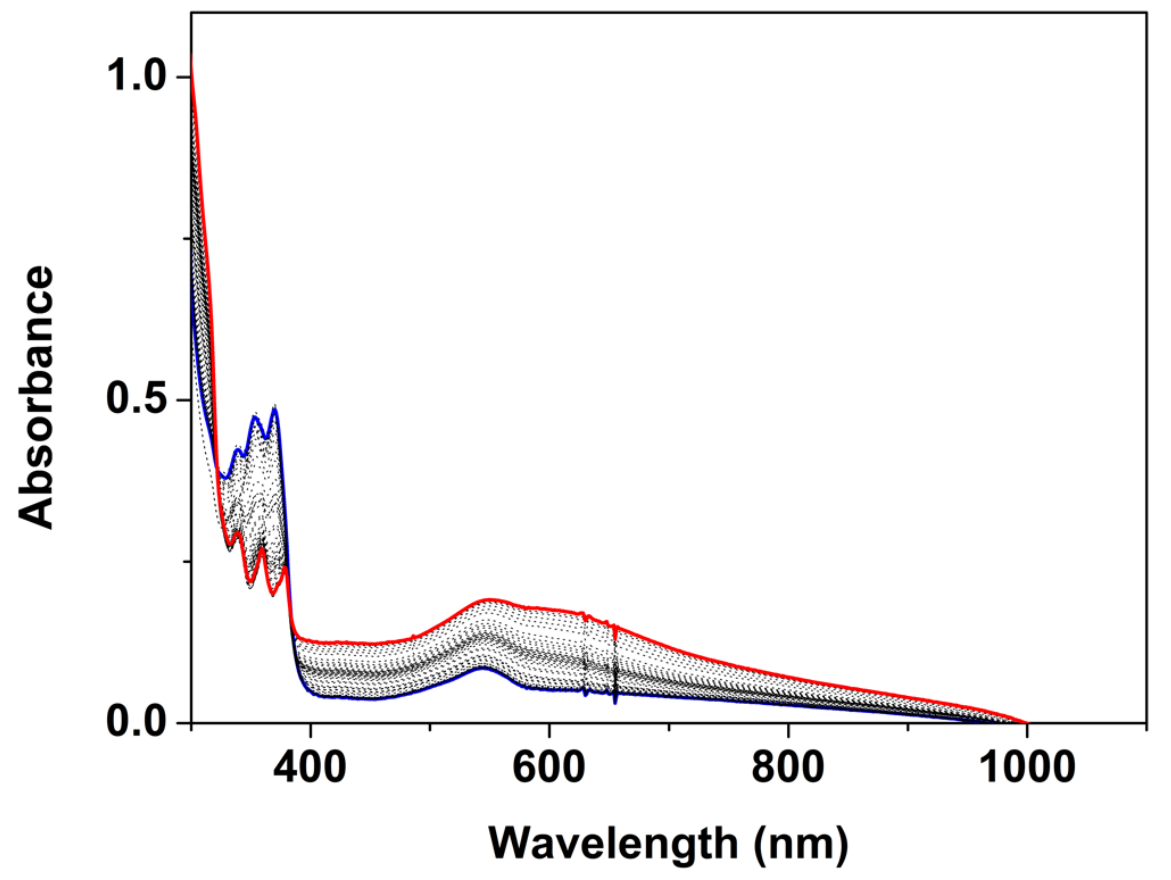

Figure S17. Electronic absorption spectra of the reaction between complex $1(0.15 \mathrm{mM}, \mathrm{DMF}$, $25^{\circ} \mathrm{C}$ ) and DHA (500 equiv.).

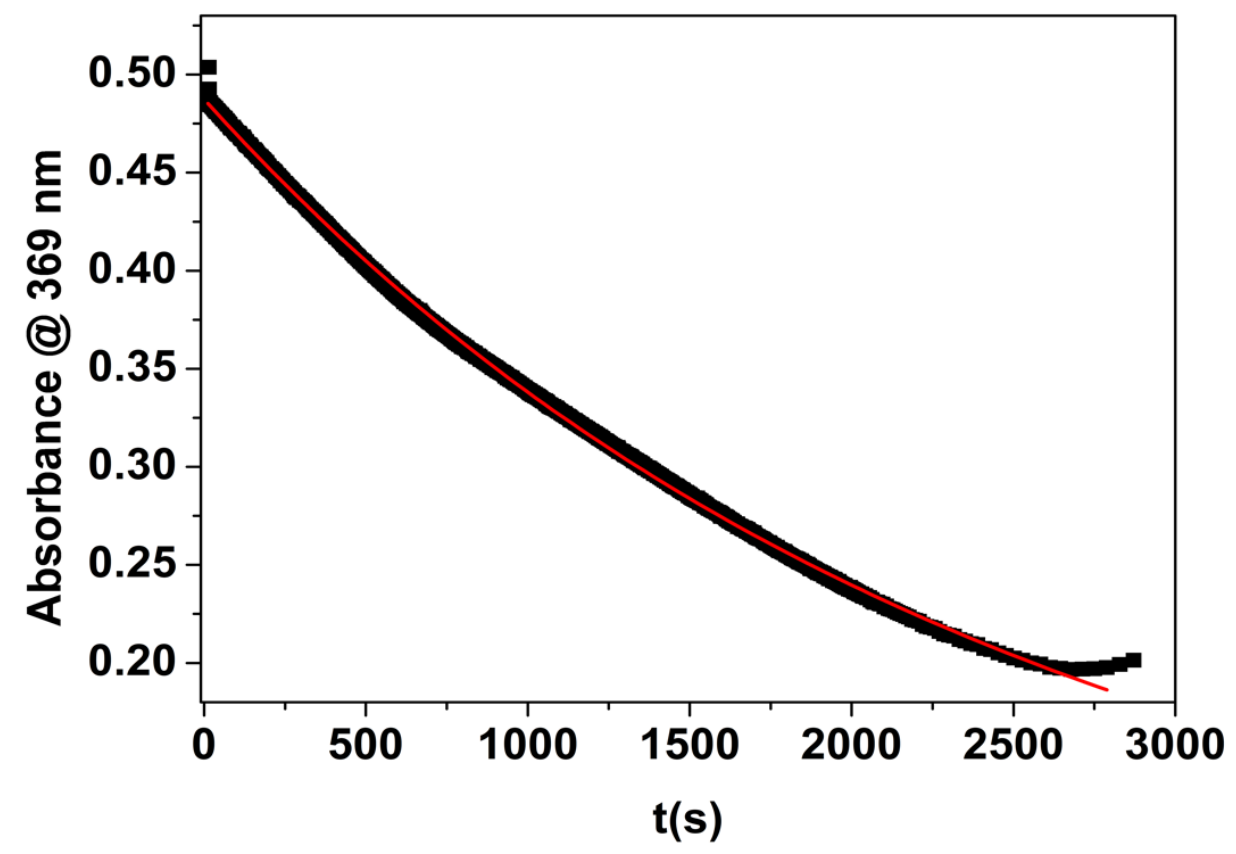

Figure S18. Plot of the absorbance at $\lambda=369 \mathrm{~nm}$ against time during the reaction between 1 (DMF, $25^{\circ} \mathrm{C}, 0.15 \mathrm{mM}$ ) and DHA (500 equiv.). 


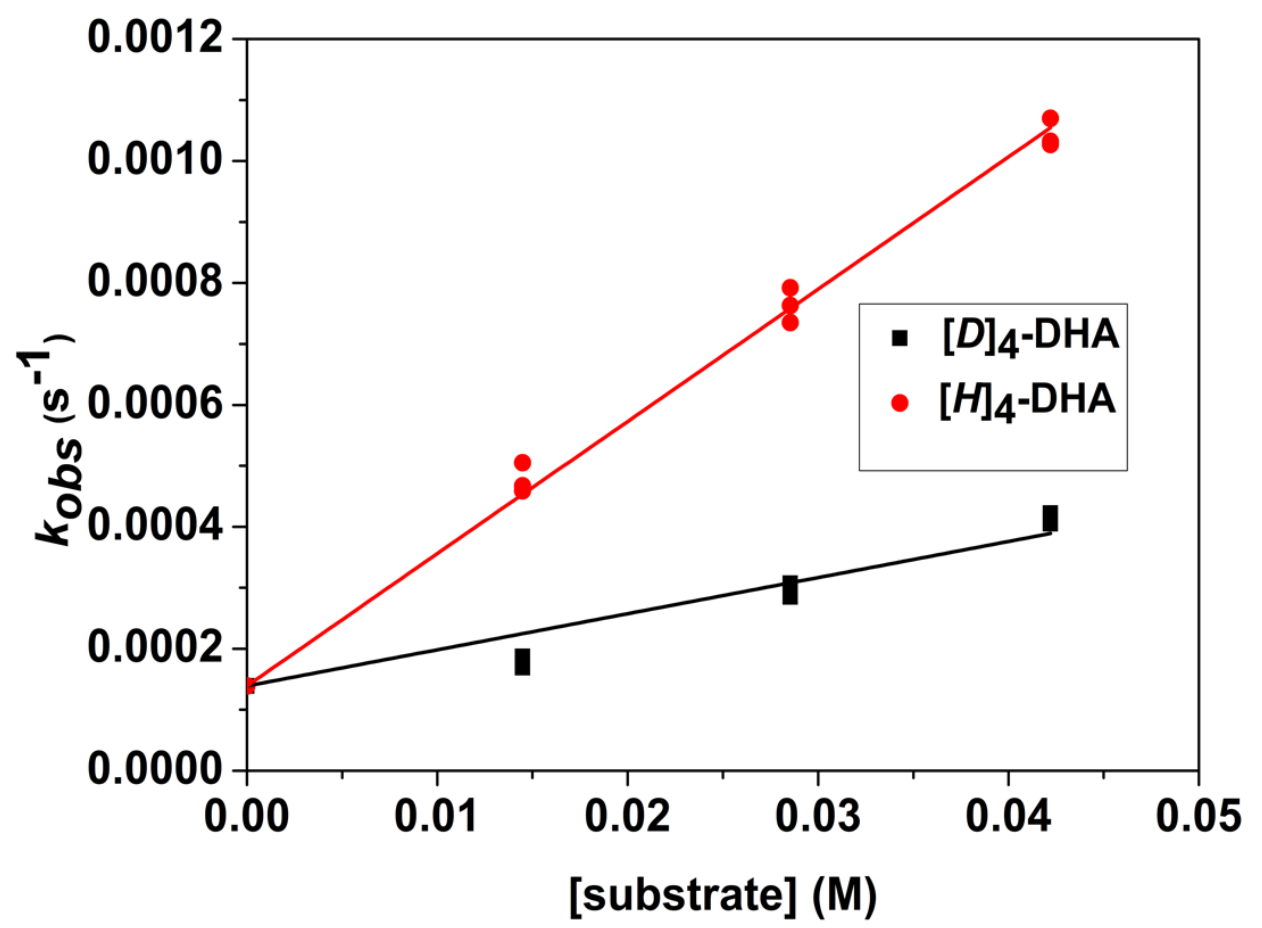

Figure S19. Plot of $k_{\mathrm{obs}}$ versus [substrate] determined for the reaction between complex $\mathbf{1}$ and $[D]_{4}$-DHA (black trace) and $[H]_{4}$-DHA (red trace).

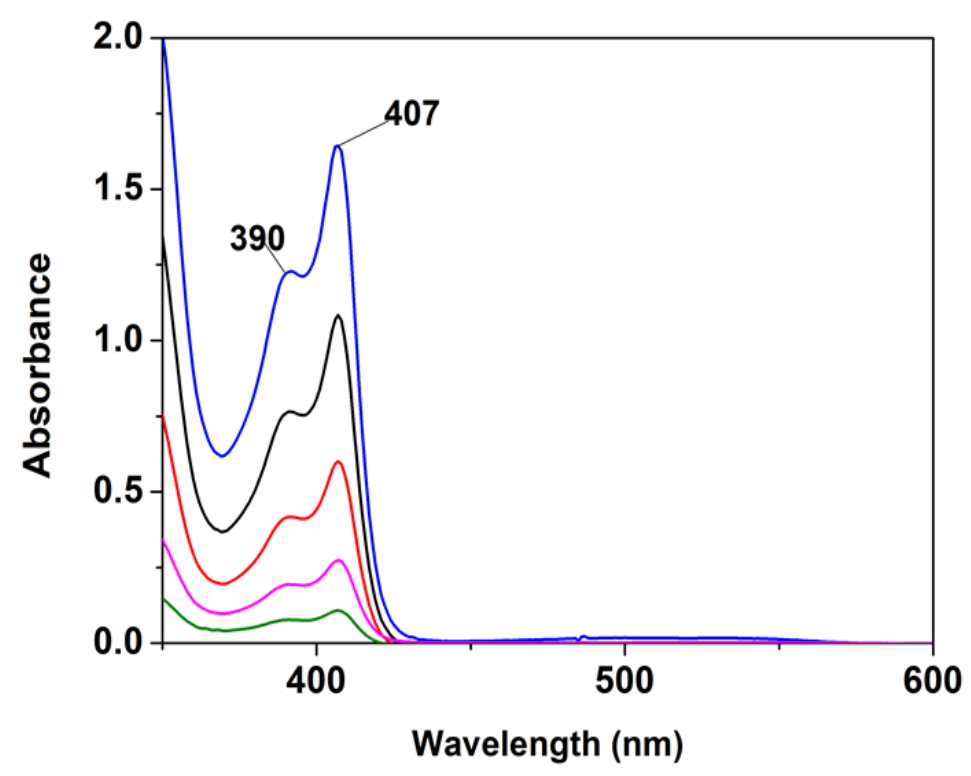

Figure S20. Electronic absorption spectra of 4-methoxy-2,6-di-tert-butylphenoxyl radical in DMF at variable concentrations $(0.052,0.13,0.26,0.52,0.78 \mathrm{mM})$. 


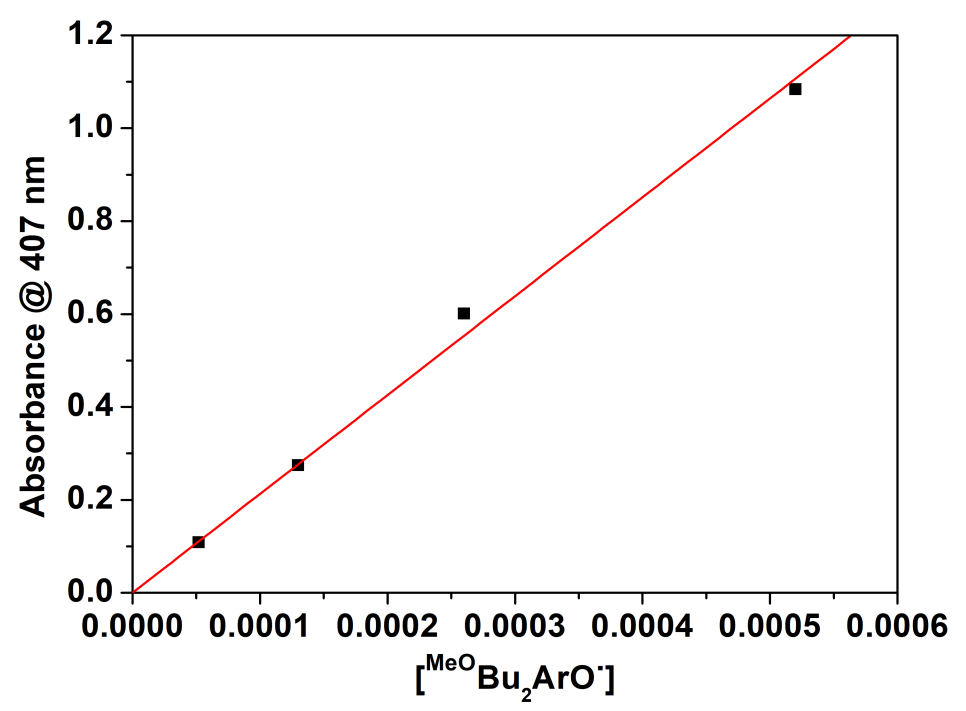

Figure S21. Plot of the absorbance vs concentration at $\lambda=407 \mathrm{~nm}$ of the 4-methoxy-2,6-ditert-butylphenoxyl radical in DMF.

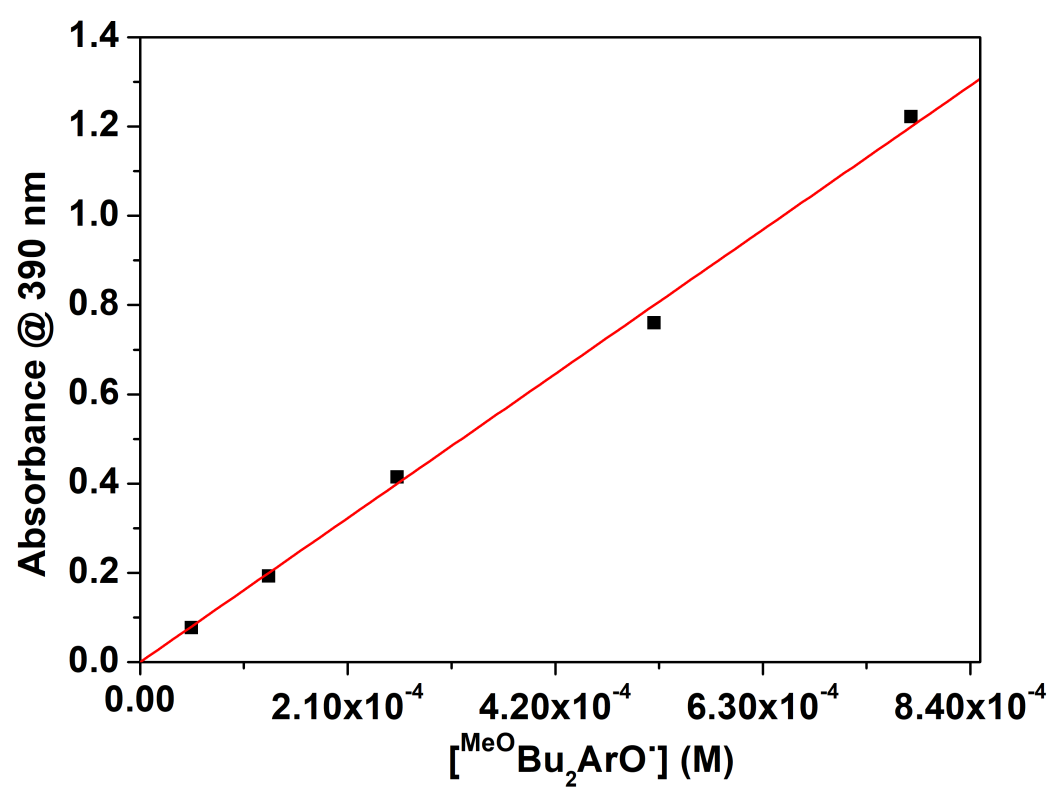

Figure S22. Plot of the absorbance vs. concentration at $\lambda=390 \mathrm{~nm}$ for the 4-methoxy-2,6-ditert-butylphenoxyl radical in DMF. 


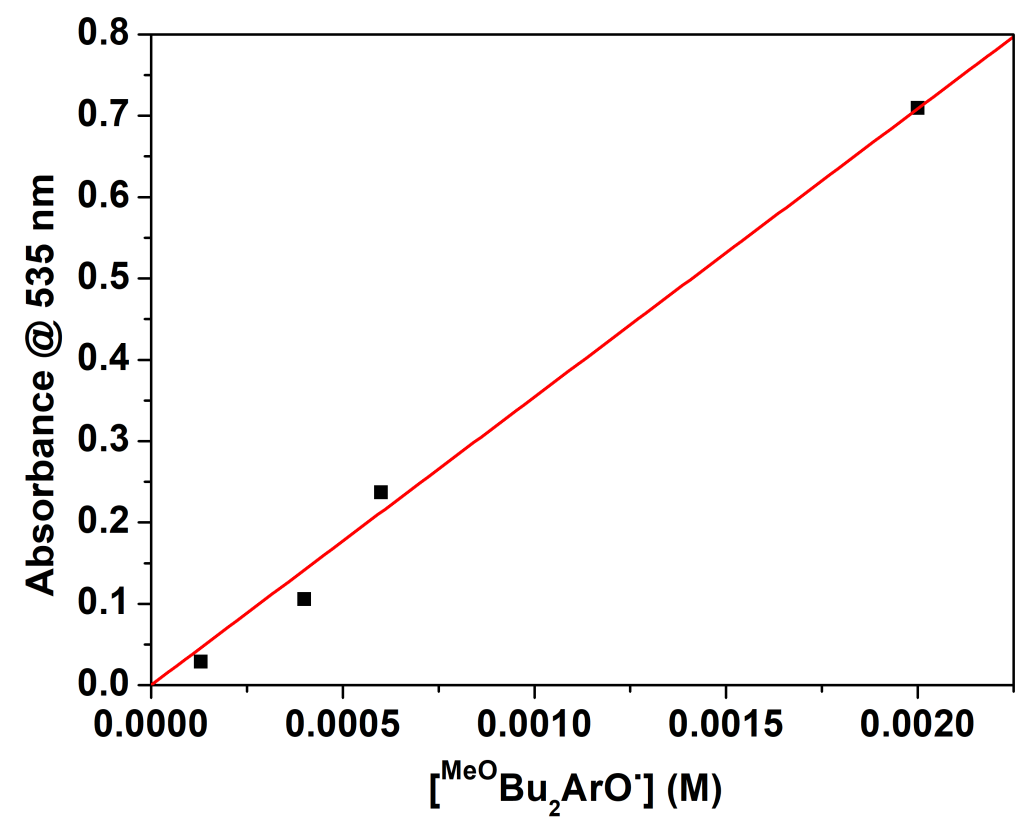

Figure S23. Plot of the absorbance vs. concentration at $\lambda=535 \mathrm{~nm}$ for the 4-methoxy-2,6-ditert-butylphenoxyl radical in DMF.

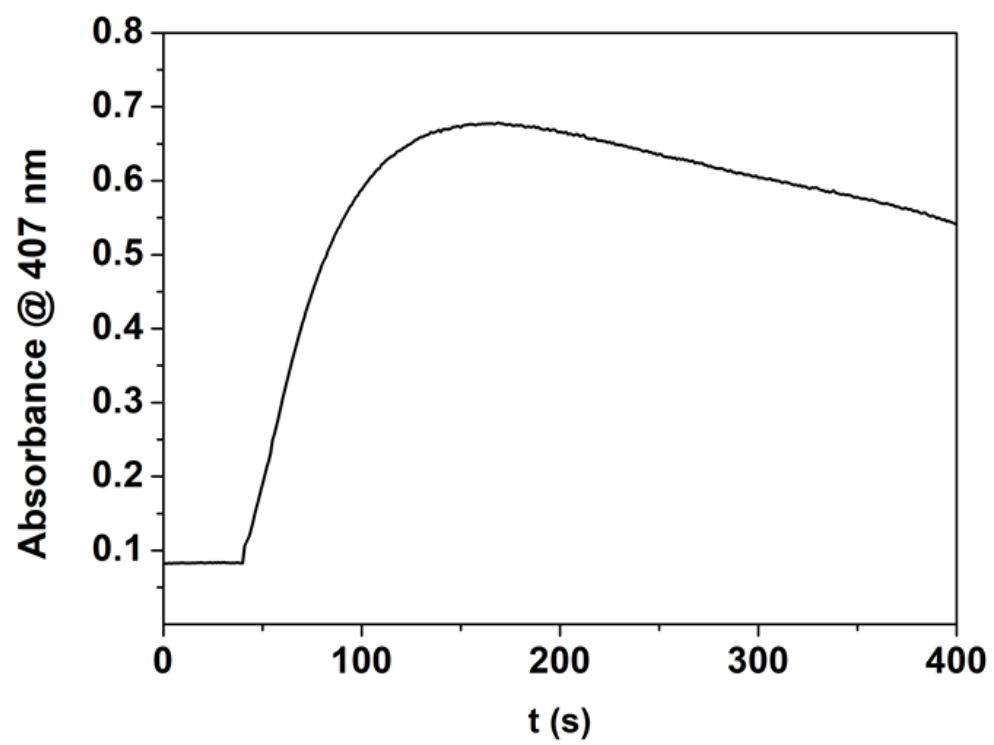

Figure S24. Plot of the absorbance at $\lambda=407 \mathrm{~nm}$ versus time during the reaction between 1 and 200 equiv. of $4-\mathrm{CH}_{3} \mathrm{O}-2,6-\mathrm{DTBP}$ at $25^{\circ} \mathrm{C}$ in DMF. 

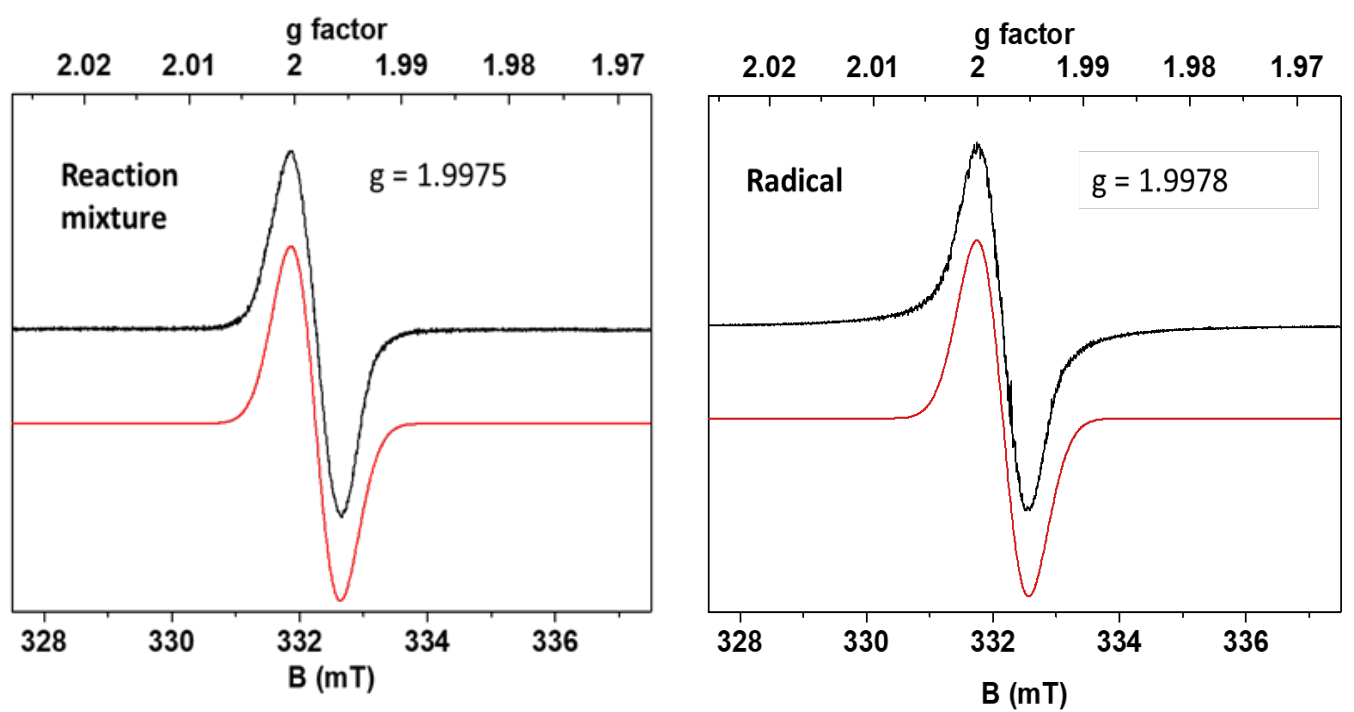

Figure S25. X-Band EPR spectra of the reaction mixture of 1 with 4-CH${ }_{3} \mathrm{O}-2,6-\mathrm{DTBP}$ (left) and the independently synthesized phenoxyl radical (right). Black = experimental spectra, red = simulated spectra. The spectra were acquired from a frozen DMF solution and measured at $77 \mathrm{~K}$ with a $0.2 \mathrm{~mW}$ microwave power and a $0.2 \mathrm{mT}$ modulation amplitude.

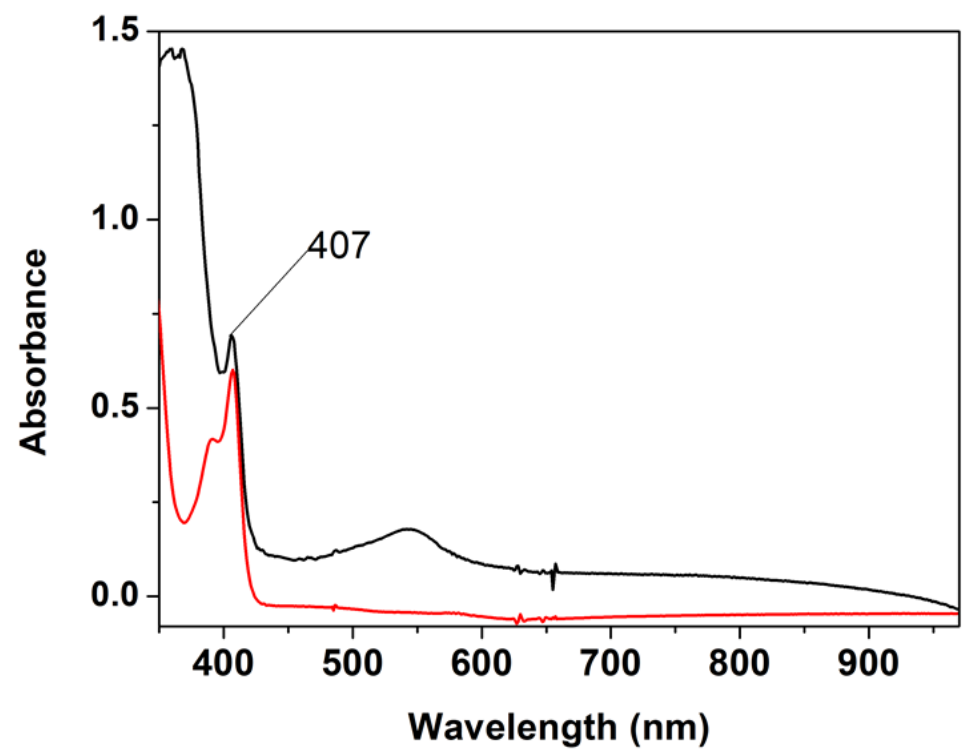

Figure S26. Electronic absorption spectra $\left(\mathrm{DMF}, 25^{\circ} \mathrm{C}\right)$ of the independently synthesized 4methoxy-2,6-di-tert-butylphenoxyl radical (red trace) and of the reaction between complex 1 and an excess of 4- $\mathrm{CH}_{3} \mathrm{O}-2,6-\mathrm{DTBP}$ (black trace). 


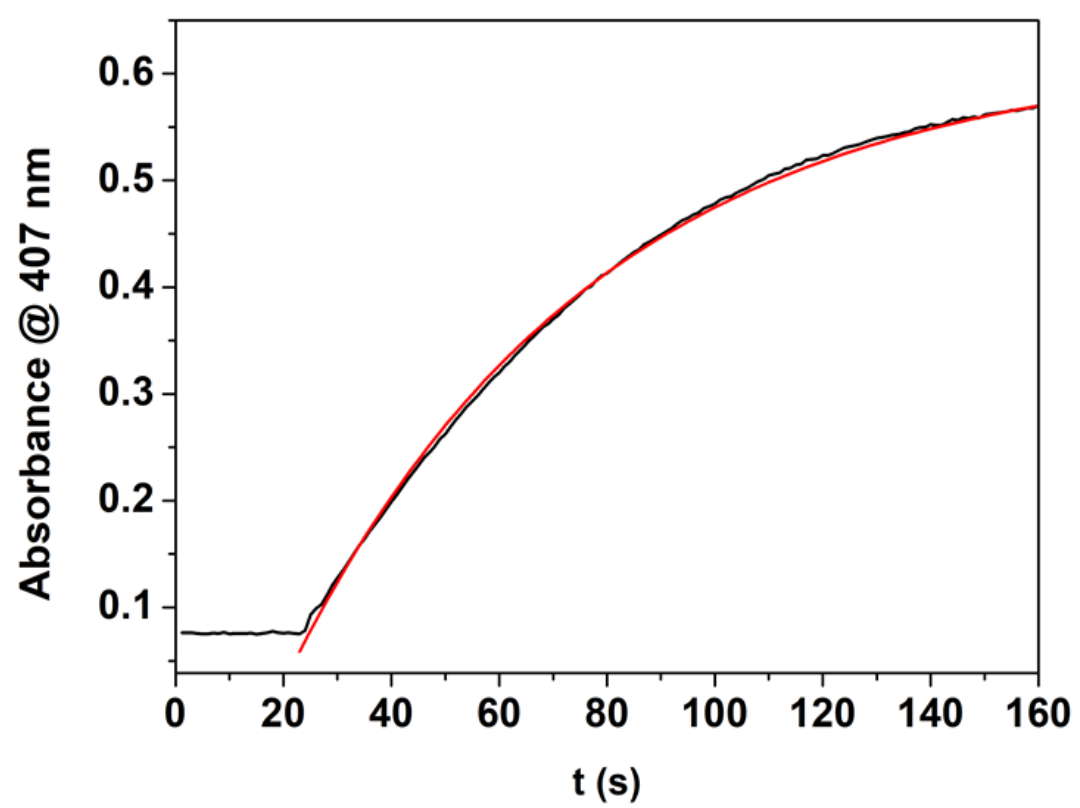

Figure S27. Fitting of the absorbance at $\lambda=407 \mathrm{~nm}$ vs. time during the reaction between 1 and 200 equiv. of $4-\mathrm{CH}_{3} \mathrm{O}-2,6-\mathrm{DTBP}$ at $25^{\circ} \mathrm{C}$ in DMF.

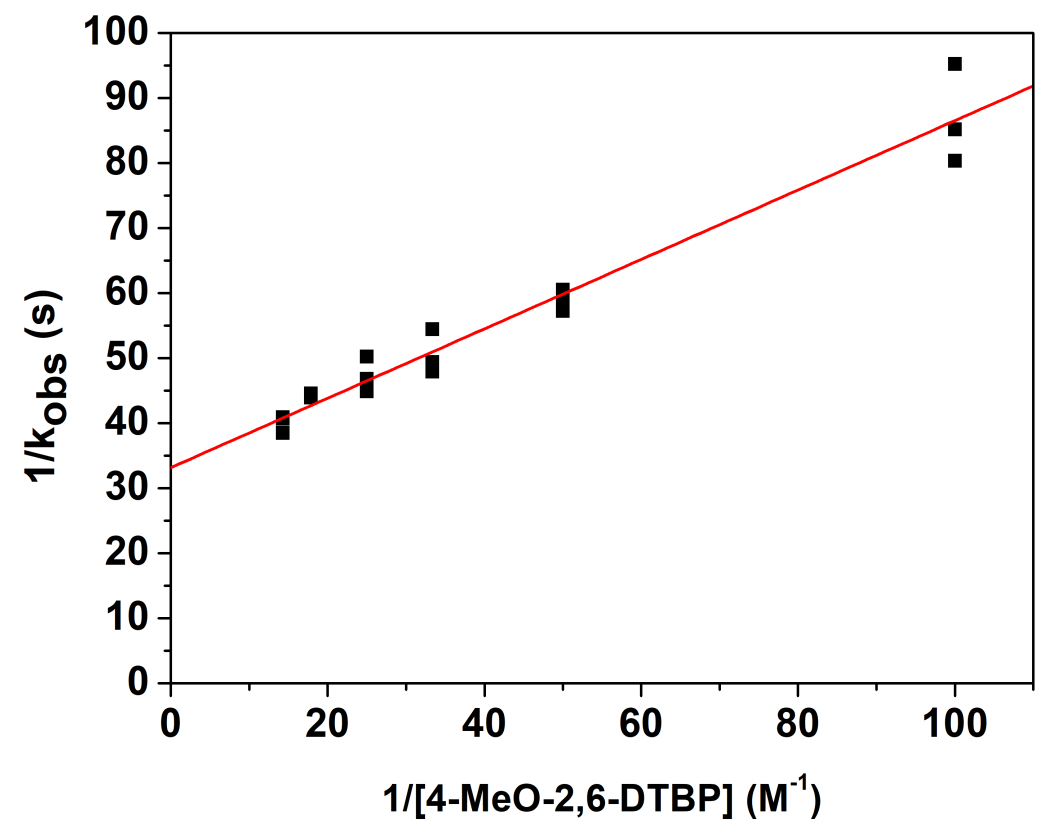

Figure S28. Plot of $1 / k_{\text {obs }}$ against $1 /\left[4-\mathrm{CH}_{3} \mathrm{O}-2,6-\mathrm{DTBP}\right]$. 


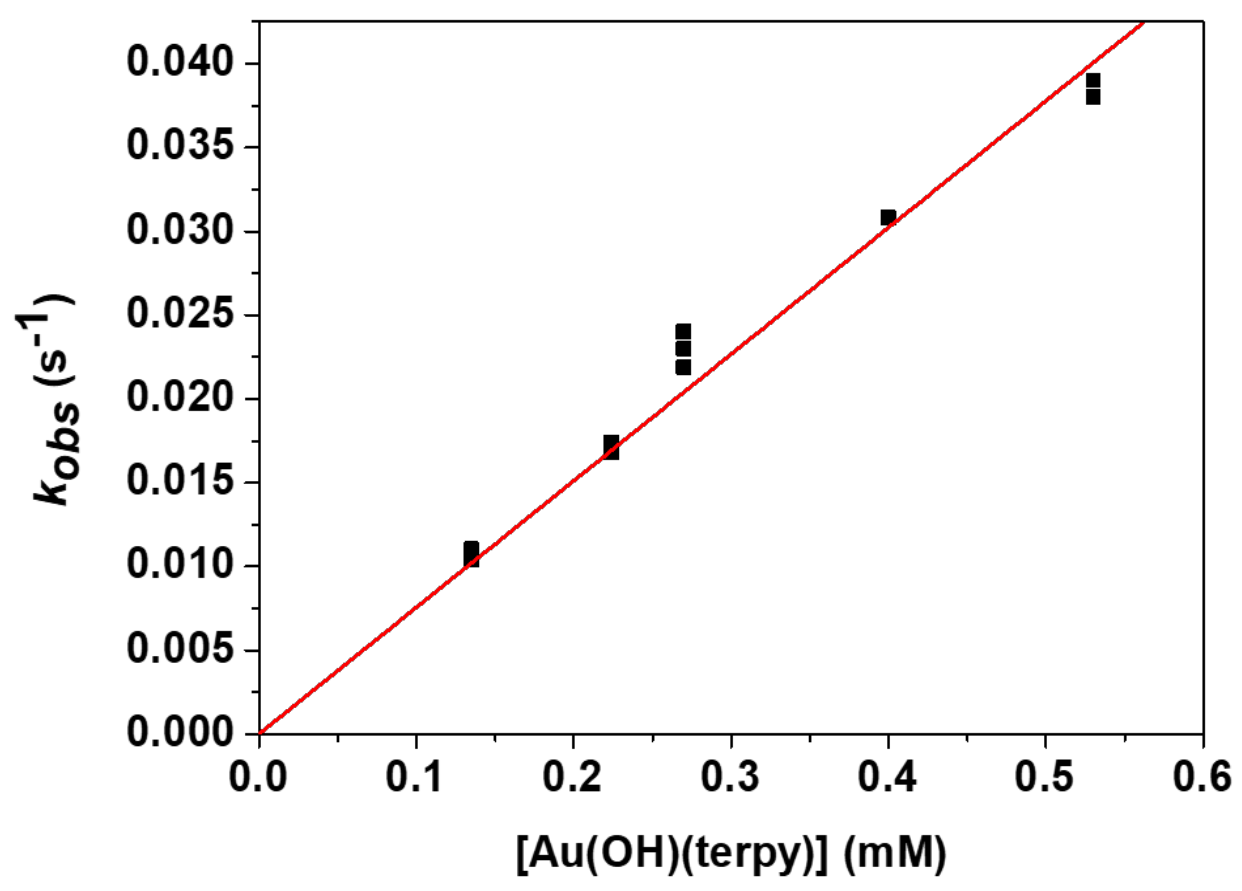

Figure S29. Plot of $k_{\mathrm{obs}}$ recorded in saturating conditions (350 equiv. of substrate) versus [1] in its reaction with 4- $\mathrm{CH}_{3} \mathrm{O}-2,6-\mathrm{DTBP}$.

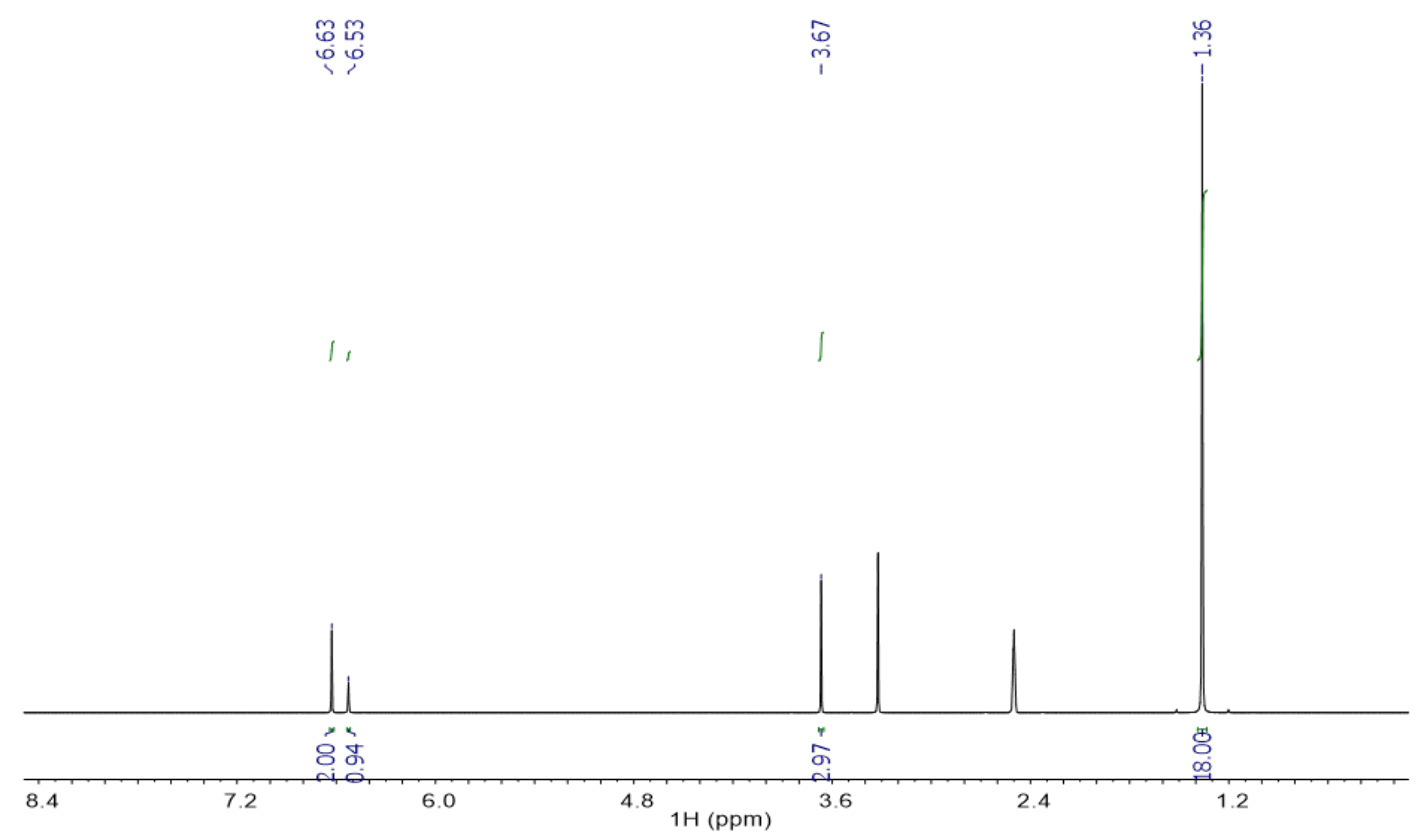

Figure S30. ${ }^{1} \mathrm{H}-\mathrm{NMR}$ spectrum in $\mathrm{DMSO}^{-\mathrm{D}_{6}}$ of $4-\mathrm{CH}_{3} \mathrm{O}-2,6-\mathrm{DTBP}$. 


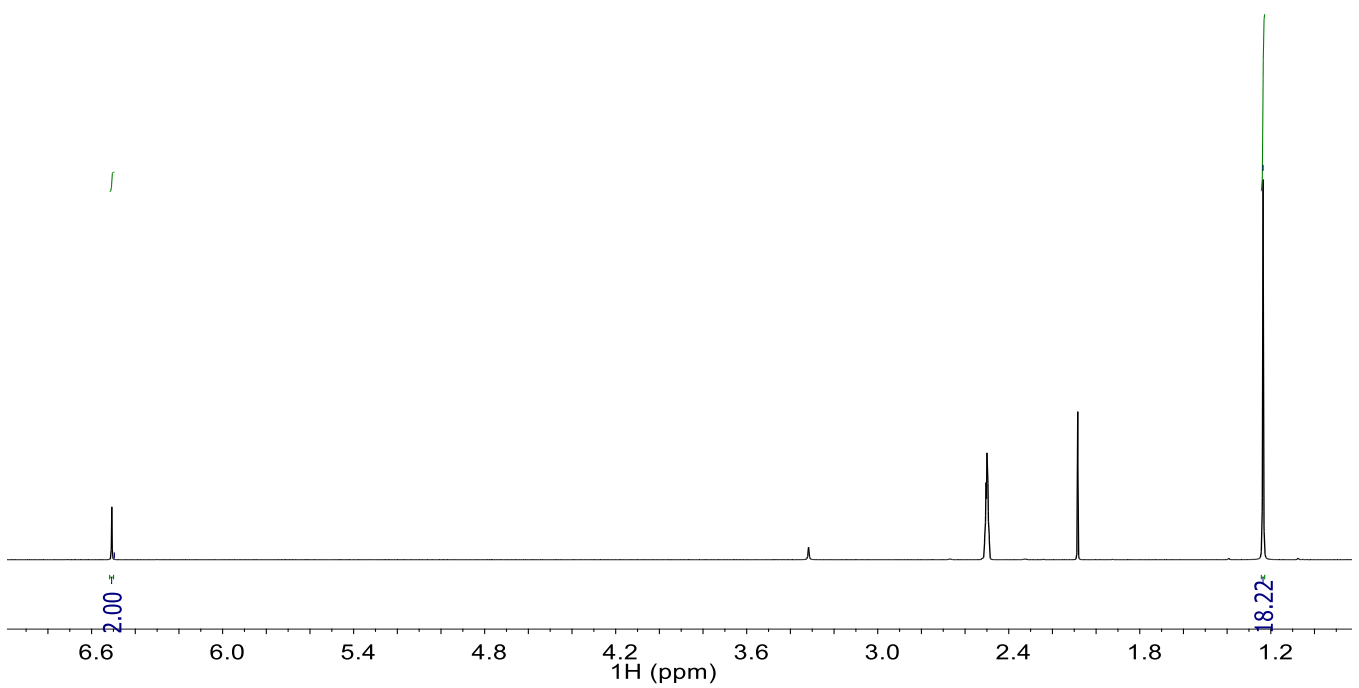

Figure S31. ${ }^{1} \mathrm{H}-\mathrm{NMR}$ in DMSO-D 6 of 2,6-di-tert-butylquinone (2,6-DTBQ).

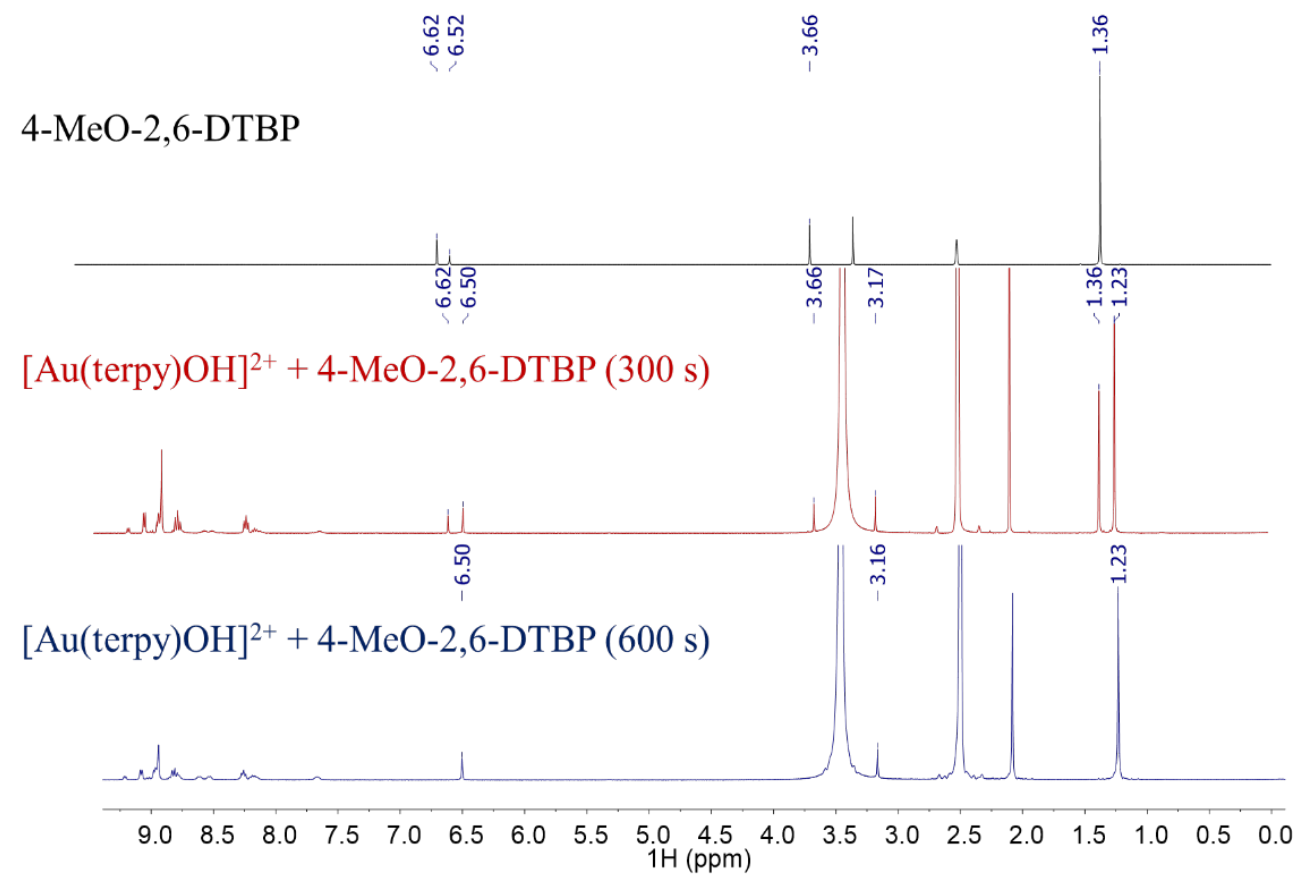

Figure S32. ${ }^{1} \mathrm{H}-\mathrm{NMR}$ in DMSO-D 6 of $4-\mathrm{CH}_{3} \mathrm{O}-2,6-\mathrm{DTBP}$ (black) and of complex 1 in the presence of $4-\mathrm{CH}_{3} \mathrm{O}-2,6-\mathrm{DTBP}(15$ equiv.). $\mathrm{Red}=\sim 300 \mathrm{~s}$, blue $=\sim 600 \mathrm{~s}$ from the mixing of reagents (blue trace). $\mathrm{H}_{2} \mathrm{O}: \delta=3.32-3.46 \mathrm{ppm}$. 


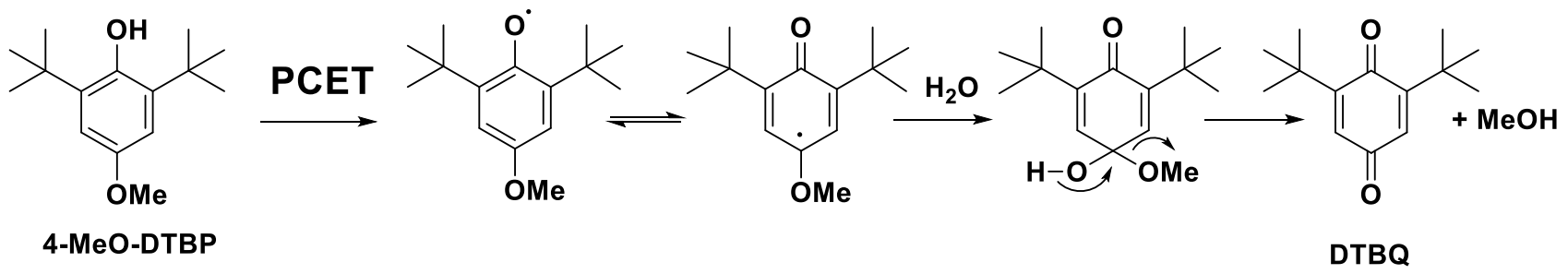

Figure S33. Proposed mechanism of formation of DTBQ by oxidation of 4- $\mathrm{CH}_{3} \mathrm{O}-2,6-\mathrm{DTBP}$.

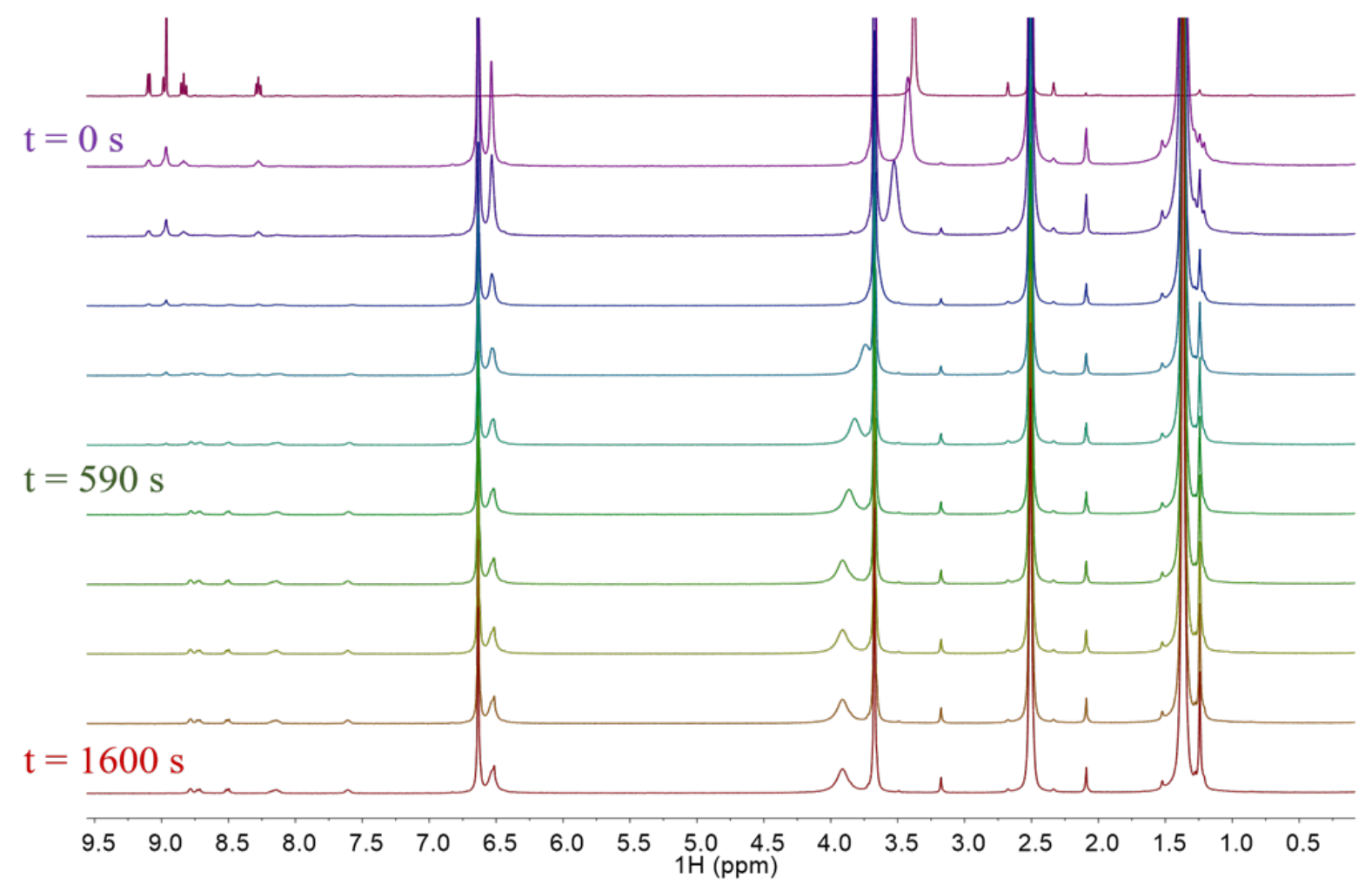

Figure S34. Selected ${ }^{1} \mathrm{H}-\mathrm{NMR}$ in $\mathrm{DMSO}_{-} \mathrm{D}_{6}$ for the reaction between 1 and $4-\mathrm{CH}_{3} \mathrm{O}-2,6$ DTBP (25 equiv.) monitored for $1600 \mathrm{~s}$. 


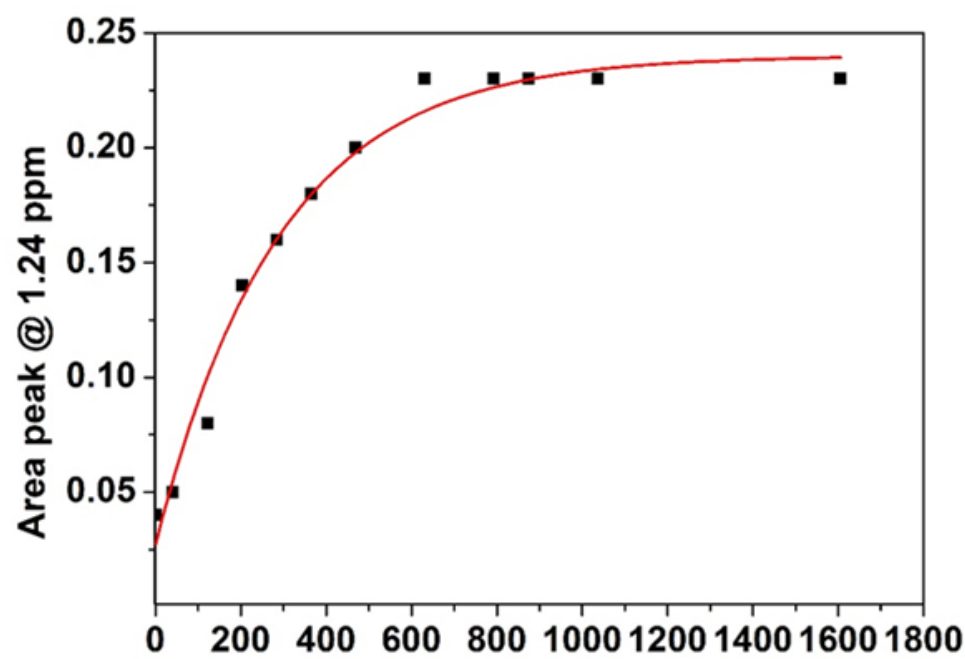

t(s)

Figure S35. Plot of the area of the peak at $\delta=1.24 \mathrm{ppm}$ in the ${ }^{1} \mathrm{H}-\mathrm{NMR}$ spectrum $\left(\mathrm{C}\left(\mathrm{CH}_{3}\right)_{3}\right.$ in 2,6-DTBQ, Figure S27) versus time. The area has been calculated with respect to the DMSO solvent residual peak.

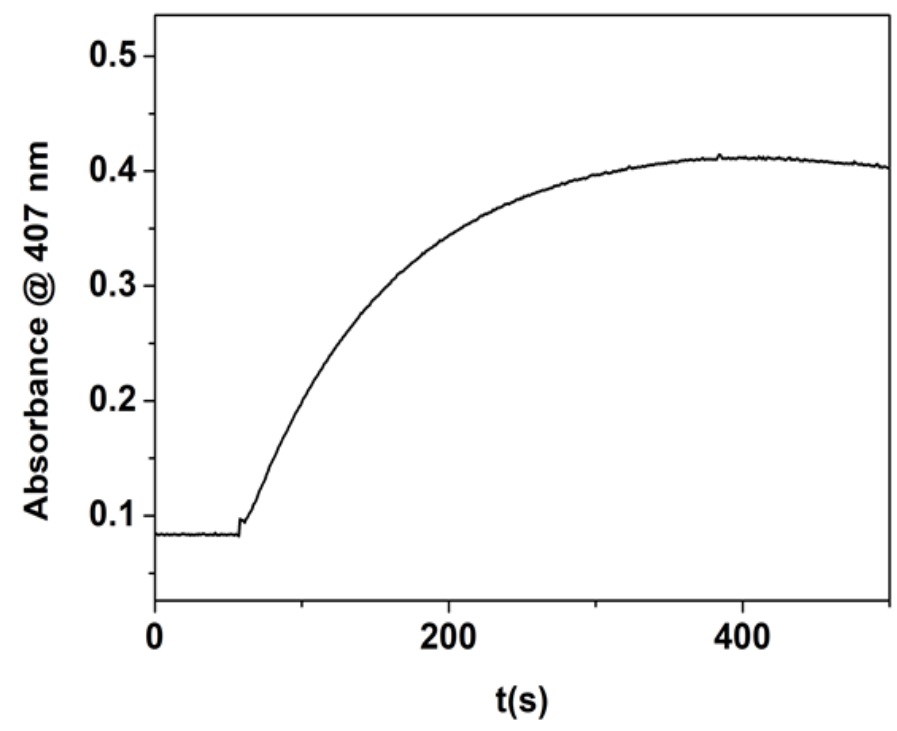

Figure S36. Plot of the absorbance at $\lambda=407 \mathrm{~nm}$ versus time during the reaction between 1 (DMF, $25^{\circ} \mathrm{C}$ ) and 4-CH3 $\mathrm{O}-2,6-\mathrm{DTBP}$ in absence of $\mathrm{O}_{2}$. 


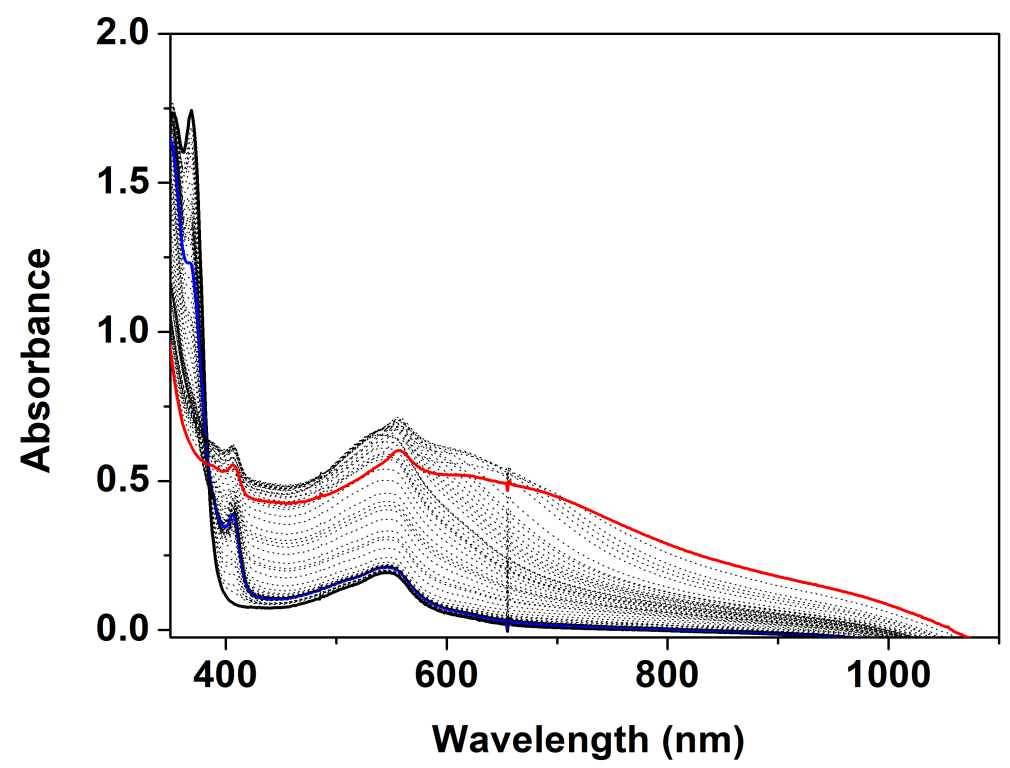

Figure S37. Electronic absorption spectra of the reaction of complex 1 (DMF, $25{ }^{\circ} \mathrm{C}, 0.45$ $\mathrm{mM}$ ) with 4- $\mathrm{CH}_{3} \mathrm{O}-2,6-\mathrm{DTBP}$ (100 equiv.) in the absence of $\mathrm{O}_{2}$ monitored for $1000 \mathrm{~s}$. Blue $=$ $200 \mathrm{~s}, \mathrm{Red}=1000 \mathrm{~s}$.

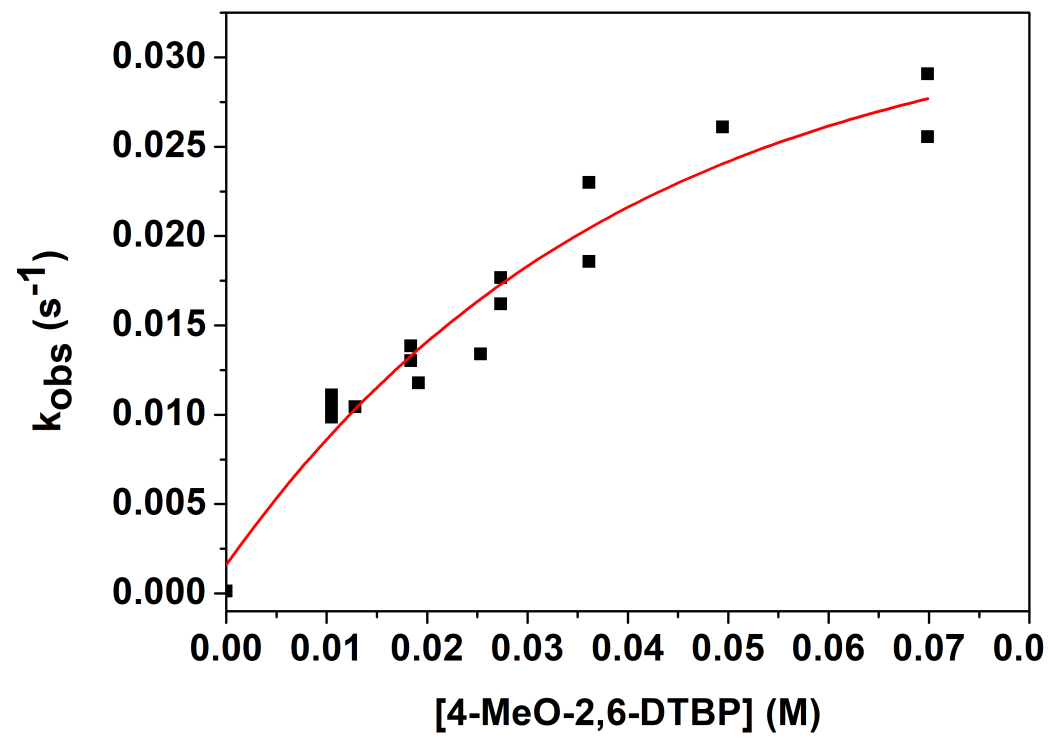

Figure S38. Plot of $k_{\text {obs }}$ versus [4- $\mathrm{CH}_{3} \mathrm{O}-2,6-\mathrm{DTBP}$ ] for the reaction between complex 1 and 4- $\mathrm{CH}_{3} \mathrm{O}-2,6-\mathrm{DTBP}$ in absence of $\mathrm{O}_{2}$. 


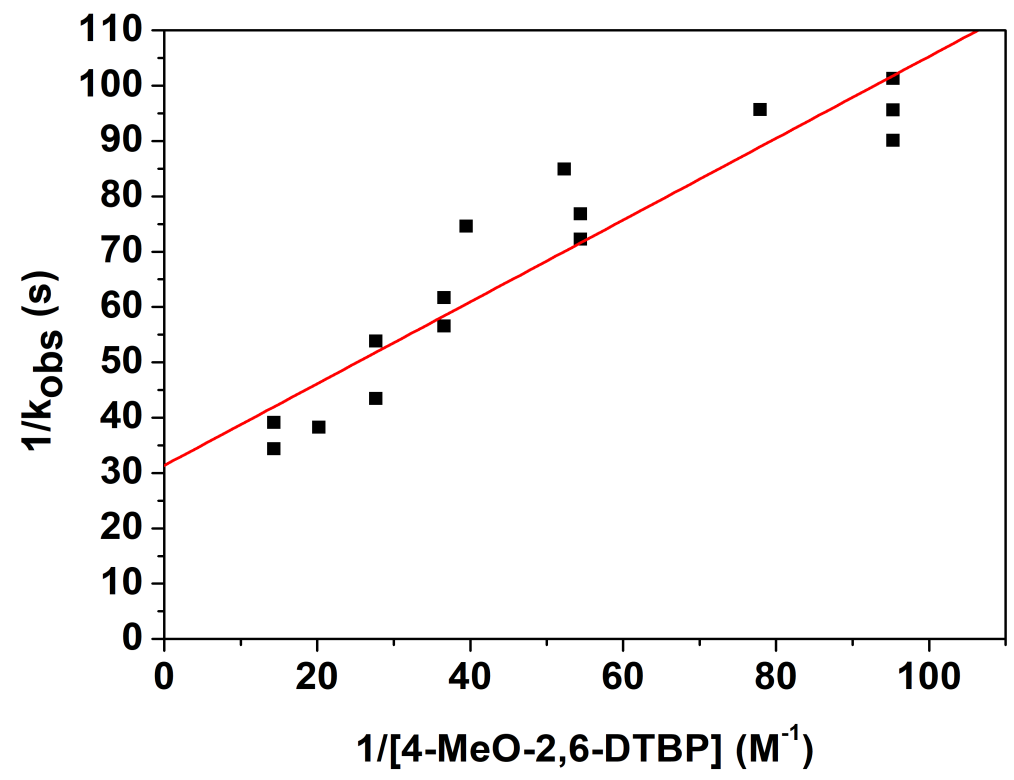

Figure S39. Plot of $1 / k_{\text {obs }}$ against $1 /\left[4-\mathrm{CH}_{3} \mathrm{O}-2,6-\mathrm{DTBP}\right]$ in absence of $\mathrm{O}_{2}$.

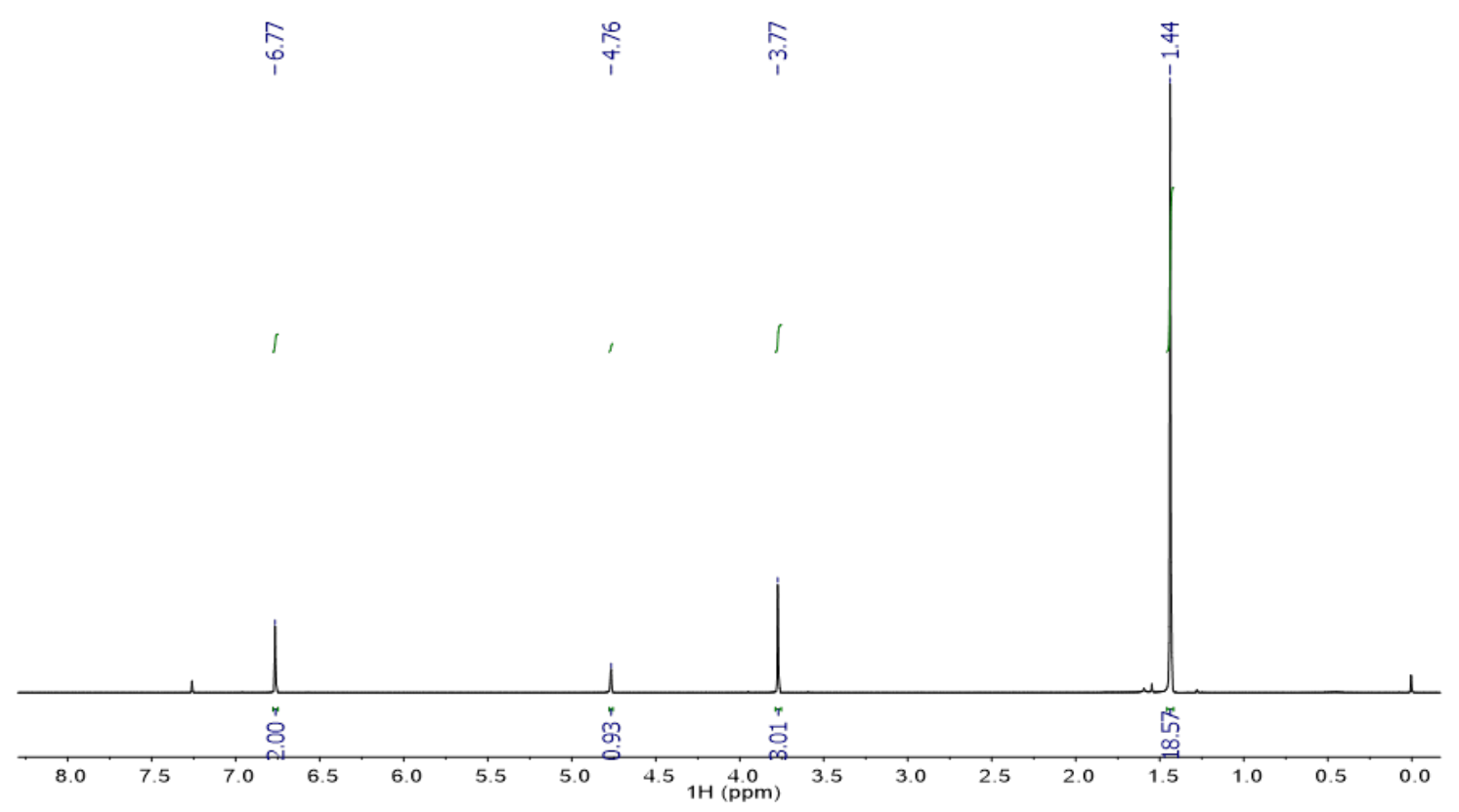

Figure S40. ${ }^{1} \mathrm{H}-\mathrm{NMR}$ in $\mathrm{CDCl}_{3}$ of $4-\mathrm{CH}_{3} \mathrm{O}-[\mathrm{H}]-2,6-\mathrm{DTBP}$. 


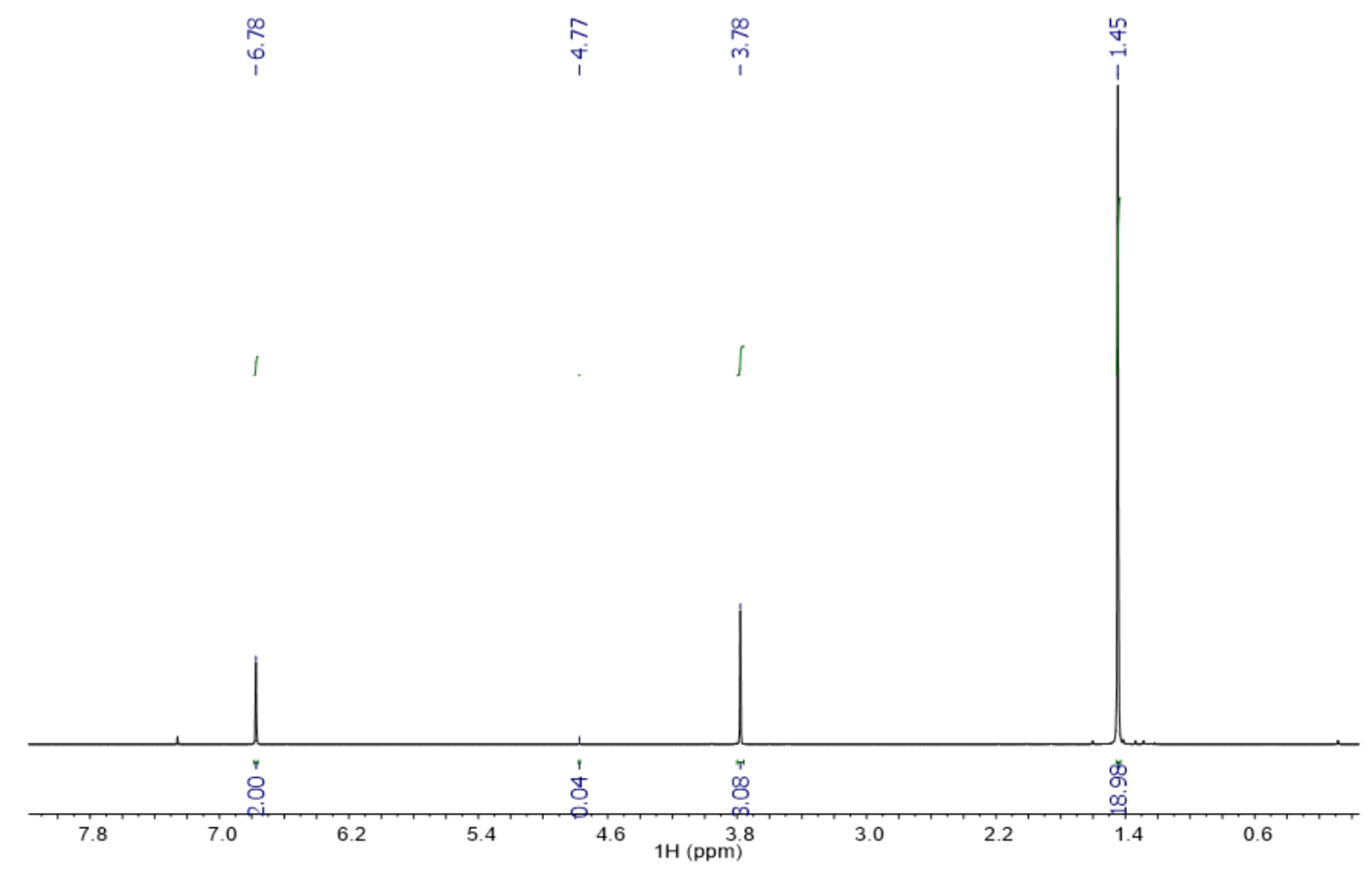

Figure S41. ${ }^{1} \mathrm{H}-\mathrm{NMR}$ in $\mathrm{CDCl}_{3}$ of $4-\mathrm{CH}_{3} \mathrm{O}-[D]-2,6-\mathrm{DTBP}$.

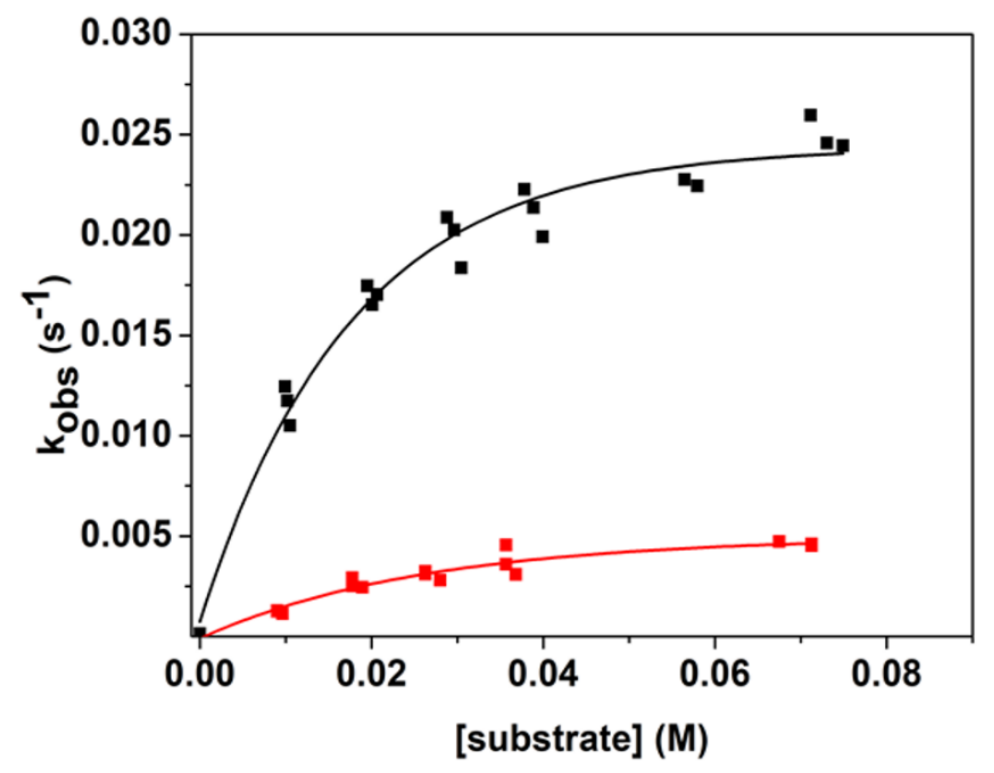

Figure S42. Plot of $k_{\mathrm{obs}}$ versus [substrate] determined for the reaction between complex $\mathbf{1}$ and 4-proto- $\mathrm{CH}_{3} \mathrm{O}-2,6-\mathrm{DTBP}$ (black trace) and 4-deutero- $\mathrm{CH}_{3} \mathrm{O}-2,6-\mathrm{DTBP}$ (red trace). 


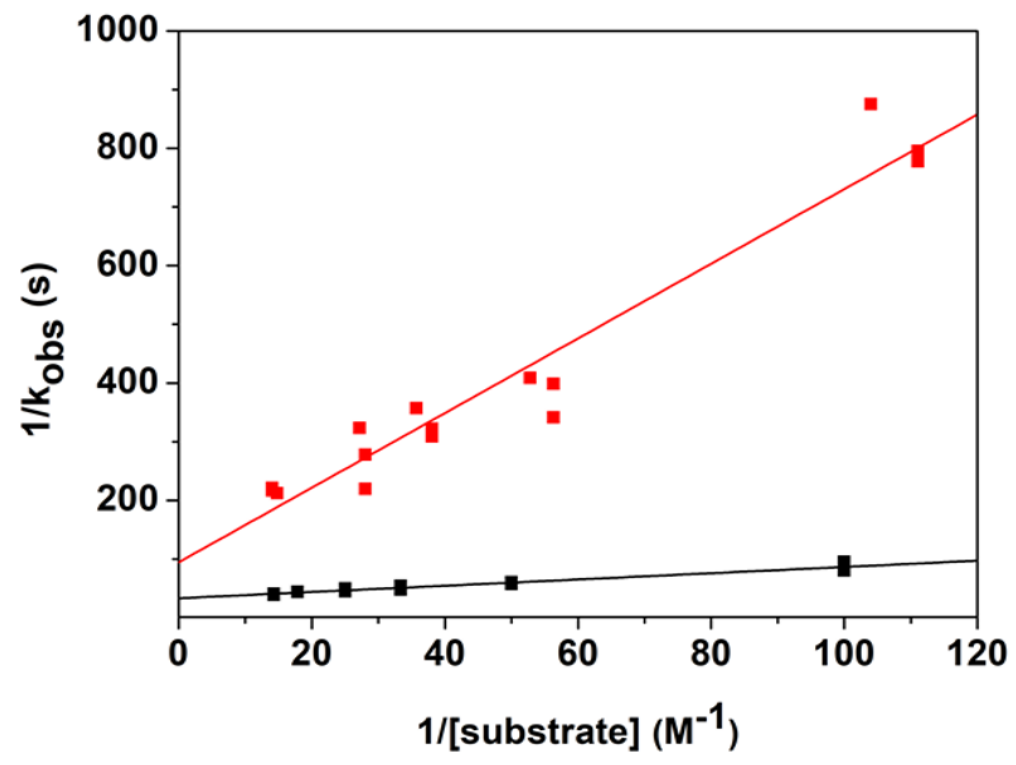

Figure S43. Plot of $1 / k_{\text {obs }}$ against $1 /[$ substrate] determined for the reaction between complex 1 and 4-proto- $\mathrm{CH}_{3} \mathrm{O}-2,6-\mathrm{DTBP}$ (black trace) and 4-deutero- $\mathrm{CH}_{3} \mathrm{O}-2,6-\mathrm{DTBP}$ (red trace).

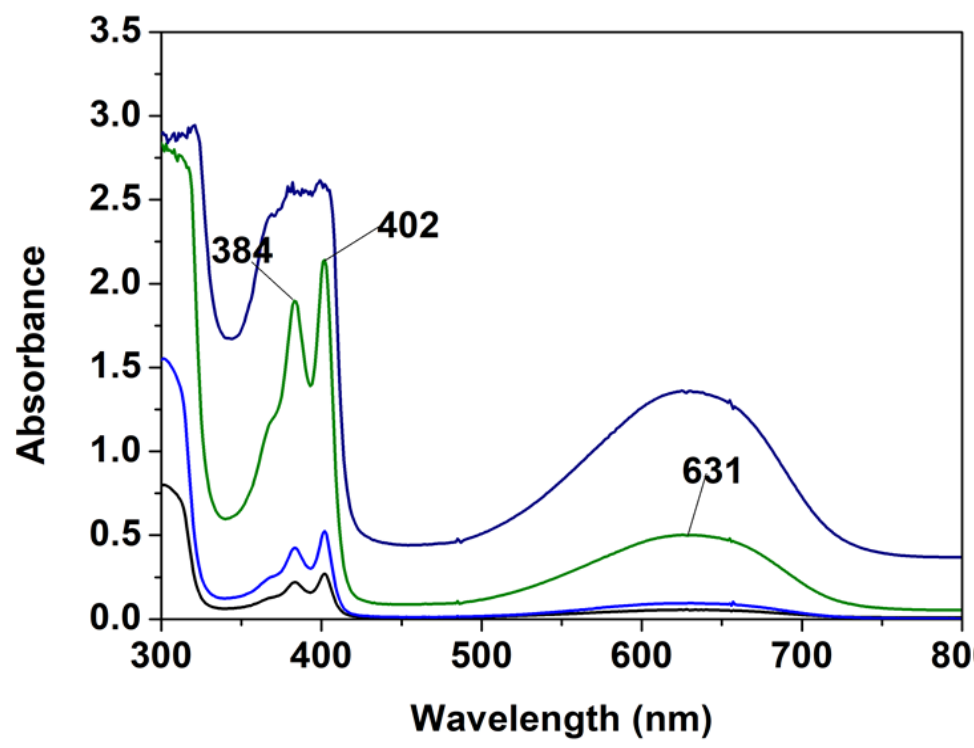

Figure S44. Electronic absorption spectra of 2,4,6-tris-tert-butylphenoxyl radical in DMF at different concentrations $(0.35,0.75,1.5$ and $3.9 \mathrm{mM})$. 


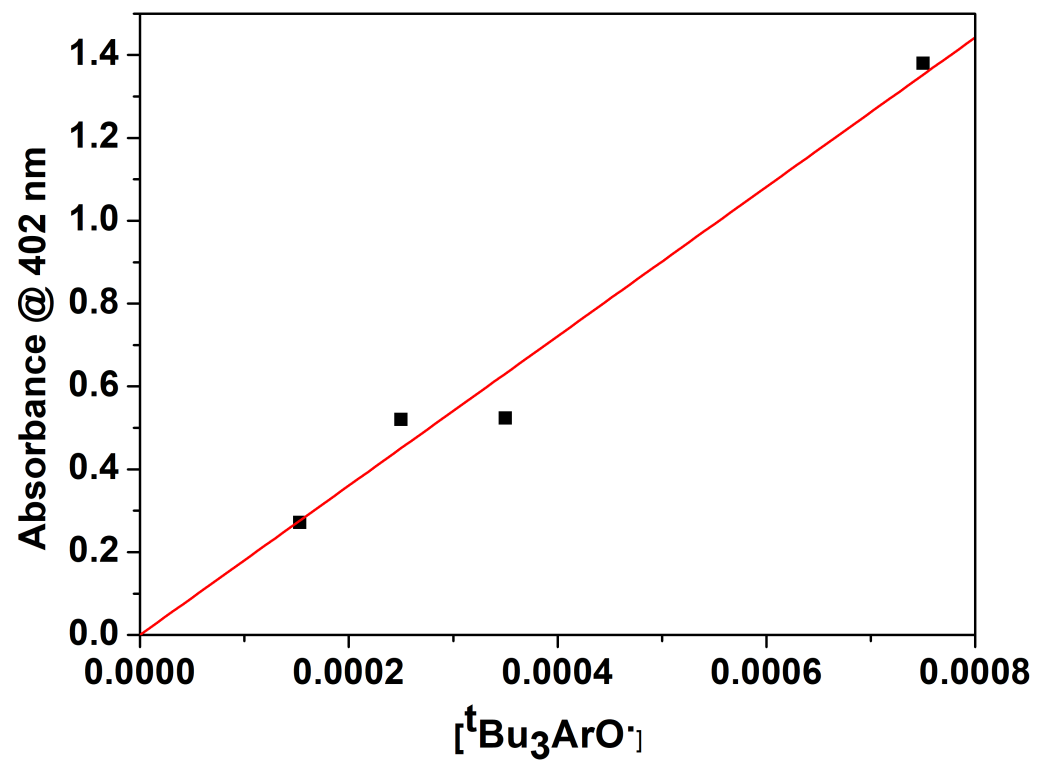

Figure S45. Plot of the absorbance vs. concentration at $\lambda=402 \mathrm{~nm}$ for the 2,4,6-tris-tertbutylphenoxyl radical in DMF.

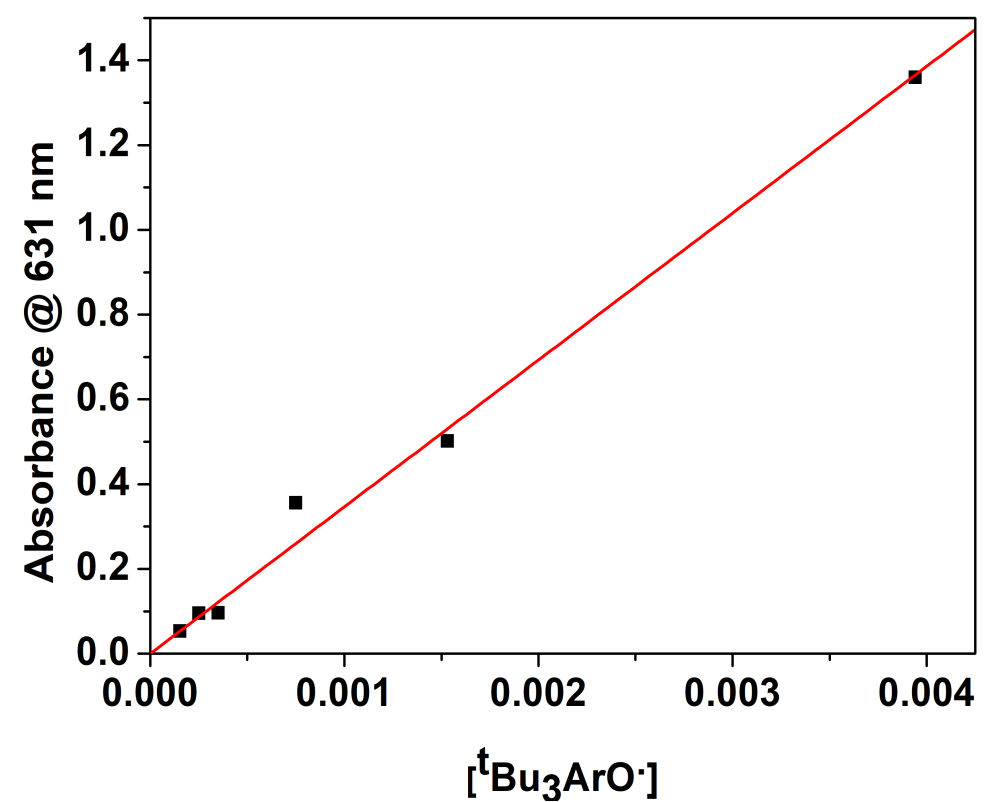

Figure S46. Plot of the absorbance vs. concentration at $\lambda=631 \mathrm{~nm}$ for the 2,4,6-tris-tertbutylphenoxyl radical in DMF. 


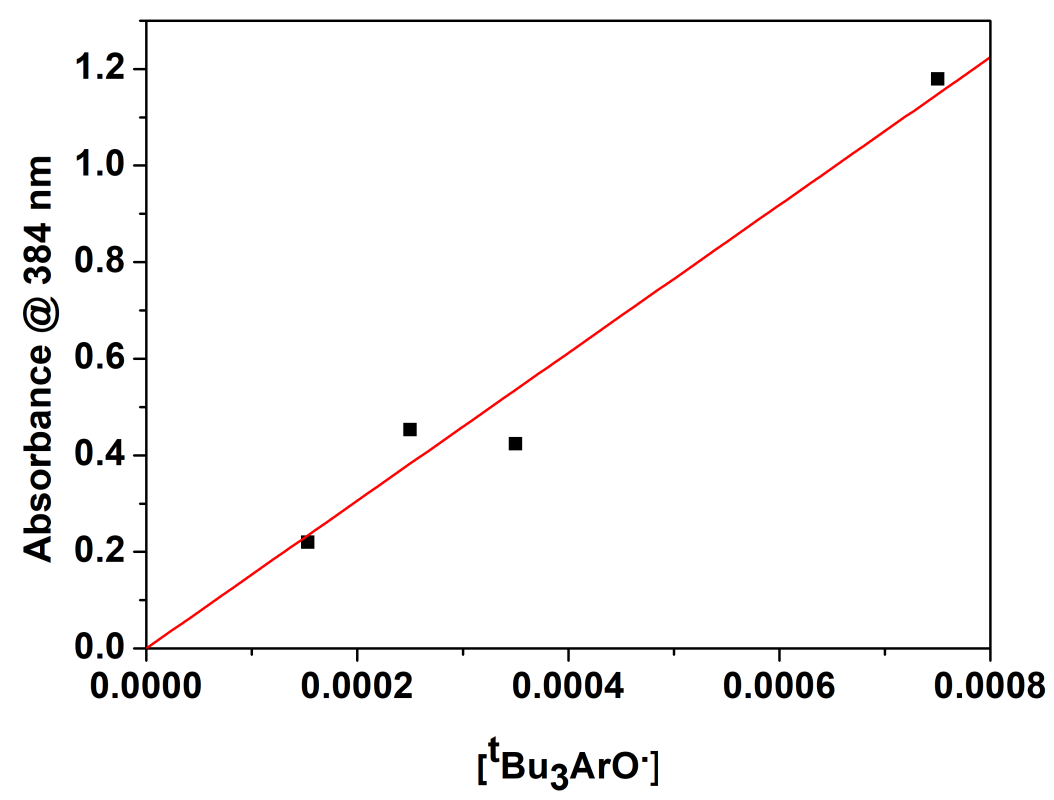

Figure S47. Plot of the absorbance vs. concentration at $\lambda=384 \mathrm{~nm}$ for the $2,4,6$-tris-tertbutylphenoxyl radical in DMF.

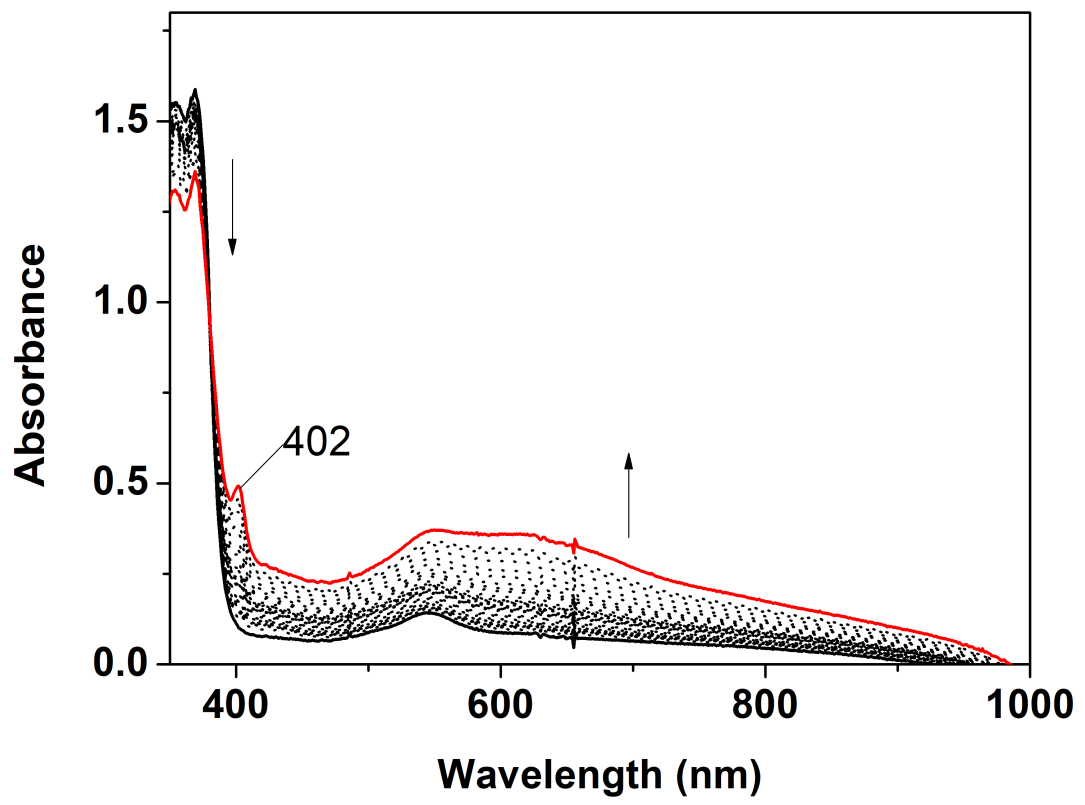

Figure S48. Electronic absorption spectra of the reaction of complex 1 (DMF, $\left.25^{\circ} \mathrm{C}, 0.4 \mathrm{mM}\right)$ with 2,4,6-TTBP (500 equiv.) monitored for $2000 \mathrm{~s}$. 


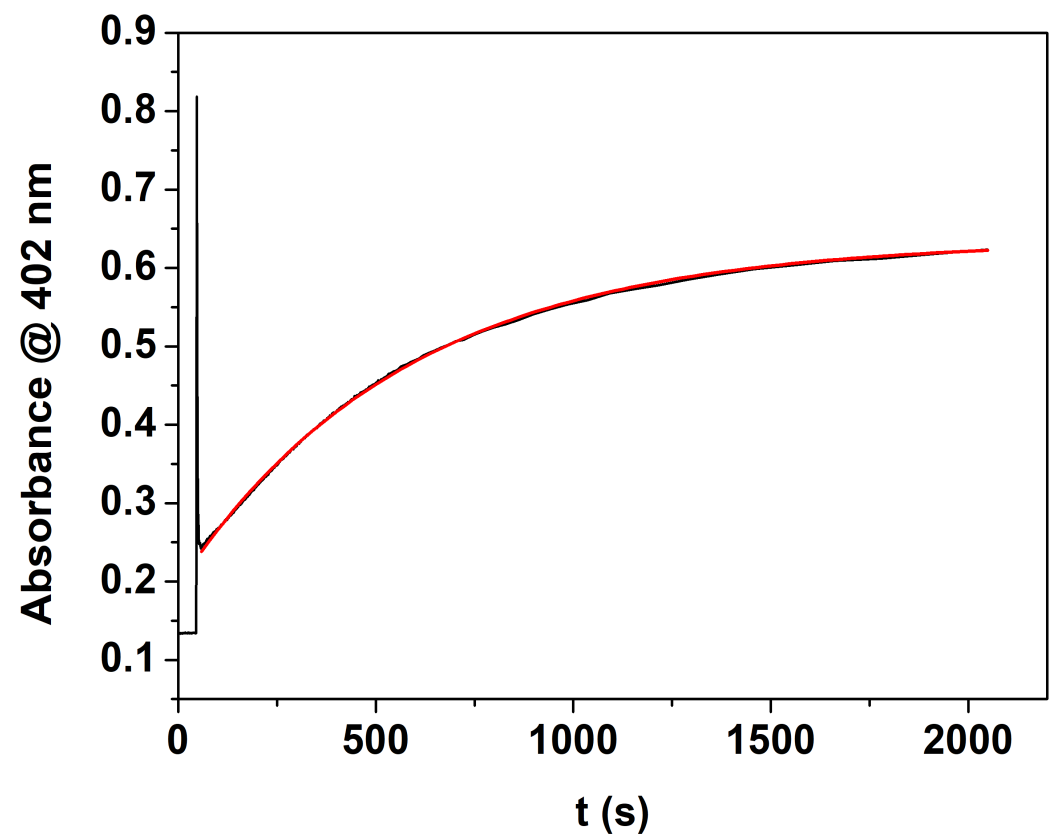

Figure S49. Plot of the absorbance at $\lambda=402 \mathrm{~nm}$ against time during the reaction between 1 $\left(\mathrm{DMF}, 25^{\circ} \mathrm{C}\right)$ and 2,4,6-TTBP $(1000$ equiv. $)$. Red line $=$ fit.
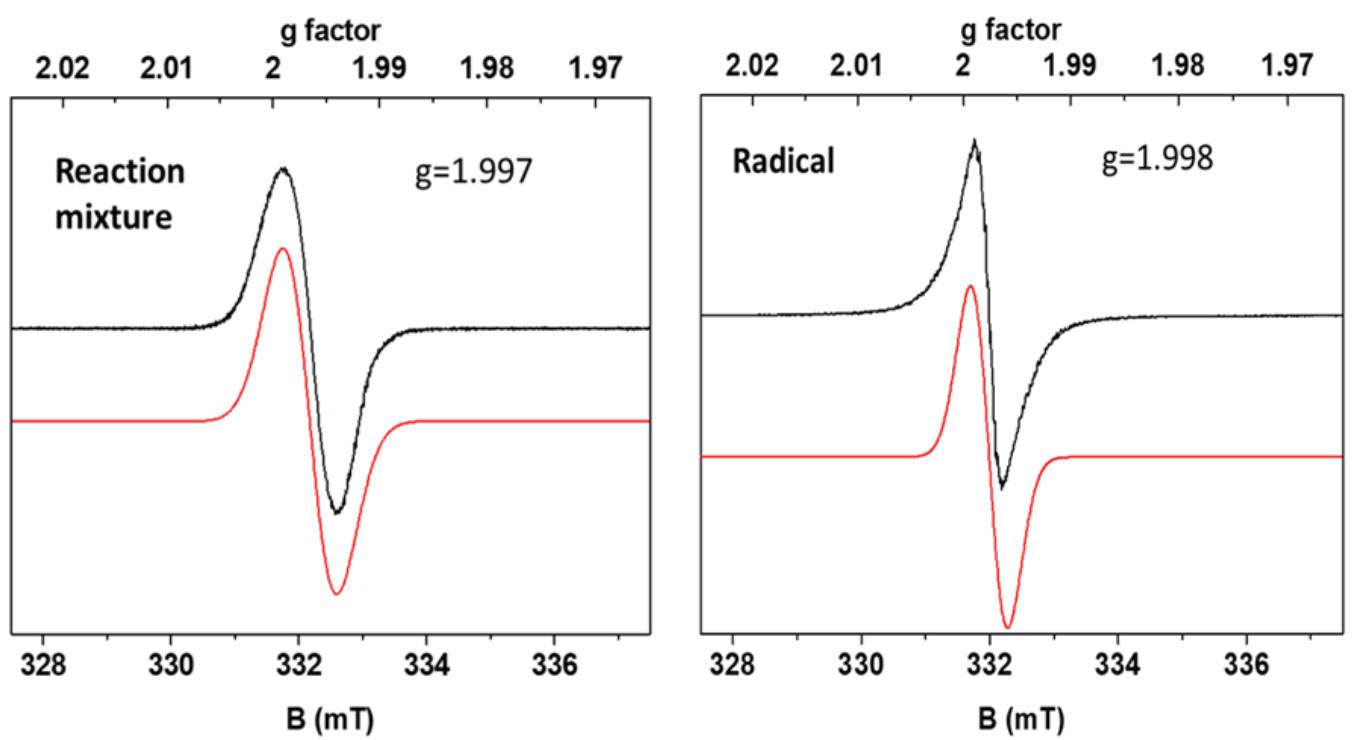

Figure S50. X-Band EPR spectra of the reaction mixture of 1 with 2,4,6-TTBP (left) and the independently synthesized 2,4,6-tris-tert-butylphenoxyl radical (right). Black: experimental spectra, Red: simulated spectra. The spectra were acquired from a frozen DMF solution and measured at $77 \mathrm{~K}$ with a $0.2 \mathrm{~mW}$ microwave power and $0.2 \mathrm{mT}$ modulation amplitude 


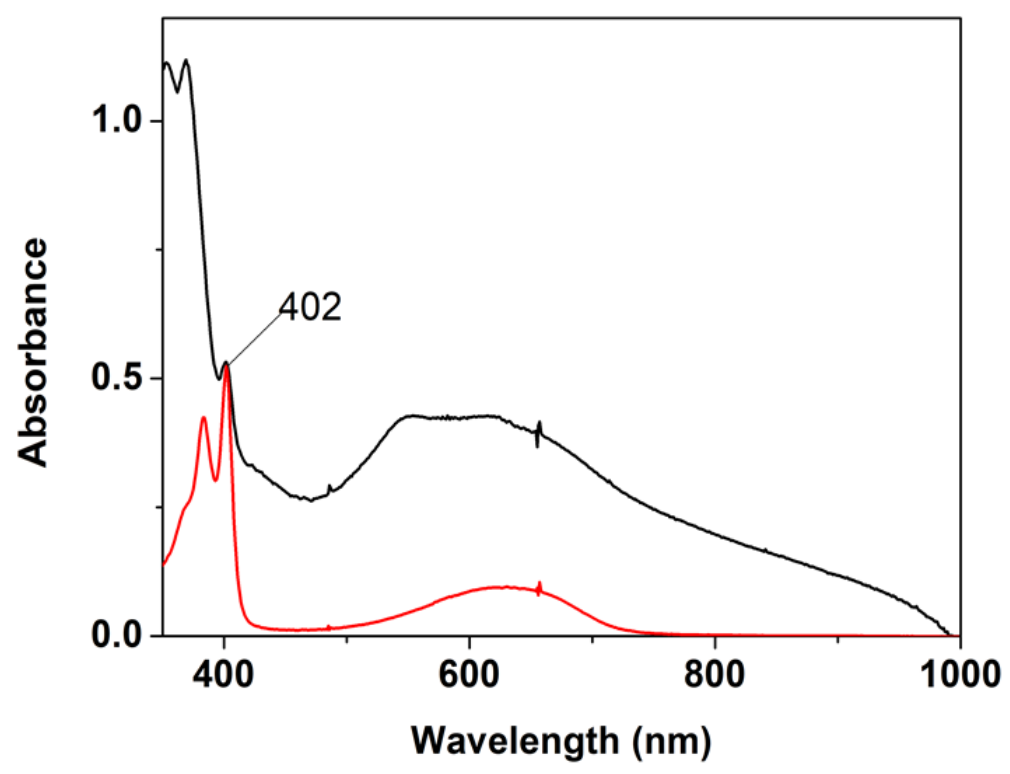

Figure S51. Electronic absorption spectra $\left(\mathrm{DMF}, 25^{\circ} \mathrm{C}\right)$ of the independently synthesized 2,4,6-tris-tert-butylphenoxyl radical (red trace) and of the reaction between complex 1 and an excess of 2,4,6-TTBP (black trace).

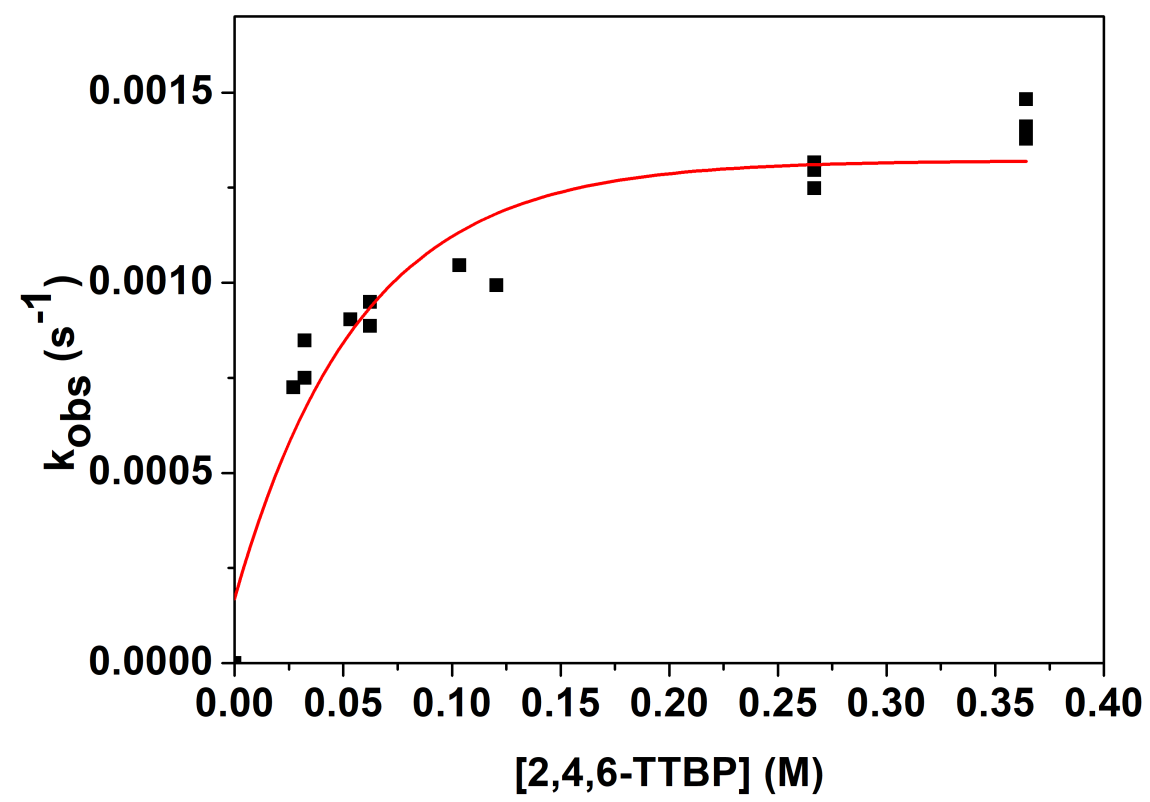

Figure S52. Plot of $k_{\text {obs }}$ against [2,4,6-TTBP] for the reaction between complex 1 and 2,4,6TTBP. 


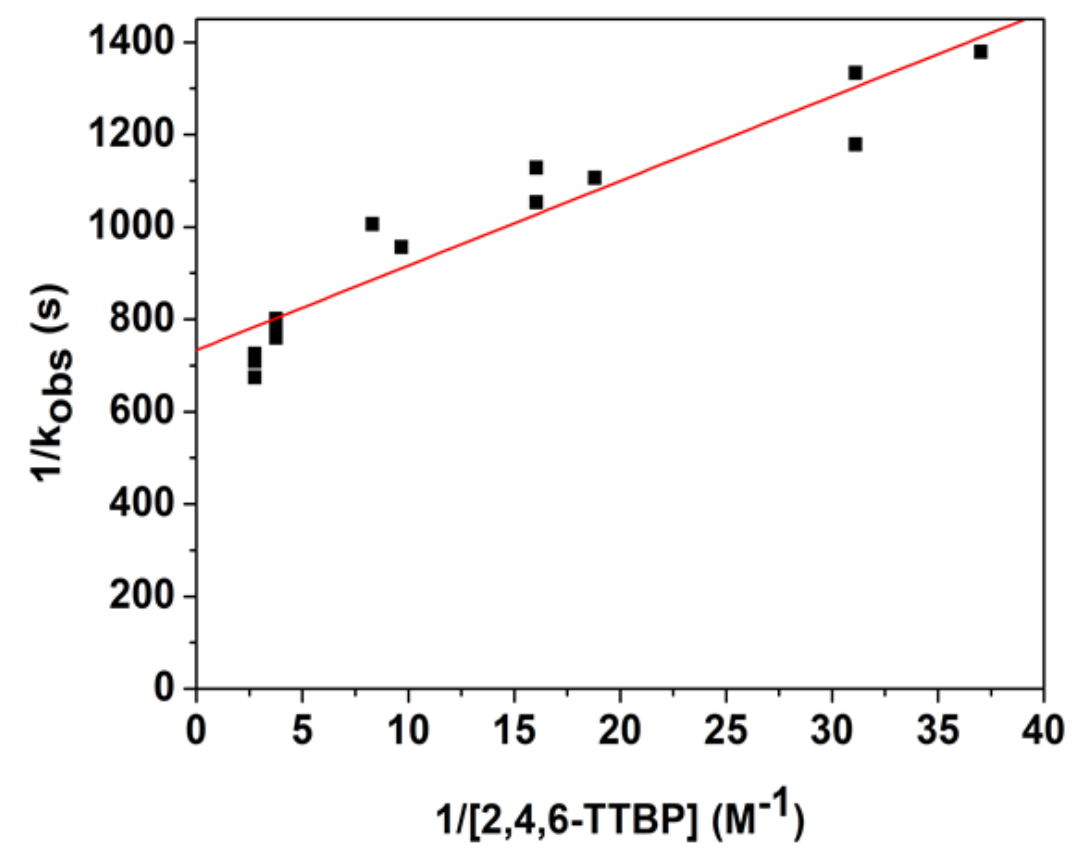

Figure S53. Plot of $1 / k_{\text {obs }}$ against $1 /[2,4,6-\mathrm{TTBP}]$.

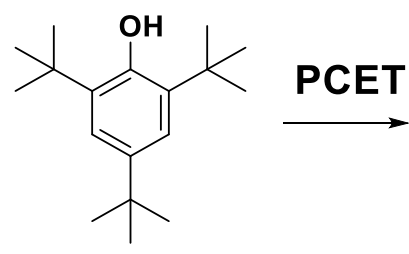

TTBP<smiles>CC(C)(C)c1cc(C(C)(C)C)c(C(C)(C)C)c(C(C)(C)C)c1</smiles><smiles>C=C(C)C[C@@H](C)C1=CC(=O)C=C(C(C)(C)C)C1=O</smiles>

DTBQ

Figure S54. Proposed mechanism of formation of the product 2,6-DTBQ by oxidation of 2,4,6TTBP. 


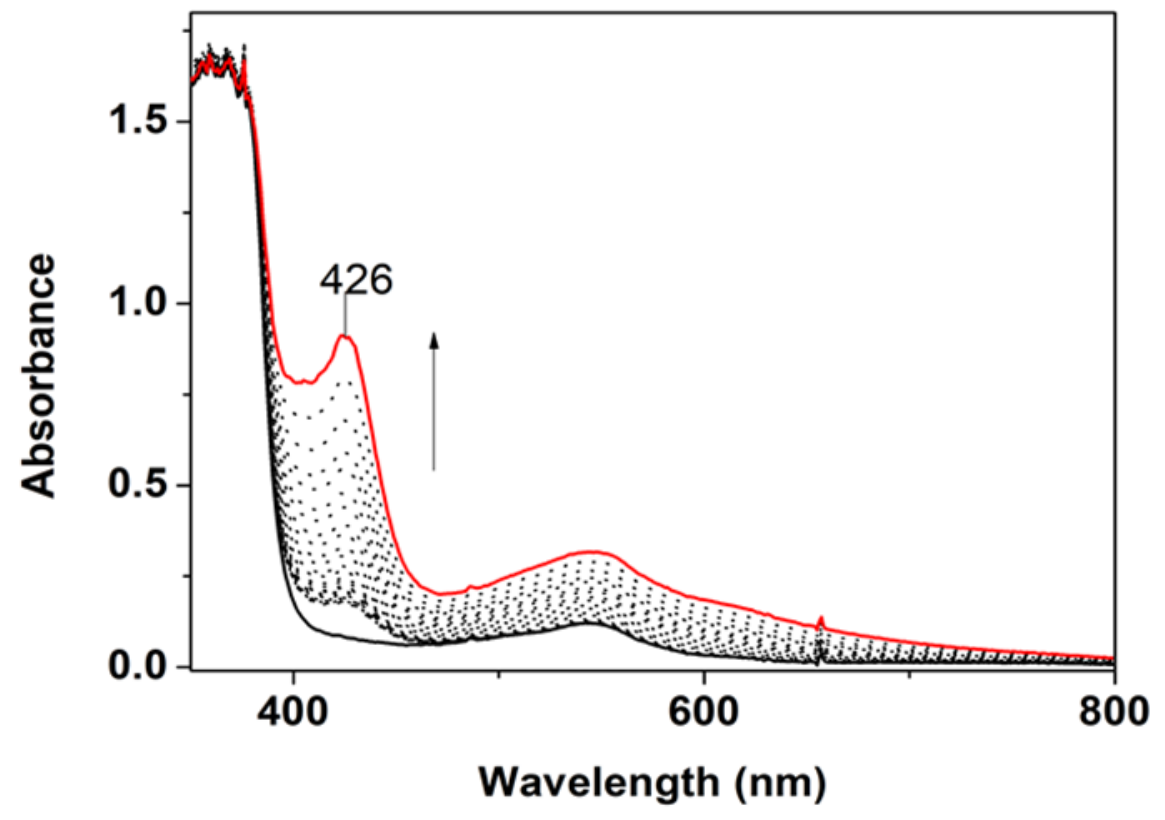

Figure S55. Electronic absorption spectra of the reaction between 1 (DMF, $\left.25^{\circ} \mathrm{C}, 0.45 \mathrm{mM}\right)$ and 2,6-DTBP (300 equiv.), monitored for $1800 \mathrm{~s}$.

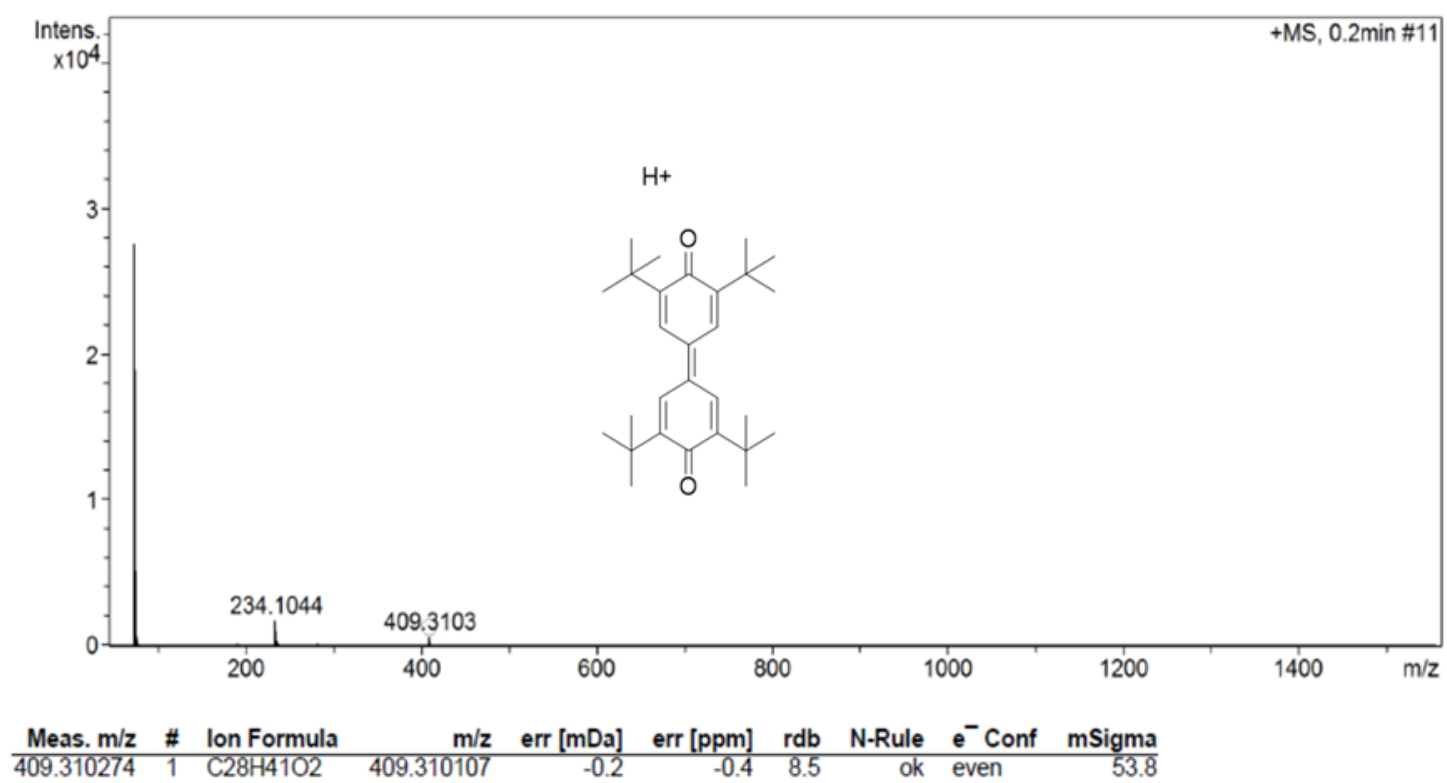

Figure S56. Positive mode ESI-MS spectrum of the reaction mixture of 1 and 2,6-DTBP showing the formation of 3,3',5,5' -tetra-tert-butyl-[1,1'-bis(cy-clohexane)]-2,2',5,5'-tetraene4,4'-dione (TTBTD). 


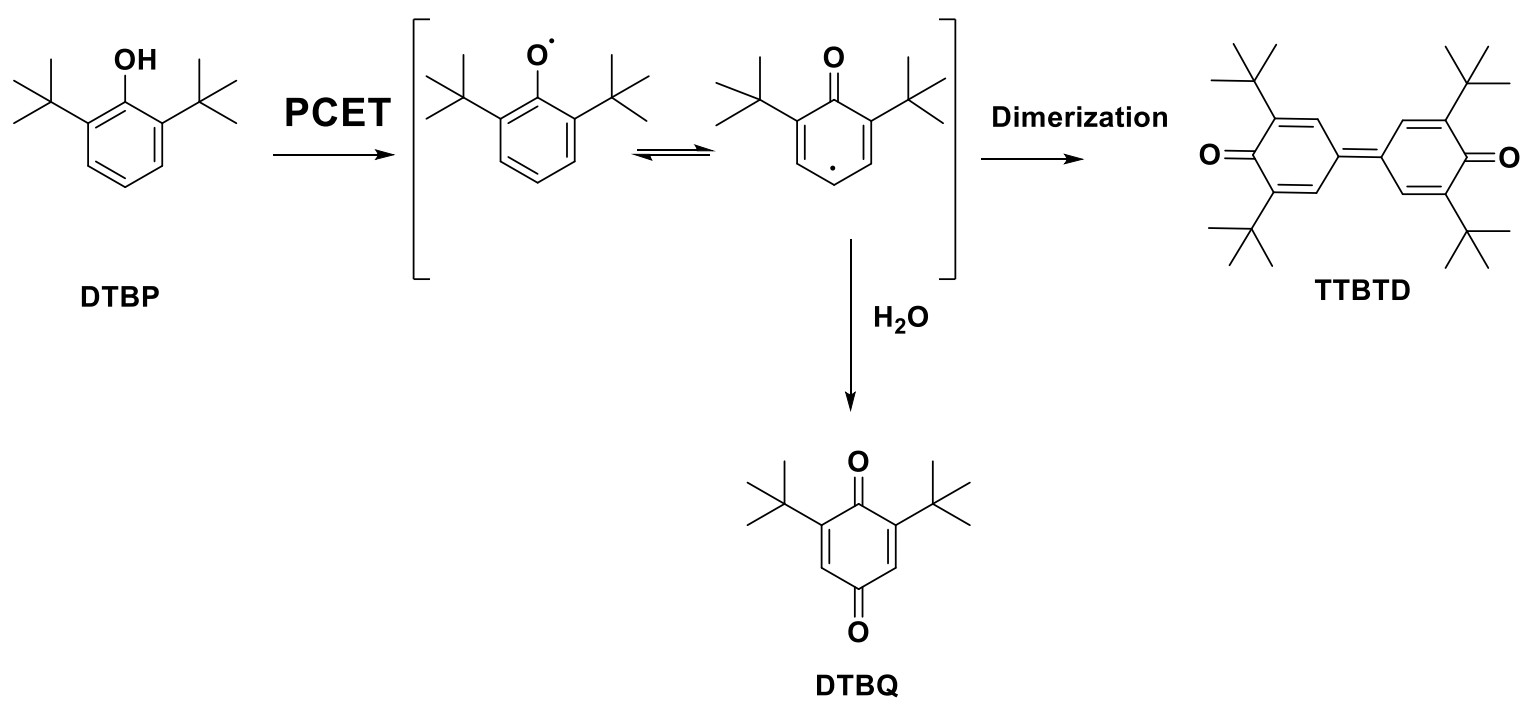

Figure S57. Proposed mechanism of formation of products TTBTD and 2,6-DTBQ by oxidation of 2,6-DTBP.

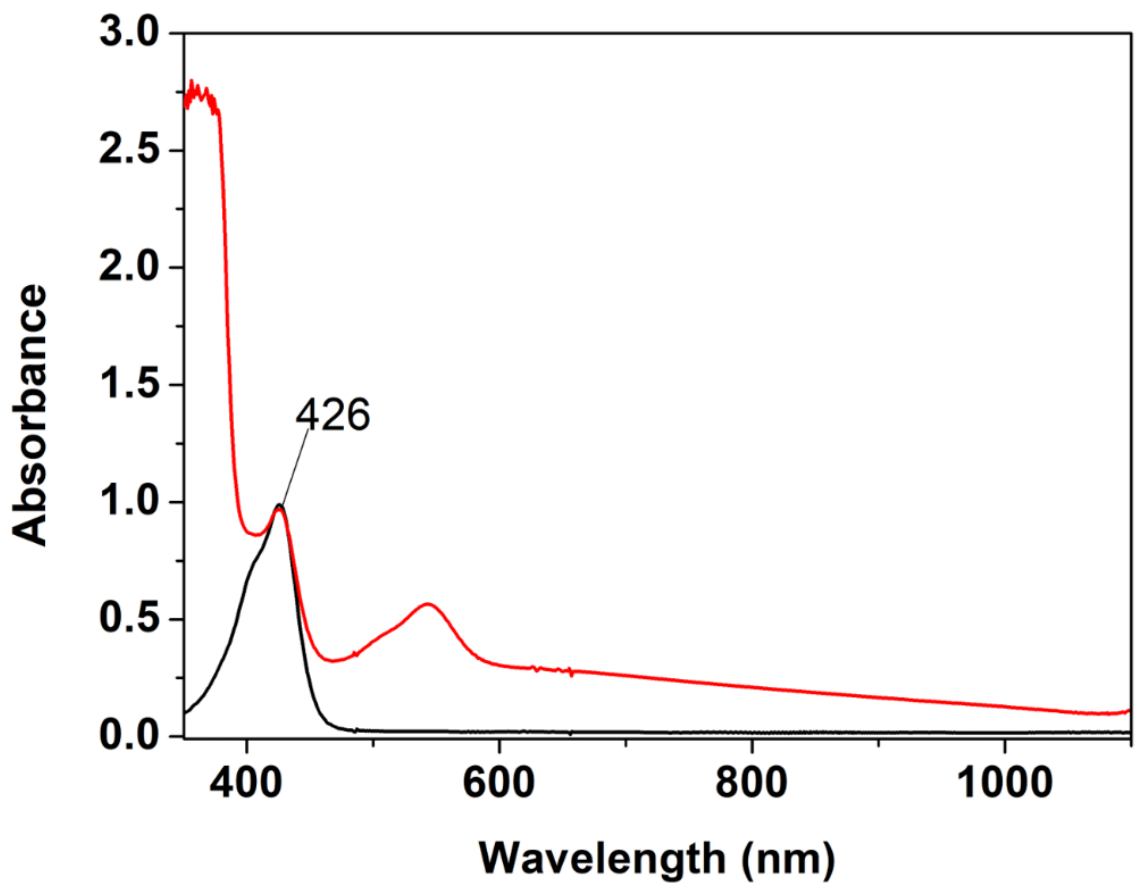

Figure S58. Electronic absorption spectra (DMF, $25^{\circ} \mathrm{C}$ ) of TTBTD (black trace) and of the reaction between 1 and an excess of 2,6-DTBP (red trace). 


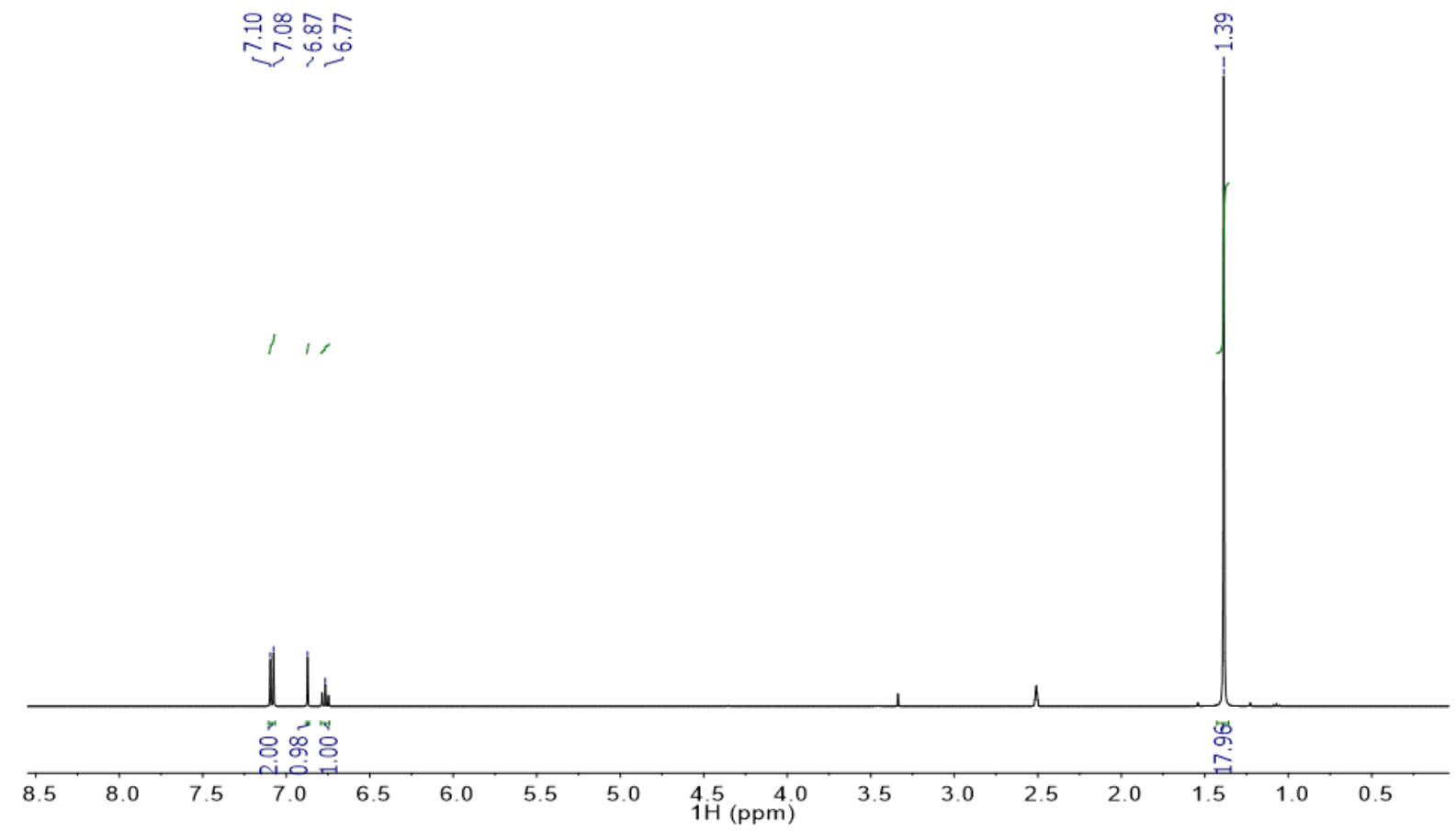

Figure S59. ${ }^{1} \mathrm{H}-\mathrm{NMR}$ spectrum in $\mathrm{DMSO}^{-\mathrm{D}_{6}}$ of 2,6-DTBP.

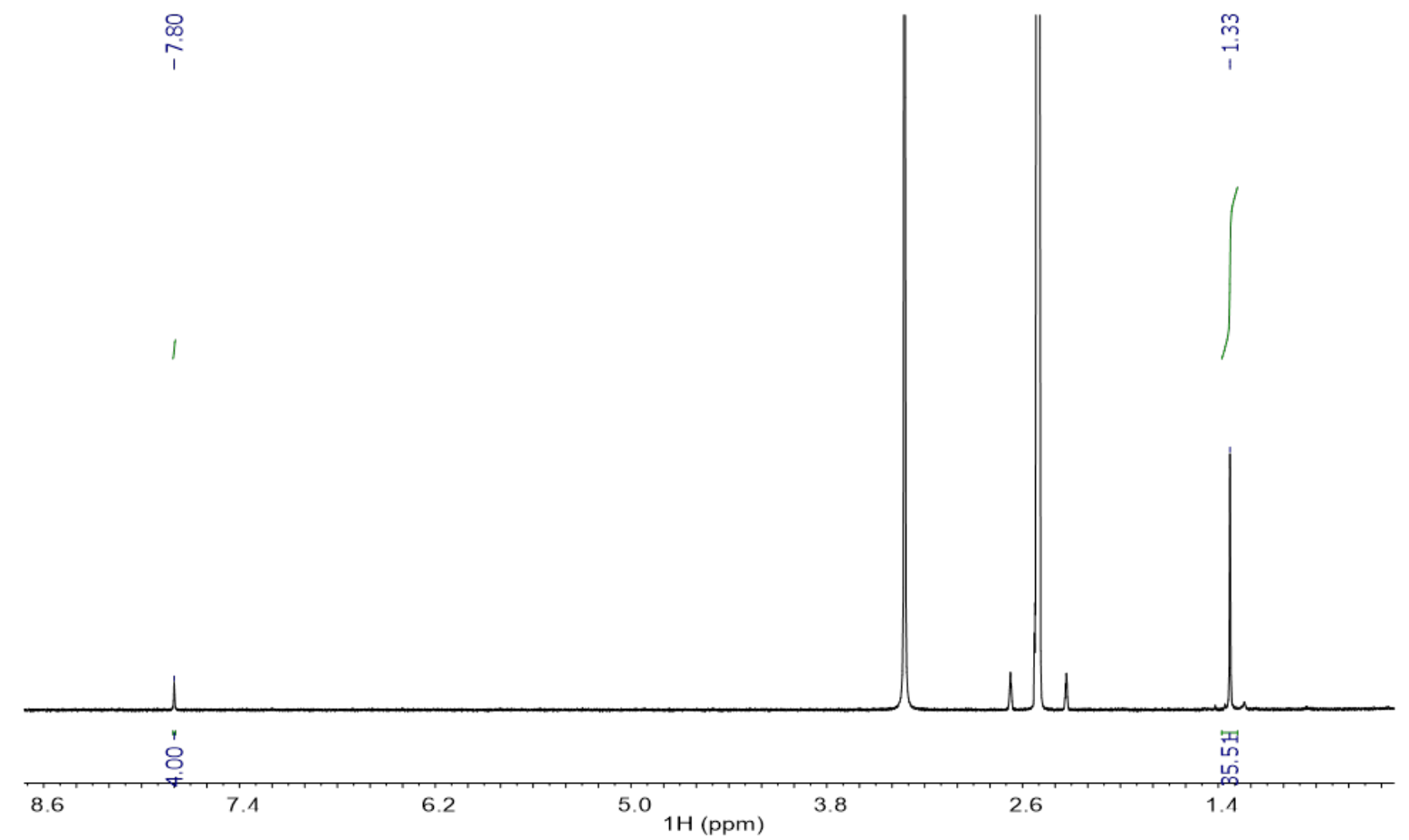

Figure S60. ${ }^{1} \mathrm{H}-\mathrm{NMR}$ spectrum in $\mathrm{DMSO}^{-\mathrm{D}_{6}}$ of $3,3^{\prime}, 5,5$ '-tetra-tert-butyl-[1,1'-bis(cyclohexane)]-2,2',5,5'-tetraene-4,4'-dione (TTBTD). 


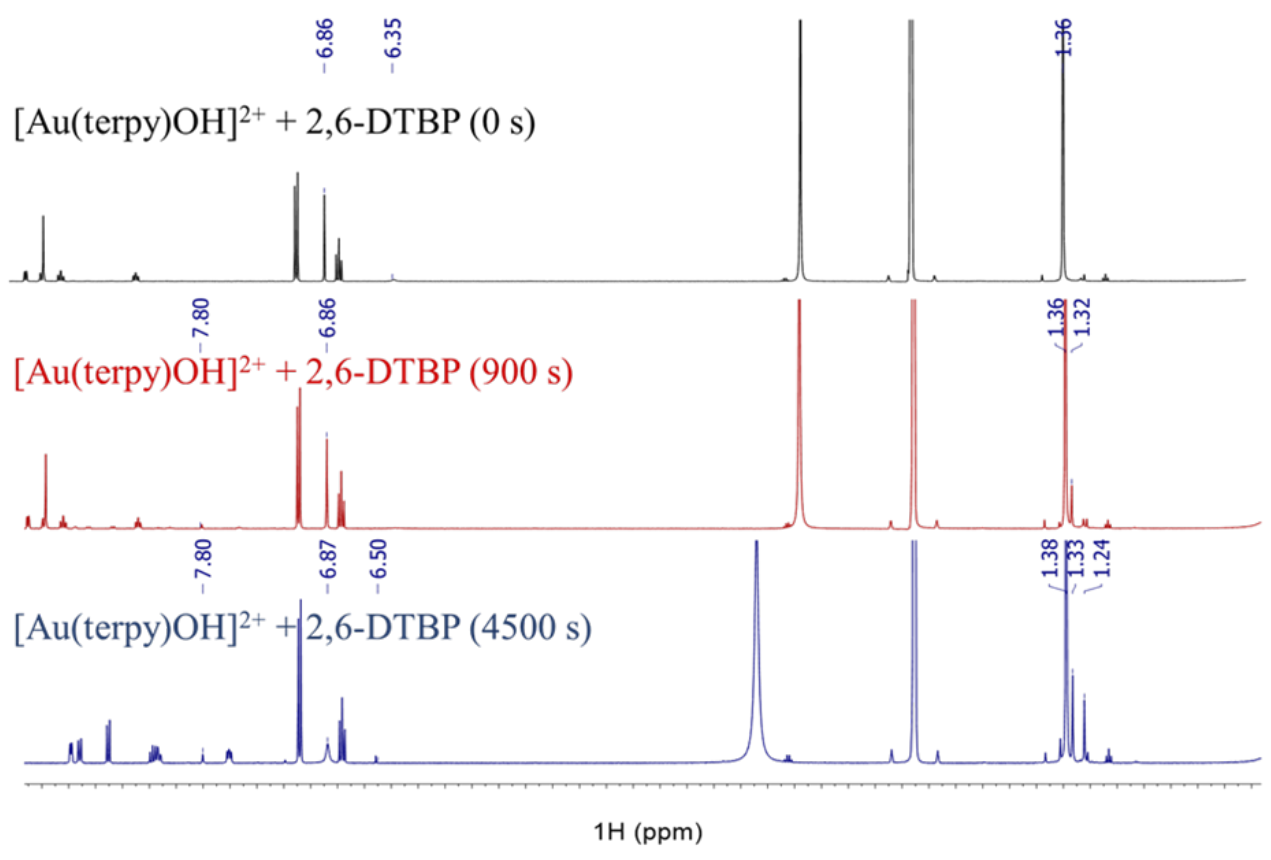

Figure S61. ${ }^{1} \mathrm{H}-\mathrm{NMR}$ spectra in $\mathrm{DMSO}^{-\mathrm{D}_{6}}$ of the reaction between 1 and 2,6-DTBP (25 equiv.). Black $=0 \mathrm{~s}, \mathrm{Red}=900 \mathrm{~s}, \mathrm{Blue}=4500 \mathrm{~s} . \mathrm{H}_{2} \mathrm{O}: \delta=3.32-3.68 \mathrm{ppm}$.

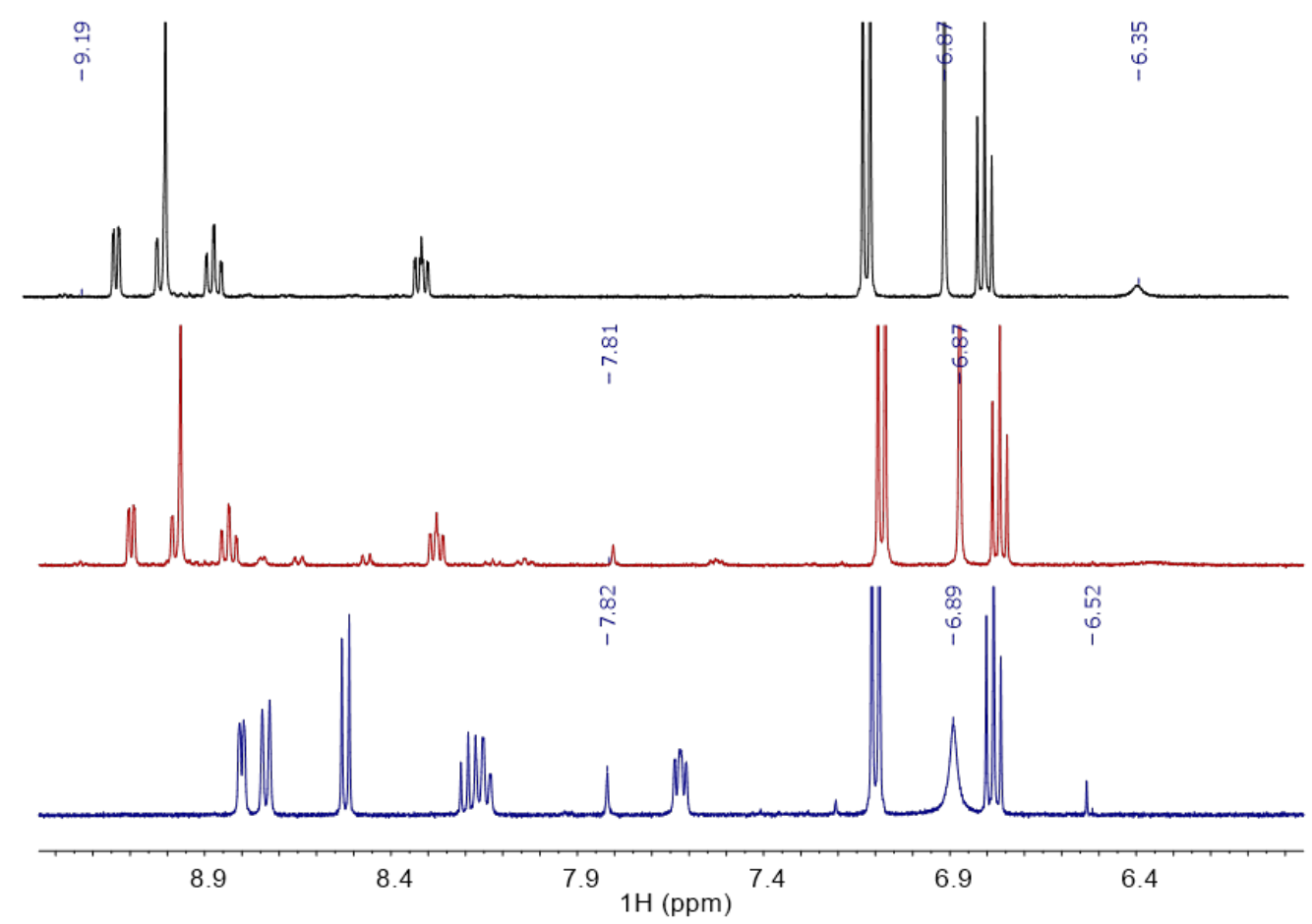

Figure S62. Zoom of the region between $\delta=6$ and $9.5 \mathrm{ppm}$ of the ${ }^{1} \mathrm{H}-\mathrm{NMR}$ spectrum (400 MHz, DMSO-D $)$ of complex 1 with 2,6-DTBP (25 equiv.). Black $=0 \mathrm{~s}$, Red $=900 \mathrm{~s}$, Blue $=$ 4500 s. $-\mathrm{OH}: \delta=6.35 \mathrm{ppm}$. 


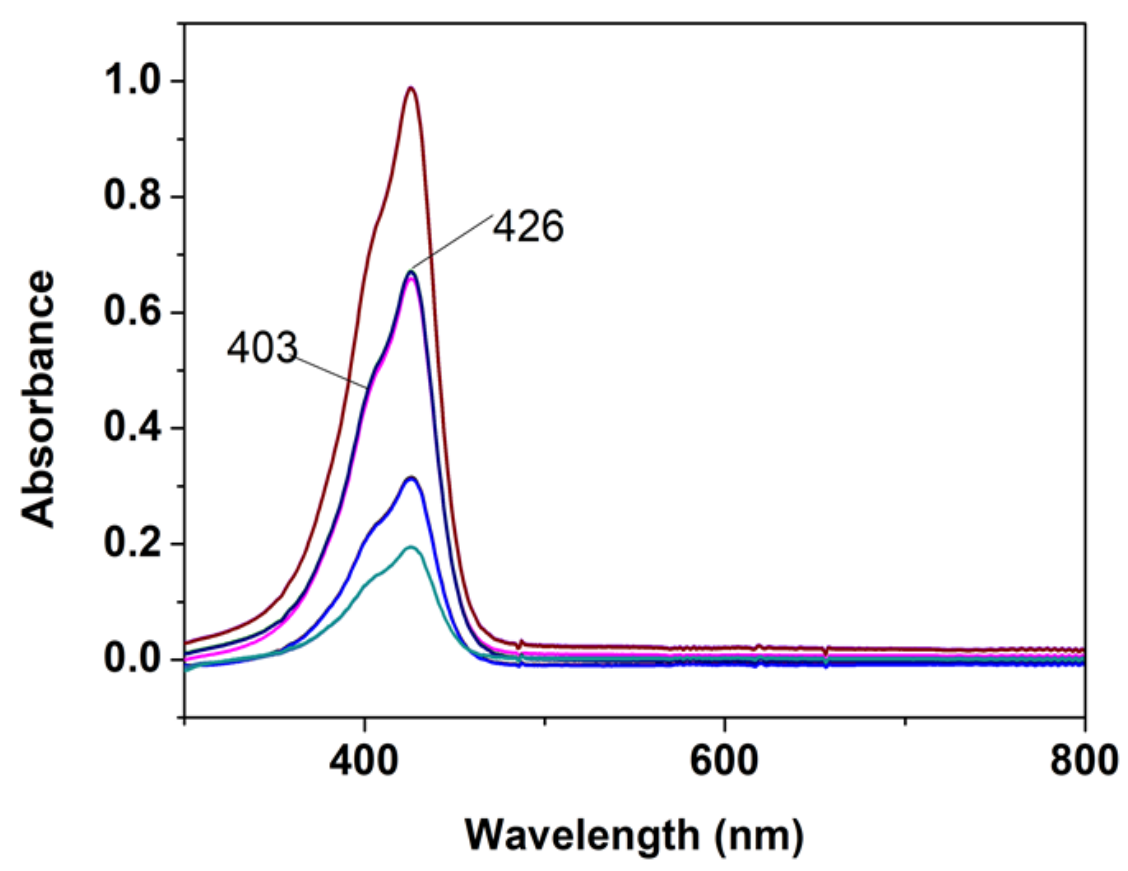

Figure S63. Electronic absorption spectra of TTBTD at $25^{\circ} \mathrm{C}$ in DMF. $\varepsilon_{426 \mathrm{~nm}}=32400 \pm 550$ $\mathrm{M}^{-1} \mathrm{~cm}^{-1}, \varepsilon_{403 \mathrm{~nm}}=23400 \pm 420 \mathrm{M}^{-1} \mathrm{~cm}^{-1}$.

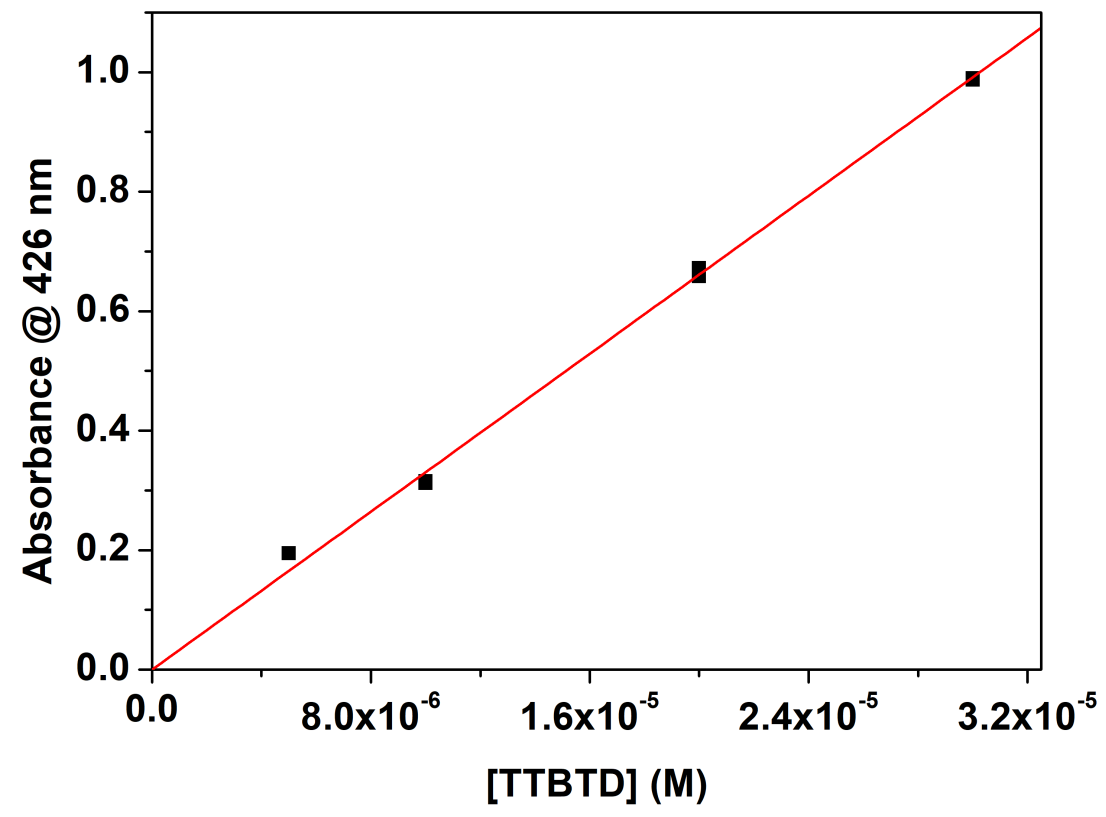

Figure S64. Plot of the absorbance vs. concentration at $\lambda=426 \mathrm{~nm}$ for TTBTD in DMF. 


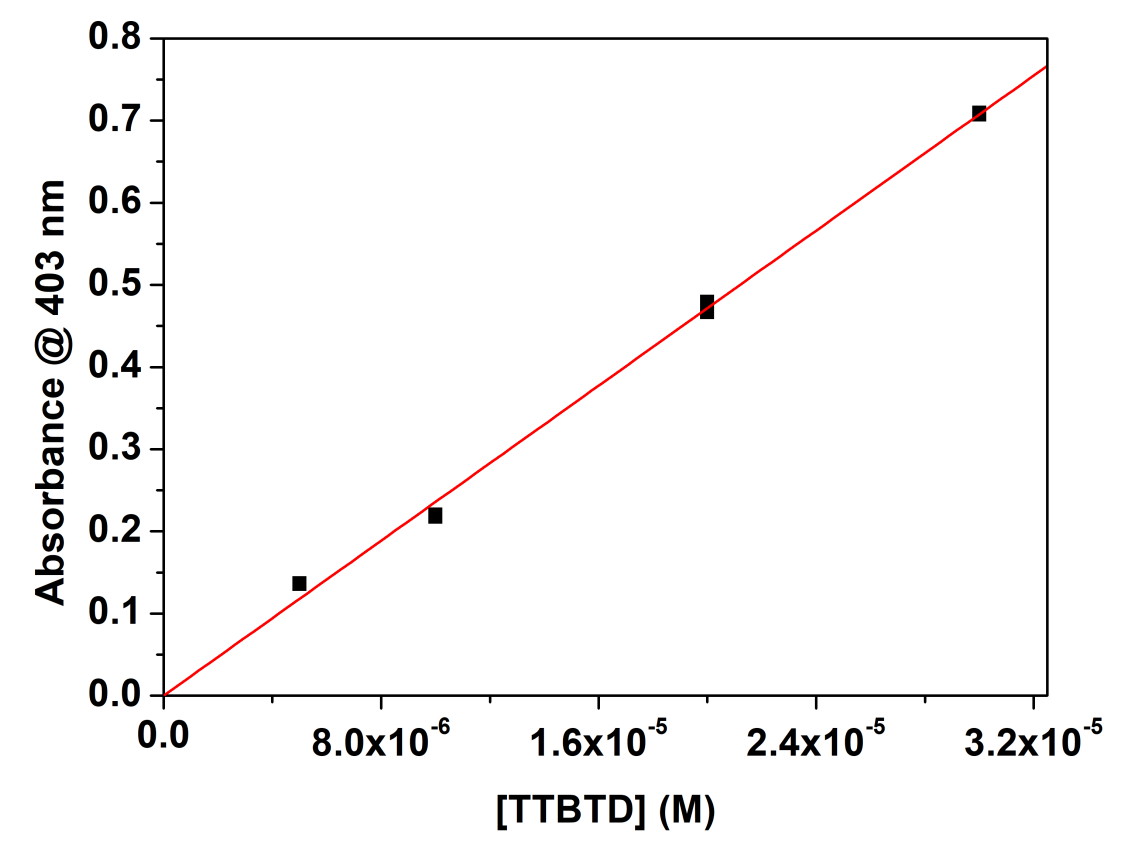

Figure S65. Plot of the absorbance vs. concentration at $\lambda=403 \mathrm{~nm}$ for TTBTD in DMF.

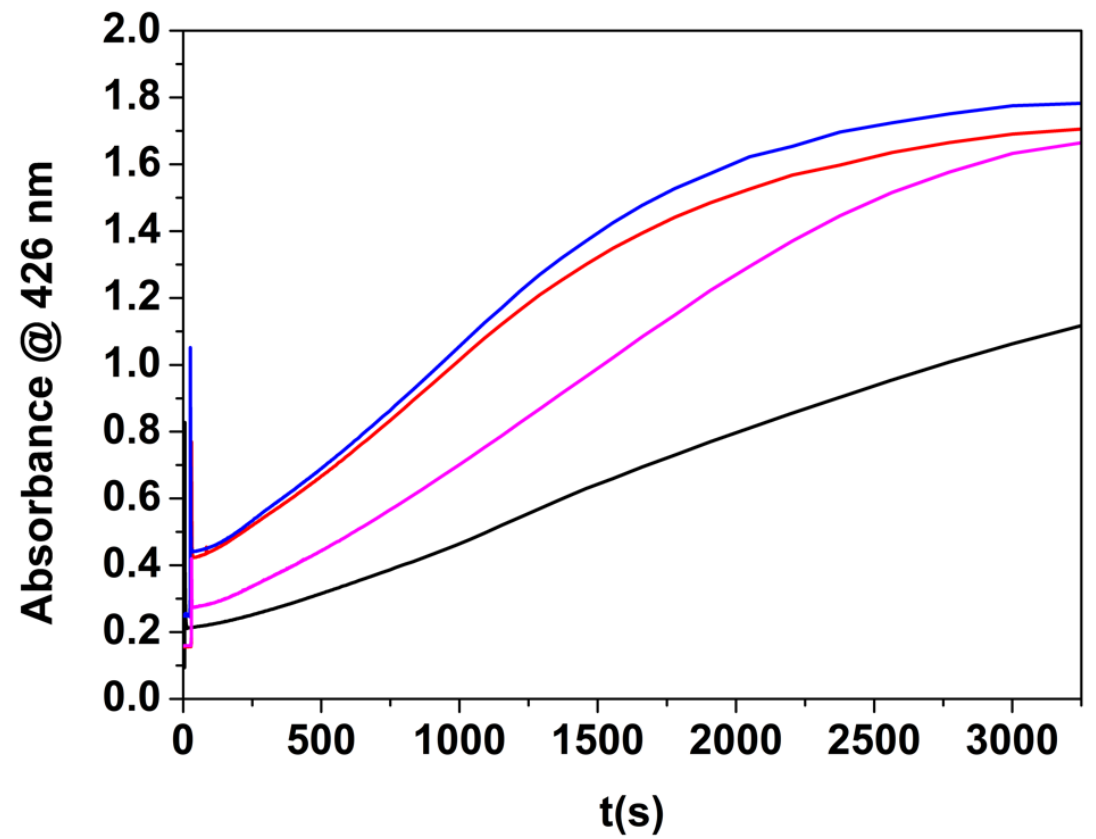

Figure S66. Plots of the absorbance at $\lambda=426 \mathrm{~nm}$ versus time for the reaction between complex 1 and 2,6-DTBP. 


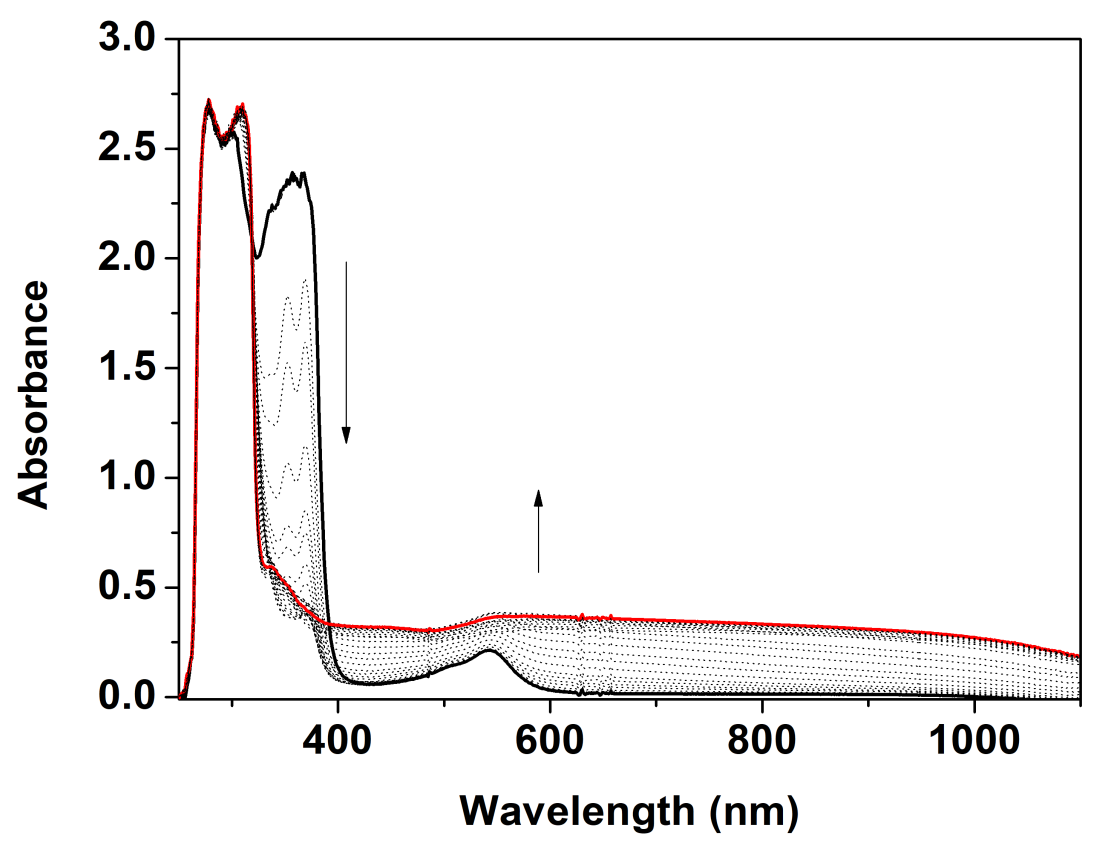

Figure S67. Electronic absorption spectra of the reaction of $1(0.7 \mathrm{mM}$ in DMF) with $4-\mathrm{H}-$ TEMPOH (50 equiv.), monitored for $1000 \mathrm{~s}$.

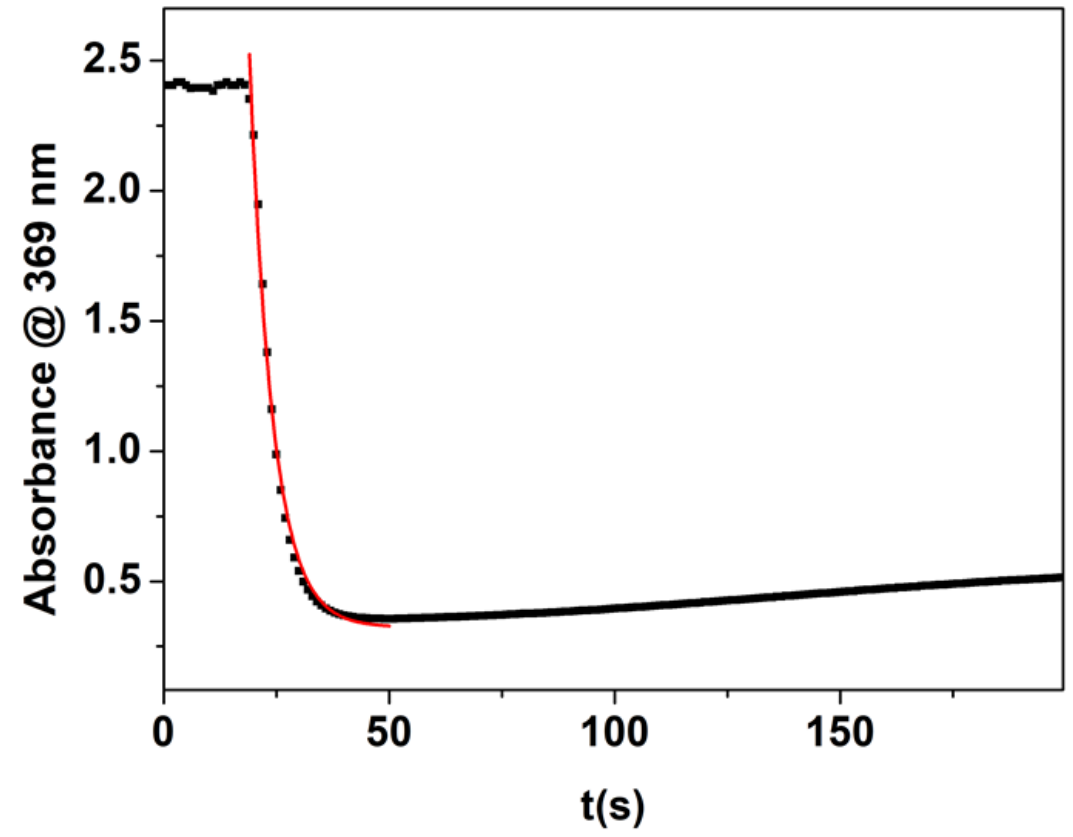

Figure S68. Plot of the absorbance at $\lambda=369 \mathrm{~nm}$ against time during the reaction between 1 and TEMPOH (50 equiv.) at $25^{\circ} \mathrm{C}$ in DMF. 


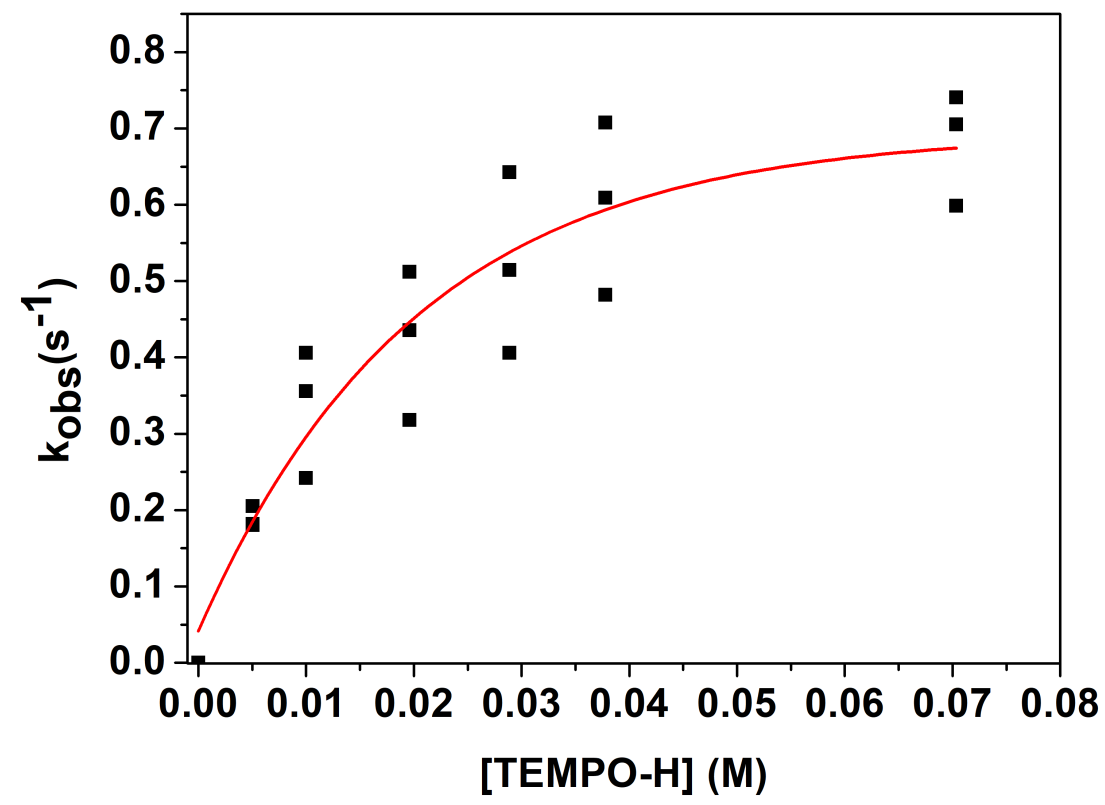

Figure S69. Plot of $k_{\mathrm{obs}}$ vs. [4-H-TEMPOH] determined for the reaction between 1 and 4-HTEMPOH.

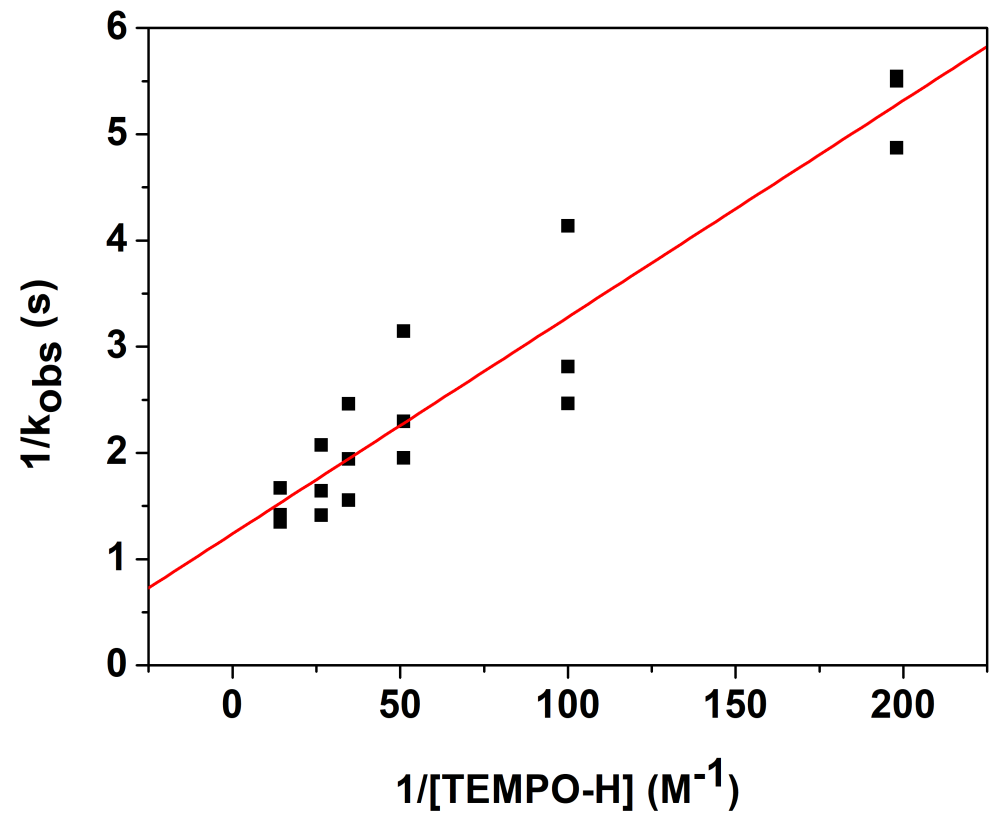

Figure S70. Plot of $1 / k_{\text {obs }}$ versus $1 /[4-\mathrm{H}-\mathrm{TEMPOH}]$. 


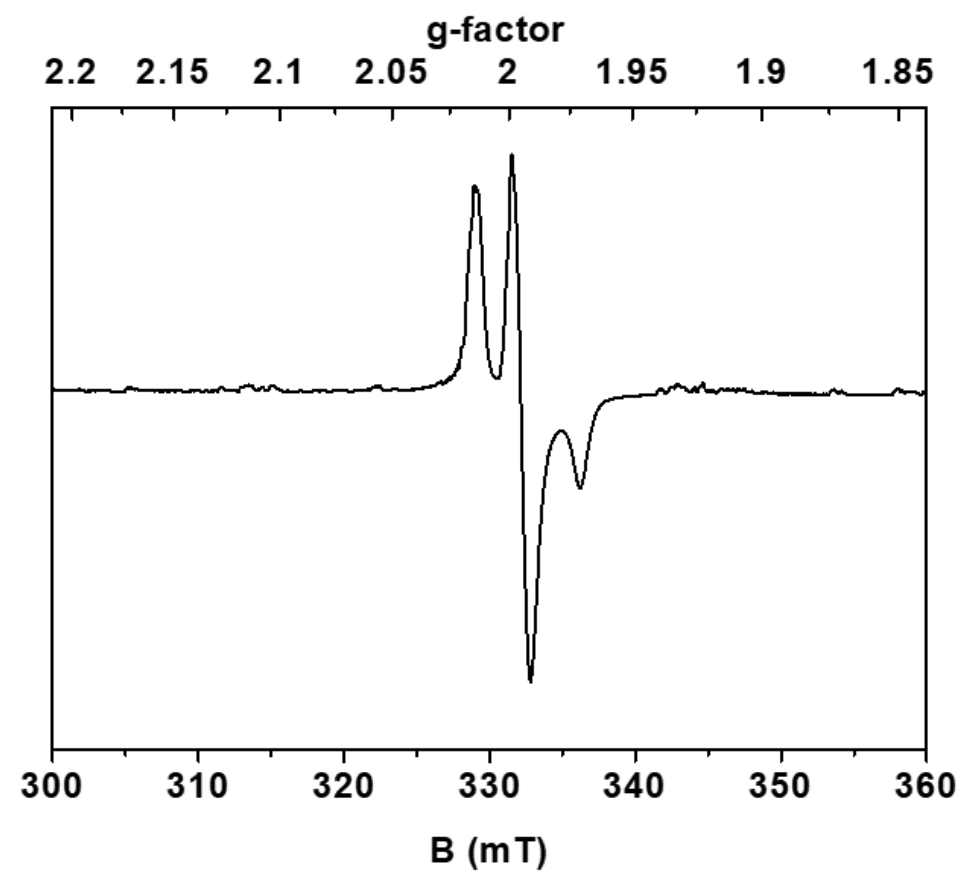

Figure S71. X-Band EPR spectrum of the reaction mixture of 1 with 4-H-TEMPOH (200 equiv.) after $150 \mathrm{~s}$. The spectrum was acquired from a frozen DMF solution and measured at $77 \mathrm{~K}$ with a $2.02 \mathrm{~mW}$ microwave power and a $0.3 \mathrm{mT}$ modulation amplitude.

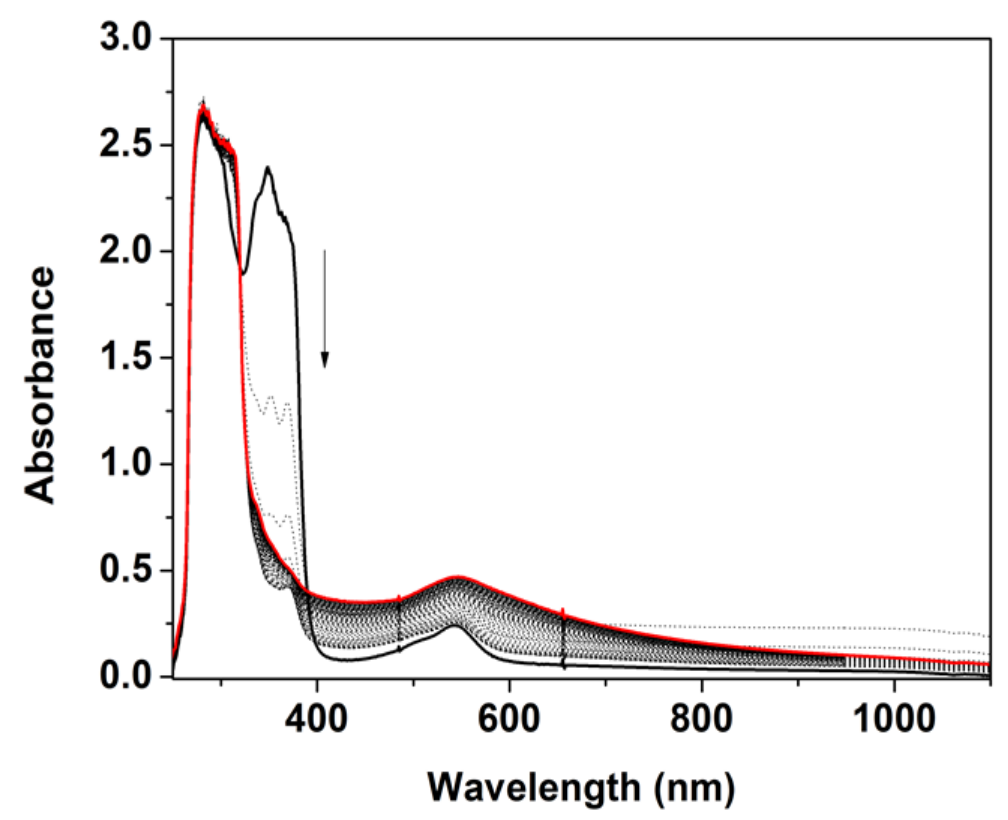

Figure S72. Electronic absorption spectra of the reaction between 1 (DMF, $\left.25{ }^{\circ} \mathrm{C}, 0.75 \mathrm{mM}\right)$ and 4-CH${ }_{3} \mathrm{O}-\mathrm{TEMPOH}$ (50 equiv.), monitored for $600 \mathrm{~s}$. 


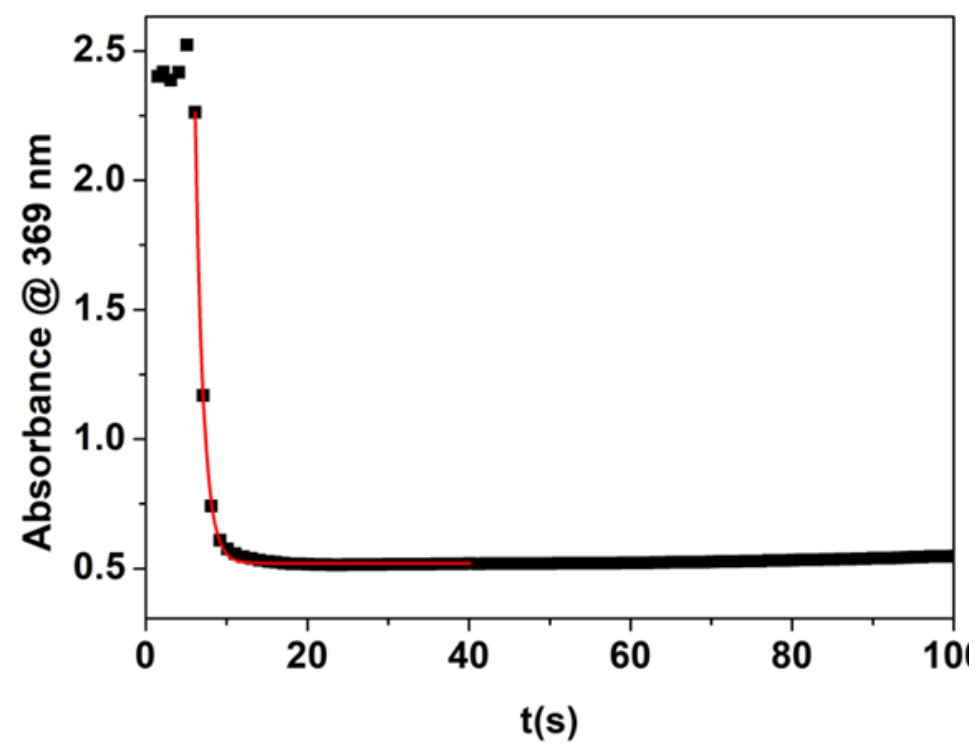

Figure S73. Plot of the absorbance at $\lambda=369 \mathrm{~nm}$ vs. time during the reaction between 1 (DMF, $25^{\circ} \mathrm{C}$ ) and $4-\mathrm{CH}_{3} \mathrm{O}-\mathrm{TEMPOH}(100$ equiv.).

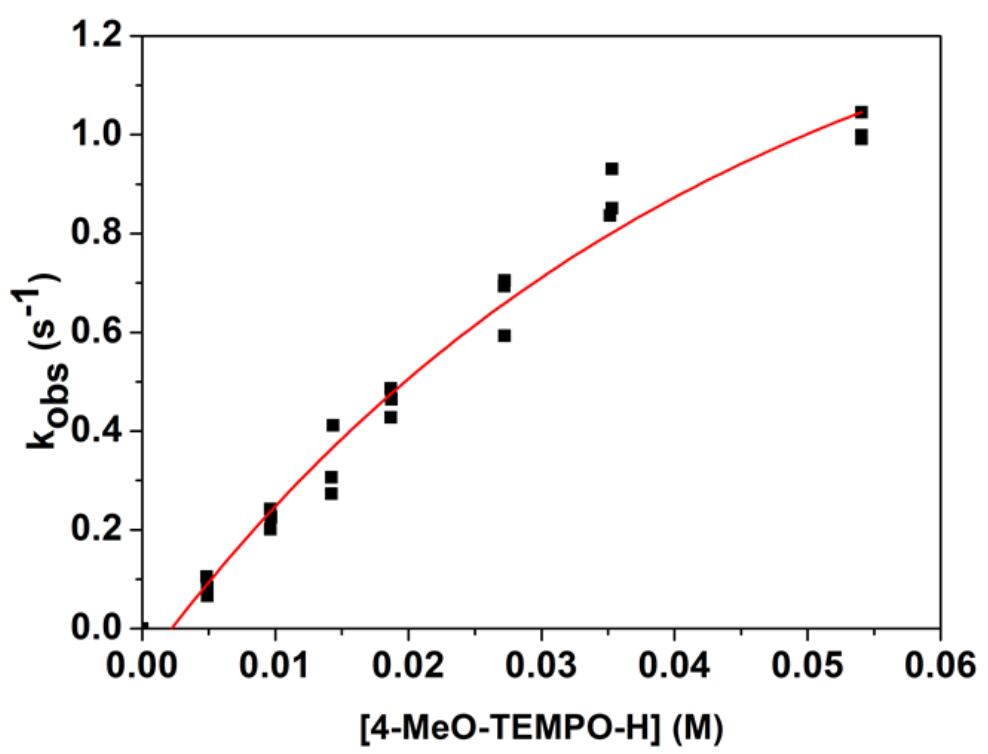

Figure S74. Plot of $k_{\text {obs }}$ against [4- $\mathrm{CH}_{3} \mathrm{O}-\mathrm{TEMPOH}$ ]. Due to our inability to fit accurately the decay of the band at $\lambda=369 \mathrm{~nm}$ with higher equivalents of substrate, $k_{1}$ was estimated to be $1.2 \mathrm{~s}^{-1}$. This was caused by the rate of the reaction being so high so as to prevent accurate kinetic analysis. 


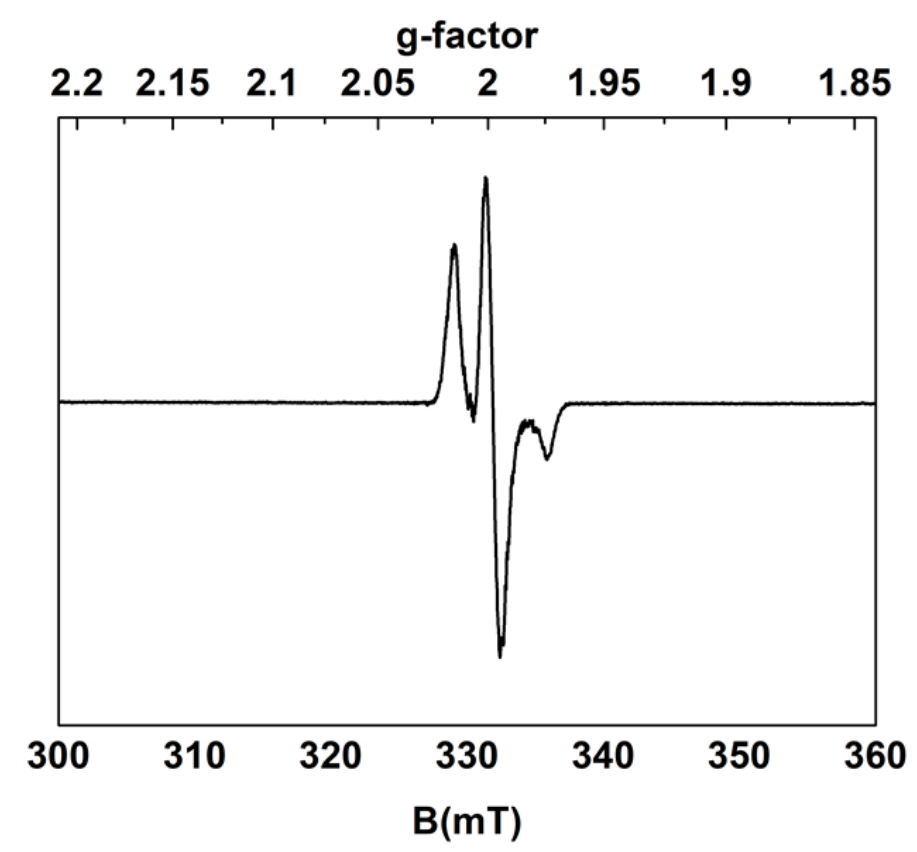

Figure S75. X-Band EPR spectrum of the reaction mixture of 1 with 4- $\mathrm{CH}_{3} \mathrm{O}-\mathrm{TEMPOH}(200$ equiv.). The spectrum was acquired from a frozen DMF solution and measured at $77 \mathrm{~K}$ with a $2.02 \mathrm{~mW}$ microwave power and a $0.3 \mathrm{mT}$ modulation amplitude.

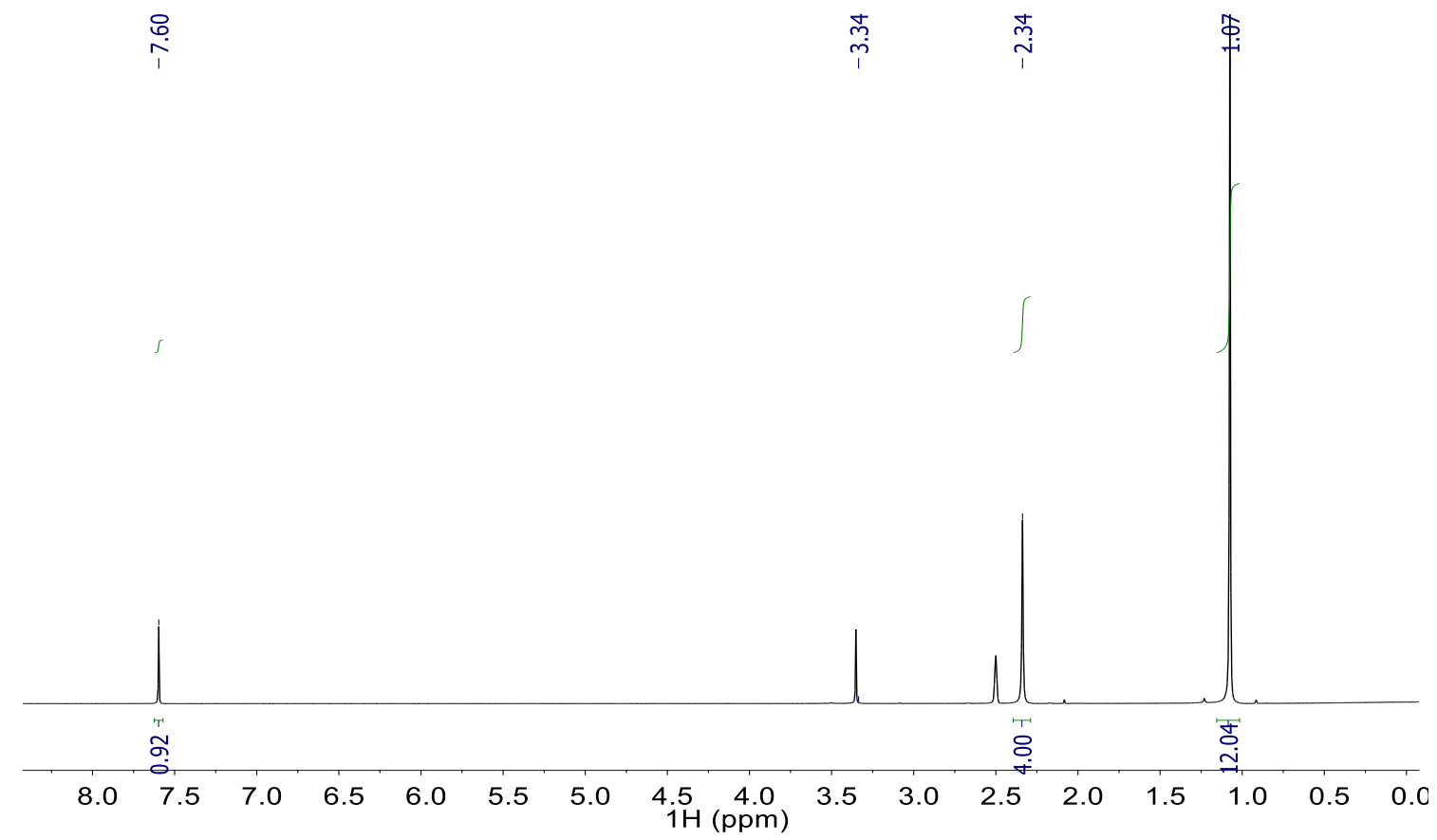

Figure S76. ${ }^{1} \mathrm{H}-\mathrm{NMR}\left(400 \mathrm{MHz}, \mathrm{DMSO}-\mathrm{D}_{6}\right)$ of 4-oxo-TEMPOH. 


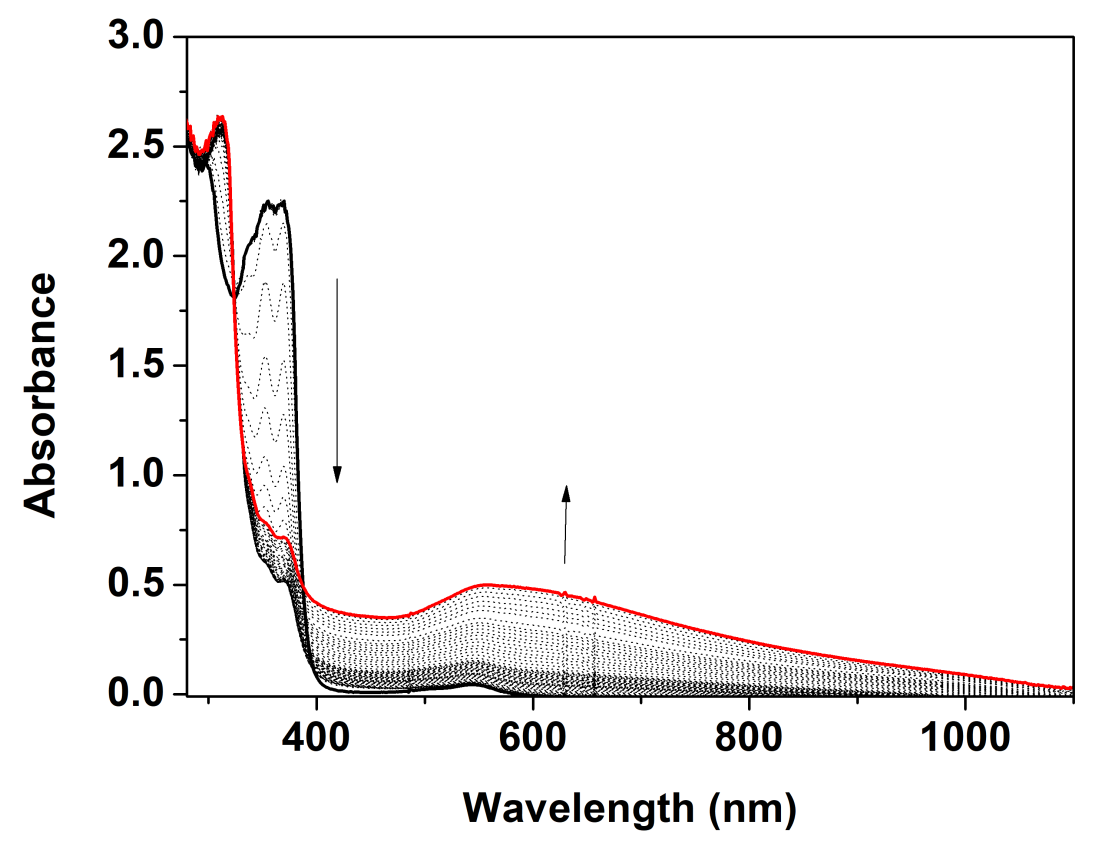

Figure S77. Electronic absorption spectra of the reaction between 1 (DMF, $\left.25^{\circ} \mathrm{C}, 0.6 \mathrm{mM}\right)$ and 4-oxo-TEMPOH (25 equiv.), monitored for $600 \mathrm{~s}$.

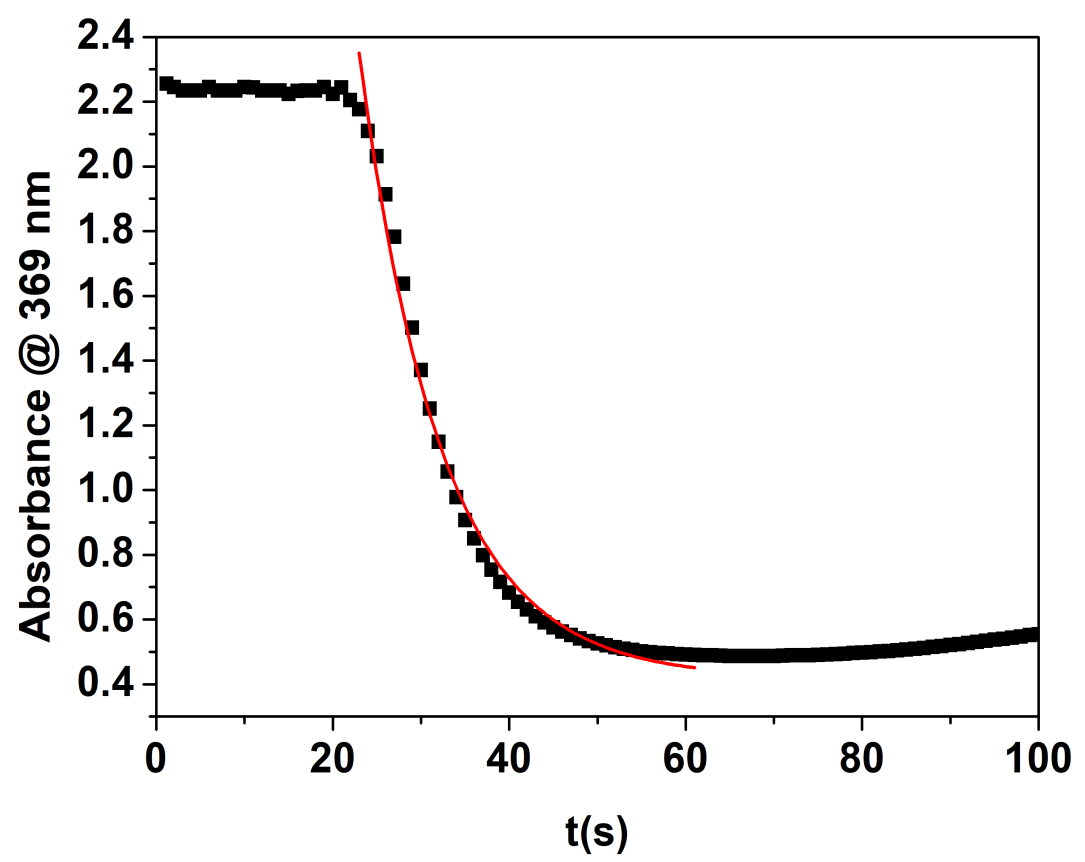

Figure S78. Plot of the absorbance at $\lambda=369 \mathrm{~nm}$ against time during the reaction between 1 (DMF, $25{ }^{\circ} \mathrm{C}, 0.6 \mathrm{mM}$ ) and 4-oxo-TEMPOH (25 equiv.). 


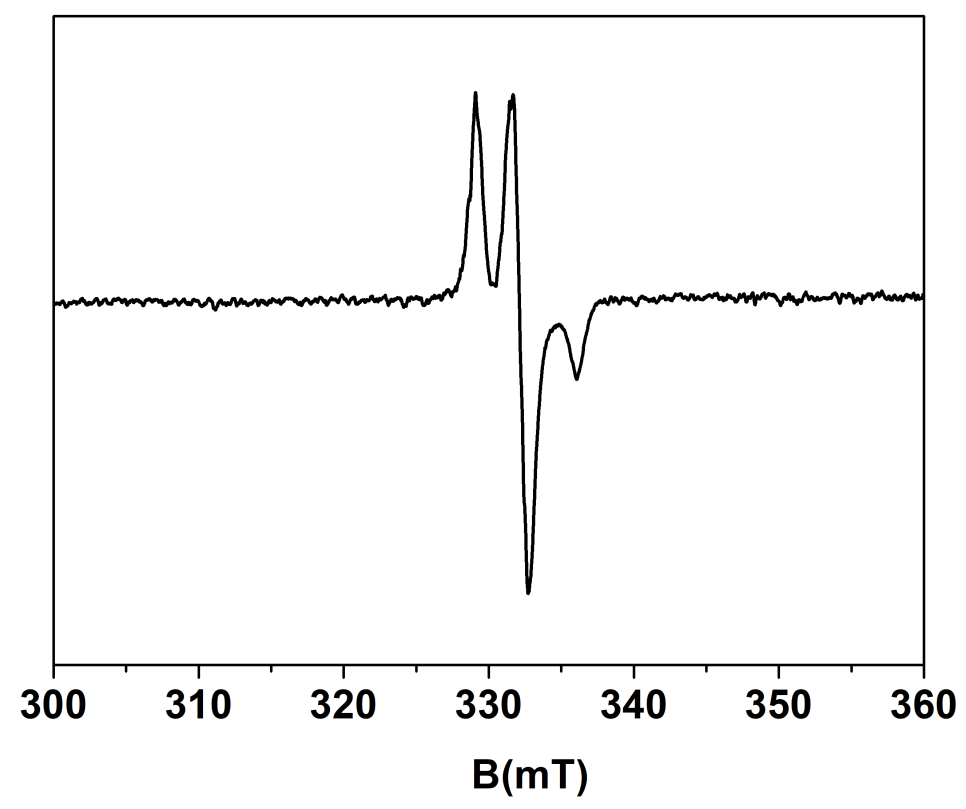

Figure S79. X-Band EPR spectrum of the reaction mixture of 1 with 4-oxo-TEMPOH (100 equiv.). The spectrum was acquired from a frozen DMF solution and measured at $77 \mathrm{~K}$ with a $2.02 \mathrm{~mW}$ microwave power and a $0.3 \mathrm{mT}$ modulation amplitude.

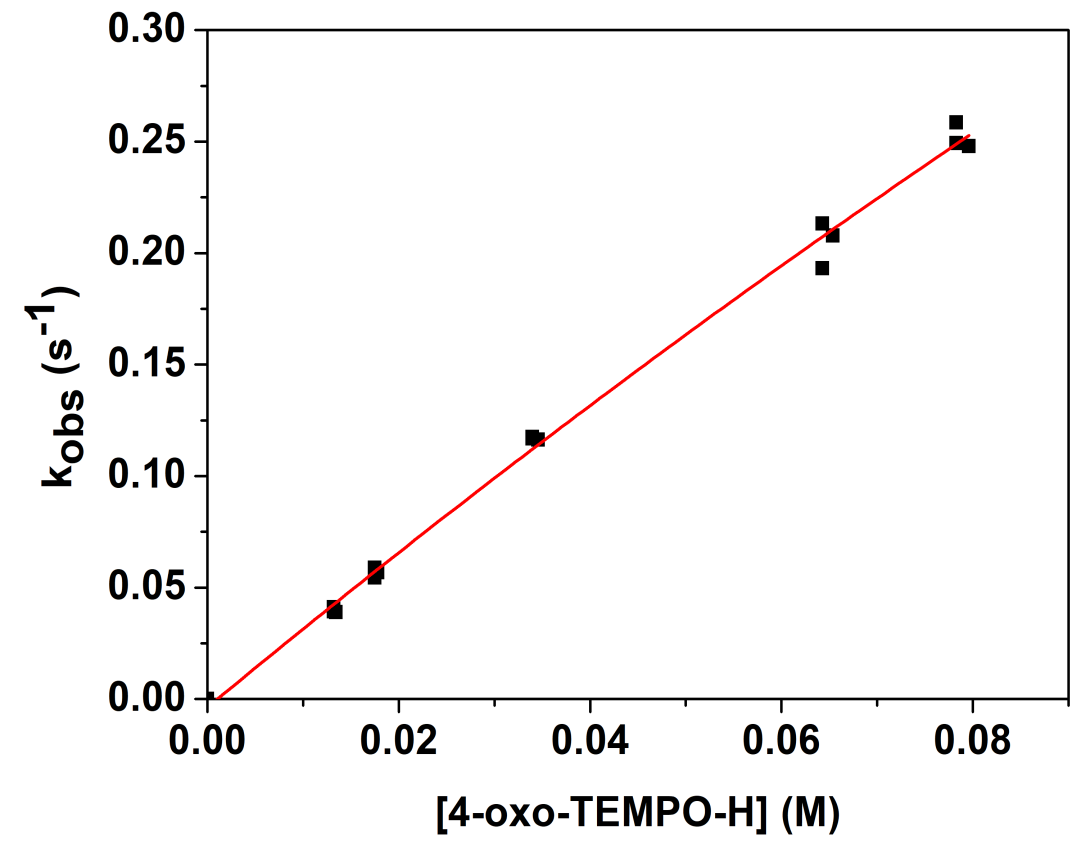

Figure S80. Plot of $k_{\mathrm{obs}}$ against [4-oxo-TEMPOH]. 


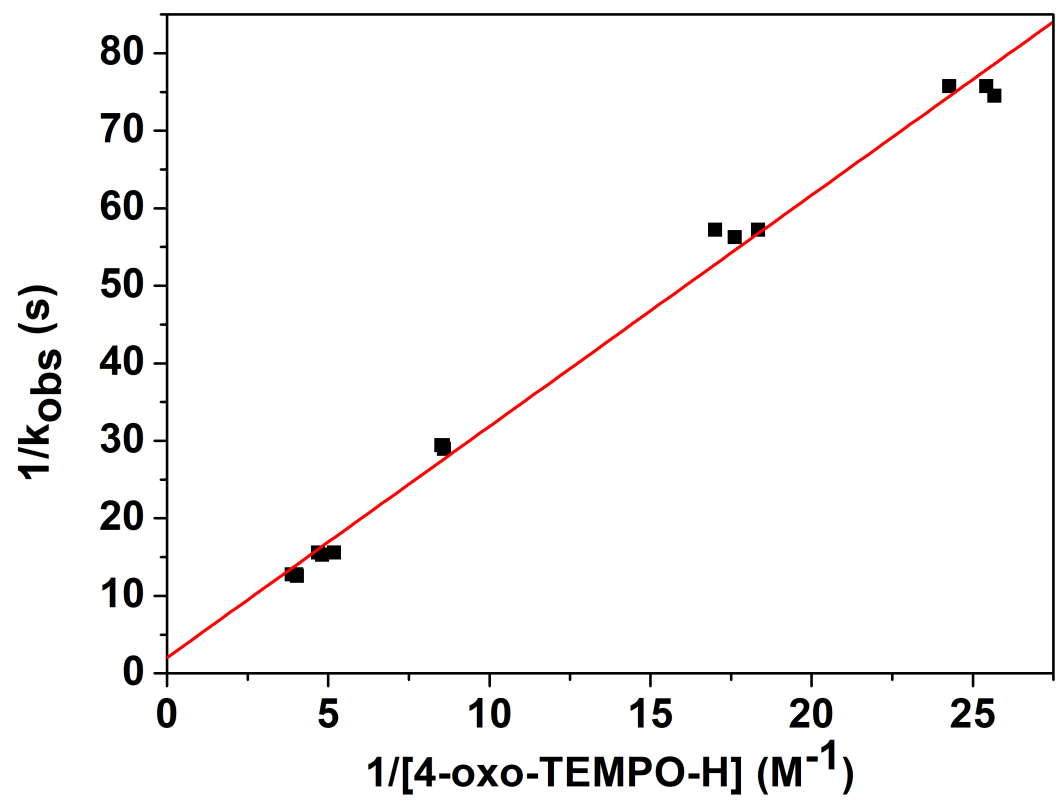

Figure S81. Plot of $1 / k_{\text {obs }}$ versus $1 /[4-\mathrm{oxo}-\mathrm{TEMPOH]}$.

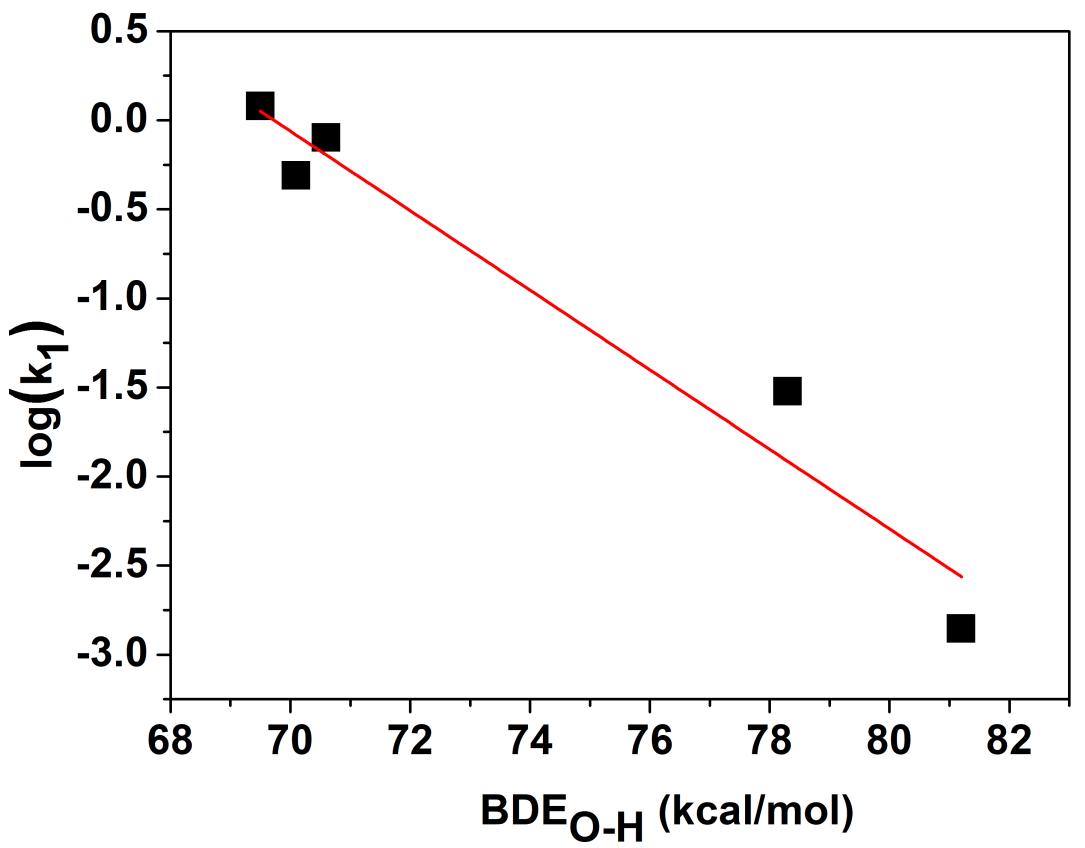

Figure S82. Plot of $\log \left(k_{1}\right)$ against the $\mathrm{BDE}_{\mathrm{O}-\mathrm{H}}$ of the substrates. Slope $=-0.21$. BDEs references. $^{12-13}$ 


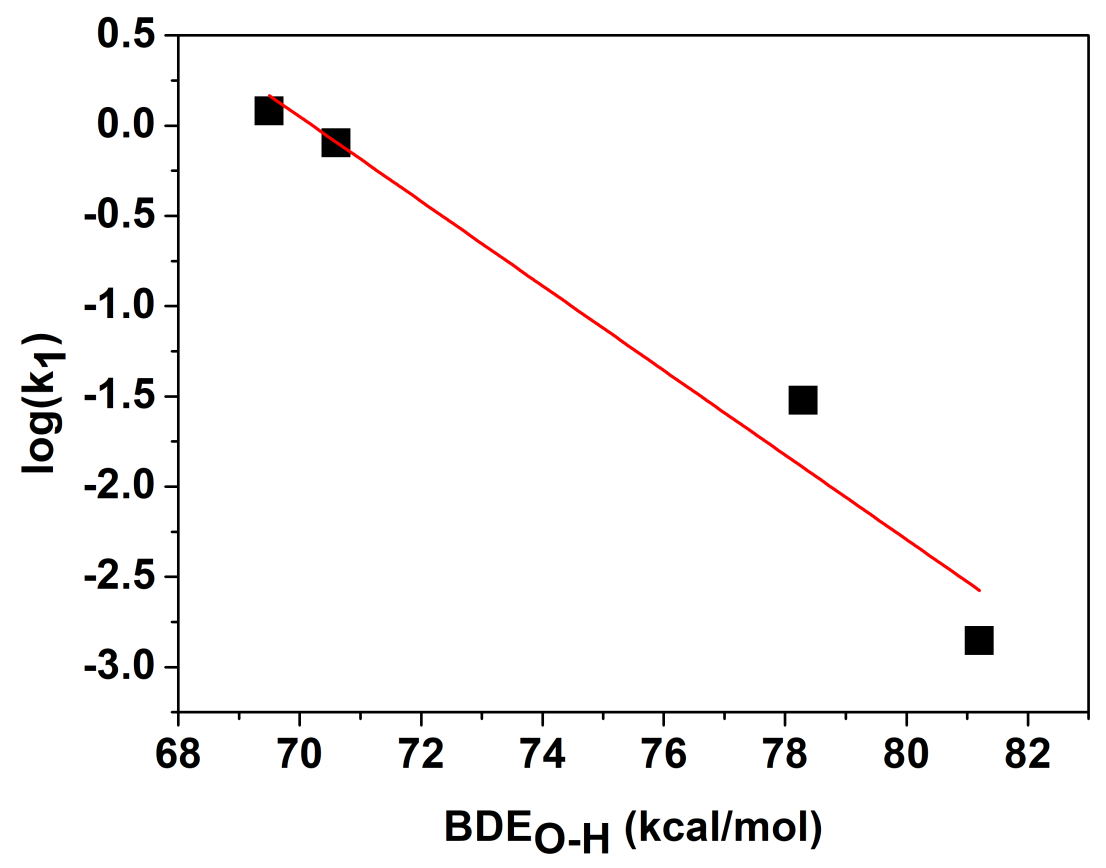

Figure S83. Plot of $\log \left(k_{1}\right)$ against the $\mathrm{BDE}_{\mathrm{O}-\mathrm{H}}$ of the substrates with exclusion of 4-oxoTEMPOH. Slope $=-0.23$. BDEs references. ${ }^{12-13}$.

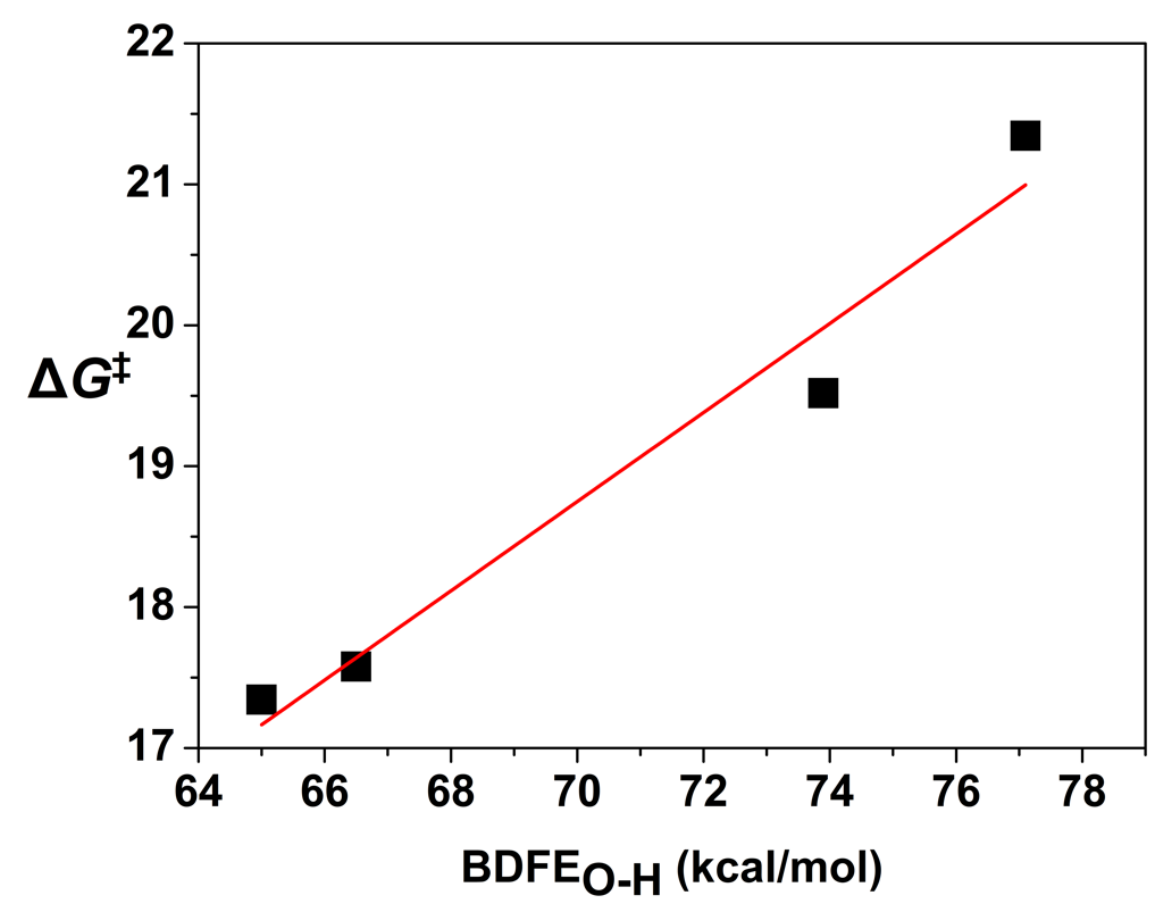

Figure S84. Plot of $\Delta G^{\ddagger}$ against the BDFE ${ }_{\mathrm{O}-\mathrm{H}}$ of the substrates with exclusion of 4-oxoTEMPOH. The values of $\Delta G^{\ddagger}$ was determined for $k_{1}$ via the Eyring equation (slope $=0.32$ ). 


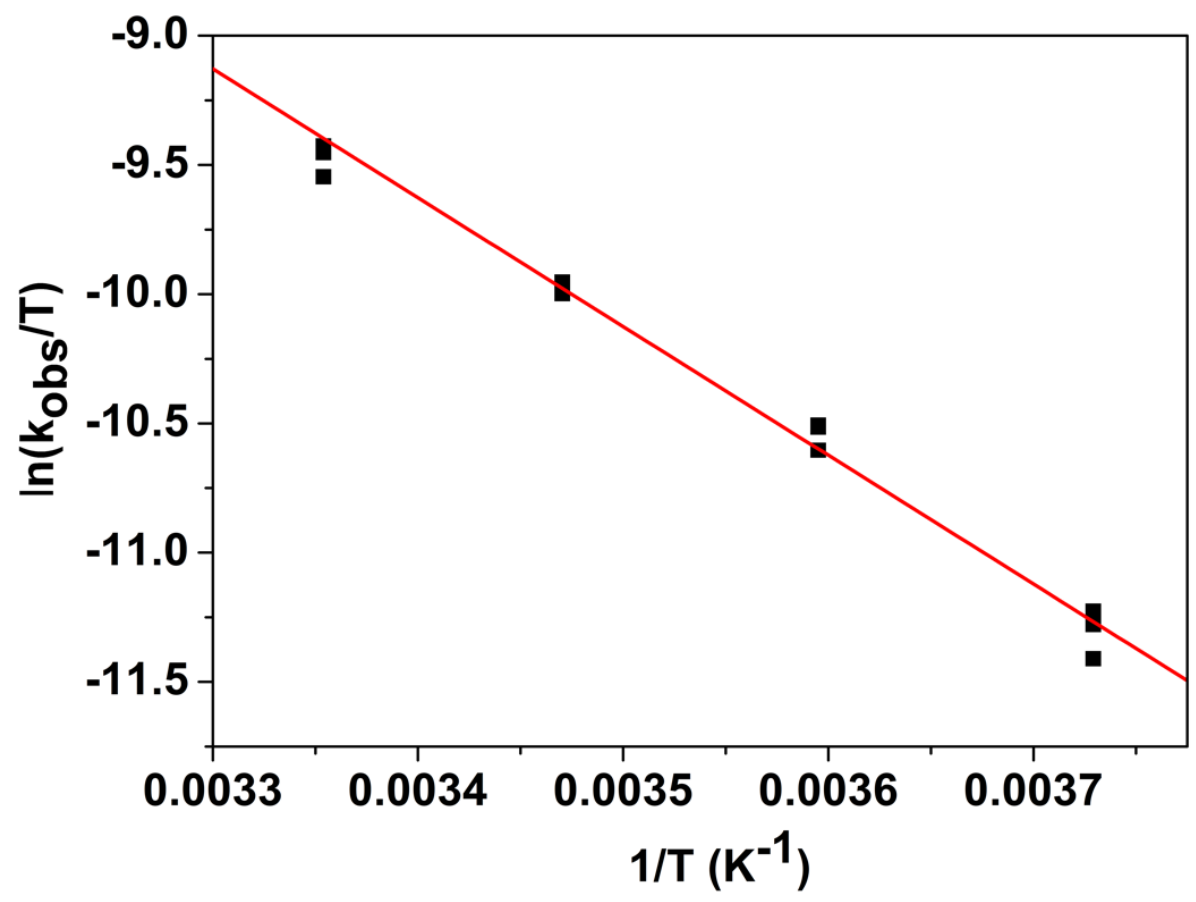

Figure S85. Plot of $\ln \left(k_{\mathrm{obs}} / \mathrm{T}\right)$ versus $1 / \mathrm{T}$ for 1 in its reaction with $4-\mathrm{CH}_{3} \mathrm{O}-2,6-\mathrm{DTBP} . \Delta H^{\ddagger}=$ 9.9(4) $\mathrm{kcal} / \mathrm{mol} ; \Delta S^{\ddagger}=-33(3) \mathrm{cal} \mathrm{mol}^{-1} \mathrm{~K}^{-1}$.

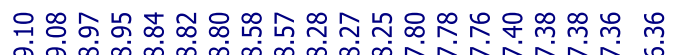
ก̃

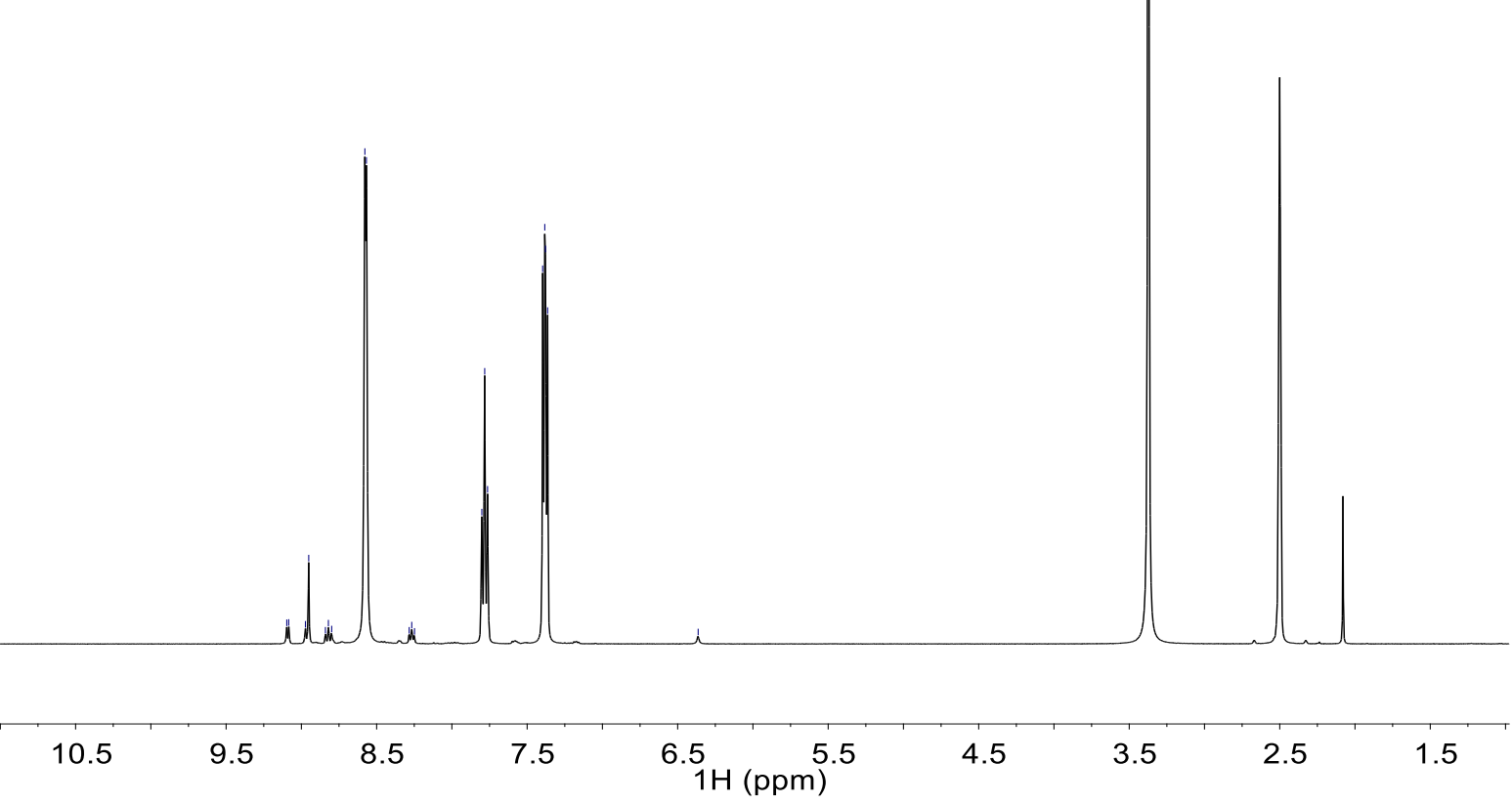

Figure S86. ${ }^{1} \mathrm{H}-\mathrm{NMR}\left(400 \mathrm{MHz}, \mathrm{DMSO}-\mathrm{D}_{6}\right)$ of the reaction between complex 1 and excess pyridine. 


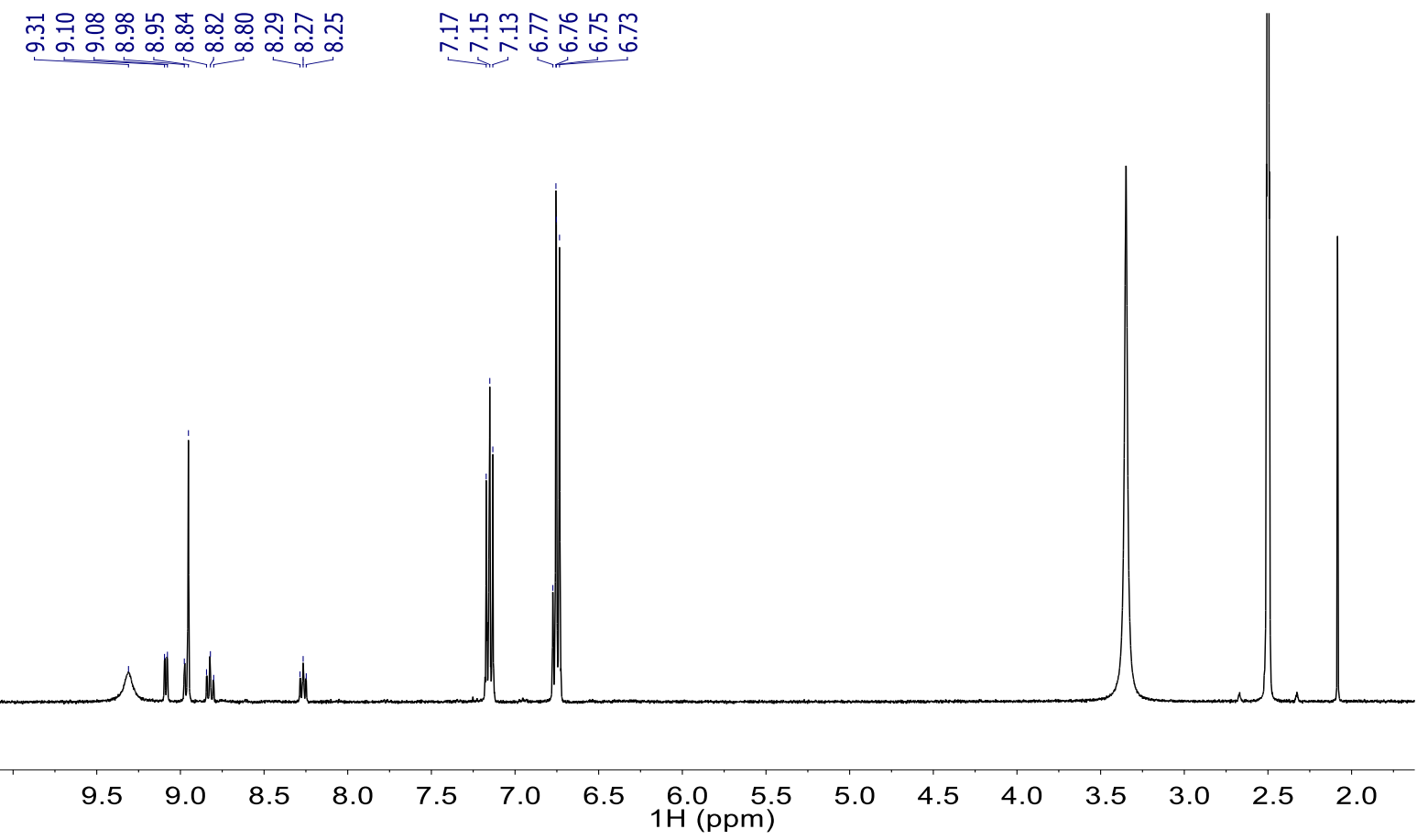

Figure S87. ${ }^{1} \mathrm{H}-\mathrm{NMR}\left(400 \mathrm{MHz}, \mathrm{DMSO}-\mathrm{D}_{6}\right)$ of the reaction between complex 1 and excess phenol. 
Table S1. Yield of products identified from the reactions of substrates with $\mathbf{1}$.

\begin{tabular}{|c|c|c|c|c|}
\hline Substrate & Product & Stoichiometry & Yield (\%) & Method \\
\hline \multirow[t]{3}{*}{$4-\mathrm{CH}_{3} \mathrm{O}-2,6-\mathrm{DTBP}$} & phenoxyl radical & 1-electron & $82 \pm 15$ & EPR \\
\hline & & & $85 \pm 15$ & UV-Vis \\
\hline & 2,6-DTBQ & 2-electrons & $80 \pm 12$ & GC-FID \\
\hline \multirow[t]{3}{*}{ 2,4,6-ТTBP } & phenoxyl radical & 1-electron & $88 \pm 15$ & EPR \\
\hline & & & $85 \pm 20$ & UV-Vis \\
\hline & 2,6-DTBQ & 2-electrons & $120 \pm 60$ & GC-FID \\
\hline 2,6-DTBP & TTBTD & 2-electrons & $10 \pm 2$ & UV-Vis \\
\hline TEMPOH & TEMPO & 1-electron & $80 \pm 10$ & EPR \\
\hline 4- $\mathrm{CH}_{3} \mathrm{O}-\mathrm{TEMPOH}$ & 4- $\mathrm{CH}_{3} \mathrm{O}-\mathrm{TEMPO}$ & 1-electron & $77 \pm 15$ & EPR \\
\hline 4-охо-ТЕМРОН & 4-охо-ТЕМРО & 1-electron & $75 \pm 15$ & EPR \\
\hline DHA & Anthracene & 2-electrons & $65 \pm 25$ & GC-FID \\
\hline CHD & Benzene & 2-electrons & $90 \pm 15$ & ${ }^{1} \mathrm{H}$ NMR \\
\hline
\end{tabular}




\section{References:}

1. Pitteri, B.; Marangoni, G.; Visentin, F.; Bobbo, T.; Bertolasi, V.; Gilli, P., Equilibrium and kinetic studies of $\left(2,2^{\prime}: 6^{\prime}, 2^{\prime \prime}\right.$-terpyridine)gold(III) complexes. Preparation and crystal structure of [Au(terpy)(OH)][ClO4]2, J. Chem. Soc., Dalton Trans. 1999, (5), 677-682.

2. Chan, K. S.; Li, X. Z.; Dzik, W. I.; de Bruin, B., Carbon-Carbon Bond Activation of 2,2,6,6-Tetramethylpiperidine-1-oxyl by a Rhll Metalloradical: A Combined Experimental and Theoretical Study, J. Am. Chem. Soc. 2008, 130 (6), 2051-2061.

3. Wu, A.; Mader, E. A.; Datta, A.; Hrovat, D. A.; Borden, W. T.; Mayer, J. M., Nitroxyl Radical Plus Hydroxylamine Pseudo Self-Exchange Reactions: Tunneling in Hydrogen Atom Transfer, J. Am. Chem. Soc. 2009, 131 (33), 11985-11997.

4. Lee, J. Y.; Peterson, R. L.; Ohkubo, K.; Garcia-Bosch, I.; Himes, R. A.; Woertink, J.; Moore, C. D.; Solomon, E. I.; Fukuzumi, S.; Karlin, K. D., Mechanistic Insights into the Oxidation of Substituted Phenols via Hydrogen Atom Abstraction by a Cupric-Superoxo Complex, J. Am. Chem. Soc. 2014, 136 (28), 9925-9937.

5. $\quad$ Arunkumar, C.; Lee, Y.-M.; Lee, J. Y.; Fukuzumi, S.; Nam, W., Hydrogen-Atom Abstraction Reactions by Manganese(V)- and Manganese(IV)-Oxo Porphyrin Complexes in Aqueous Solution, Chem. Eur. J. 2009, 15 (43), 11482-11489.

6. Stoll, S.; Schweiger, A., EasySpin, a comprehensive software package for spectral simulation and analysis in EPR, J. Magn. Reson. 2006, 178 (1), 42-55.

7. Czerwińska, K.; Golec, M.; Skonieczna, M.; Palion-Gazda, J.; Zygadło, D.; Szlapa-Kula, A.; Krompiec, S.; Machura, B.; Szurko, A., Cytotoxic gold(iii) complexes incorporating a 2,2':6',2"'-terpyridine ligand framework the impact of the substituent in the 4'-position of a terpy ring, Dalton Trans. 2017, 46 (10), 3381-3392.

8. Wittman, J. M.; Hayoun, R.; Kaminsky, W.; Coggins, M. K.; Mayer, J. M., A C-C Bonded Phenoxyl Radical Dimer with a Zero Bond Dissociation Free Energy, J. Am. Chem. Soc. 2013, 135 (35), 12956-12959.

9. Manner, V. W.; Markle, T. F.; Freudenthal, J. H.; Roth, J. P.; Mayer, J. M., The first crystal structure of a monomeric phenoxyl radical: 2,4,6-tri-tert-butylphenoxyl radical, Chem. Commun. 2008, (2), 256-258.

10. Wijeratne, G. B.; Corzine, B.; Day, V. W.; Jackson, T. A., Saturation Kinetics in Phenolic O-H Bond Oxidation by a Mononuclear Mn(III)-OH Complex Derived from Dioxygen, Inorg. Chem. 2014, 53 (14), 76227634.

11. Dhar, D.; Tolman, W. B., Hydrogen Atom Abstraction from Hydrocarbons by a Copper(III)-Hydroxide Complex, J. Am. Chem. Soc. 2015, 137 (3), 1322-1329.

12. Warren, J. J.; Tronic, T. A.; Mayer, J. M., Thermochemistry of Proton-Coupled Electron Transfer Reagents and its Implications, Chem. Rev. 2010, 110 (12), 6961-7001.

13. Kundu, S.; Chernev, P.; Engelmann, X.; Chung, C. S.; Dau, H.; Bill, E.; England, J.; Nam, W.; Ray, K., A cobalt(ii) iminoiodane complex and its scandium adduct: mechanistic promiscuity in hydrogen atom abstraction reactions, Dalton Trans. 2016, 45 (37), 14538-14543. 